Iibrary, N. W. Bldg

SEP 91963

NBS

Eechnical Note

No. 181

\title{
COMPUTER PROGRAM FOR IONOSPHERIC \\ MAPPING BY NUMERICAL METHODS
}

MARTHA E. HINDS AND WILLIAM B. JONES

U. S. DEPARTMENT OF COMMERCE

NATIONAL BUREAU OF STANDARDS 


\section{THE NATIONAL BUREAU OF STANDARDS}

\section{Functions and Activities}

The functions of the National Bureau of Standards are set forth in the Act of C'ongress, Mnrch 3, 1901, as amended by Congress in Public Law 619, 1950. These include the development and maintenance of the national standards of measurement and the provision of means and methods for making measurements consistent with these standards; the determination of physical constants and properties of materials; the development of methods and instruments for testing materials, devices, and structures; advisory services to government agencies on scientific and technical problems; invention and development of devices to serve special needs of the Government; and the development of standard practices, codes, and specifications. The work includes basic and applied research, development, engineering, instrumentation, testing, evaluation, calibration services, and various consultation and information services. Research projects are also performed for other government agencies when the work relates to and supplements the basic program of the Bureau or when the Bureau's unique competence is required. The scope of activities is suggested by the listing of divisions and sections on the inside of the back cover.

\section{Publications}

The results of the Bureau's research are published either in the Bureau's own series of publications or in the journals of professional and scientific societies. The Bureau publishes three periodicals available from the Government Printing Office: The Journal of Research, published in four separate sections, presents complete scientific and technical papers; the Technical News Bulletin presents summary and preliminary reports on work in progress; and the Central Radio Propagation Laboratory Ionospheric Predictions provides data for determining the best frequencies to use for radio communications throughout the world. There are also five series of nonperiodical publications: Monographs, Applied Mathematics Series, Handbooks, Miscellaneous Publications, and Technical Notes.

A complete listing of the Bureau's publications can be found in National Bureau of Standards Circular 460, Publications of the N'ational Bureau of Standards, 1901 to June 1947 (\$1.25), and the Supplement to National Bureau of Standards Circular 460, July 1947 to June 1957 (\$1.50), and Miscellaneous Publication 240, July 1957 to June 1960 (includes Titles of Papers Published in Outside Journals 1950 to 1959) (\$2.25); available from the Superintendent of Documents, Government Printing Office, Washington D.C. 20402. 


\section{NATIONAL BUREAU OF STANDARDS Eechnical Mote 181 Issued August 20, 1963}

\section{COMPUTER PROGRAM FOR IONOSPHERIC MAPPING BY NUMERICAL METHODS}

Martha E. Hinds and William B. Jones

NBS Boulder Laboratories

Boulder, Colorado

NBS Technical Notes are designed to supplement the Bureau's regular publications program. They provide a means for making available scientific data that are of transient or limited interest. Technical Notes may be listed or referred to in the open literature.

For sale by the Superintendent of Documents, U. S. Government Printing Office Washington, D.C. 20402

\section{Price $50 \%$}



1. INTRODUCTION

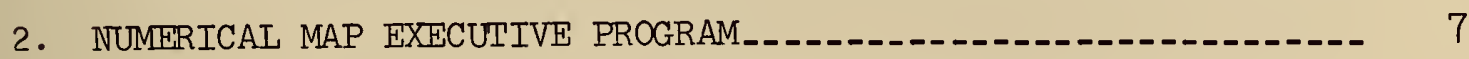

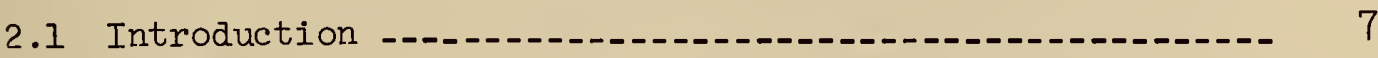

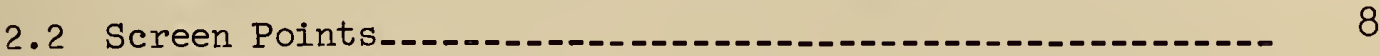

2.3 Program Description--1-1-1-10

3. DATA READ SUBROUTINE OI__._. 23

4. FOURIER ANALYSIS SUBROUTINE O2--1-1.-- 27

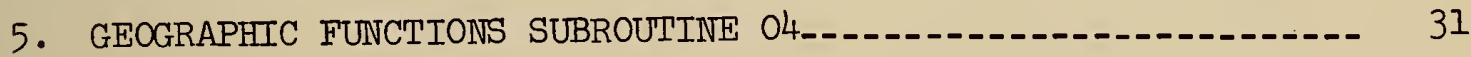

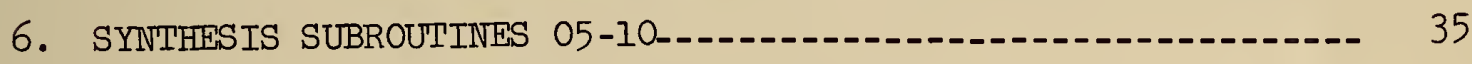

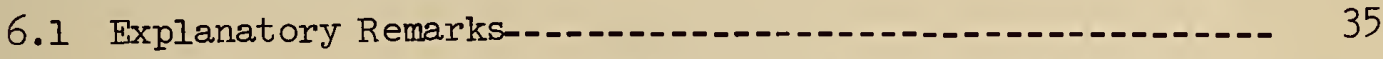

6.2 Program Description (for subroutines 08, 09 and 10)_...- 38

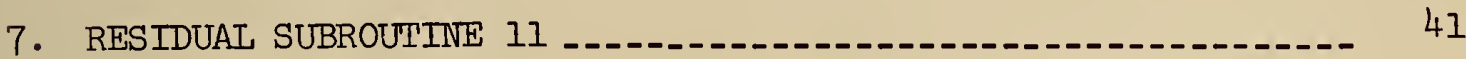

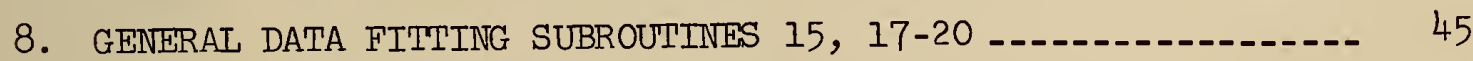

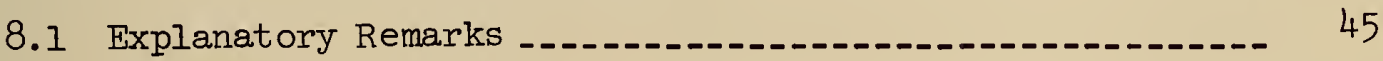

8.2 Program Description

9. INTERCOMPARISON COEFFICIENTS SUBROUTINES 16 AND 21 _......- 55

9.1 Summary of Method and Formulas _.................. 55

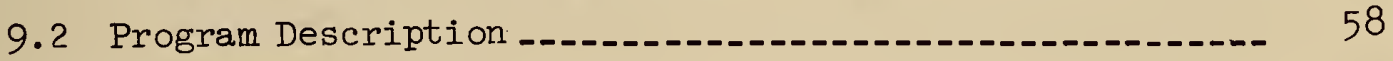

ACKINOWLEDGEMENTS _.

10. REFERENCES (... 63

APPENDIX A

APPENDIX B -.- 

A solution has recently been given to the problem of representing the complex variations of ionospheric characteristics on a world-wide scale, including their diurnal variation, by numerical analysis of ionospheric data as measured at a network of stations [Jones and Gallet, 1962a]. The present paper describes the IBM 7090 (FAP) program of the methods of numerical mapping referred to above. Included are detailed flow charts of the program logic, and all necessary information for applying the program. Thus it fills the gap between the publications giving the scientific bases for the methods of mapping and the practical problem of producing ionospheric maps. This program, applied to ionospheric characteristics foF2 and F2-M3000, forms the basis for the new series, Central Radio Propagation Laboratory Ionospheric Predictions.

\section{INTRODUCTION}

A solution has recently been given to the problem of representing the complex variations of ionospheric characteristics by numerical analysis of ionospheric data as measured at a network of stations [Jones and Gallet, 1962a]. ${ }^{1}$ The methods employed consist of well-defined mathematical operations which are readily adapted to high-speed automatic computing. 2 The principal output of these methods is a set of numerical coefficients defining a continuous function of latitude, longitude and time which represents the ionospheric characteristic on a world-wide scale, including its diurnal variation. The ionospheric representation thus obtained is called a numerical map.

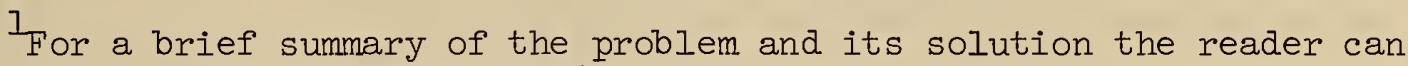
refer to [Jones and Gallet, 1960].

2 The need for world-wide mapping methods based on numerical analysis and the use of high-speed computers has been felt for many years [C.C.I.R., 1959]. 
An integral part of the work in forming and testing the mapping methods referred to above was the parallel development and application of computer programs. This work evolved over a period of several years, beginning with an IBM 650 computer (in SOAP language), then with an IBM 704 (in SAP language) for its increased size and speed, and finally with the IBM 7090 (in FAP language). The present paper describes the 7090 program, referred to here as the Numerical Map Program. ${ }^{1}$ The 7090 FAP listing of the Numerical Map Program is contained in [Hinds and Jones, 1962], which has been revised and condensed to form the present NBS Technical Note.

The numerical methods of mapping and computer programs referred to above, together with extensive applications made with the ionospheric characteristics foF2 and F2-M3000, form the basis for the new series, 2 Central Radio Propagation Laboratory Ionospheric Predictions, commencing in January 1963 [Ostrow, 1962; CRPL, 1963]. Amung the advantages of this new series is that it is based on objective methods of mapping which are repeatable and well-defined in the mathematical sense, so that anyone starting with the same data will obtain an identical map. Although most of the mapping methods appear in published papers, there are many details of the mapping process which can be given only in a description of the computer program; for example, detailed flow charts of the program and all necessary information for applying the Numerical Map Program.

\section{${ }^{1}$ other 7090 computer programs (closely related to the one given} here) have also been developed and extensively used. These include: (a) a Numerical Predictions Program for computing predicted numerical maps of ionospheric characteristics for future months (or days) and (b) a Contour Map Program for computing world-wide or polar contour maps in either universal time or local mean time.

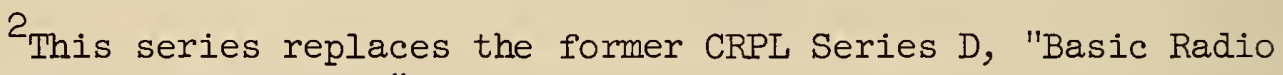
Propagation Predictions". 
Flow Chart I

NUMERICAL MAP PROGRAM

SUMMARY FLOW DIAGRAM OF MAIN PROGRAM STEPS

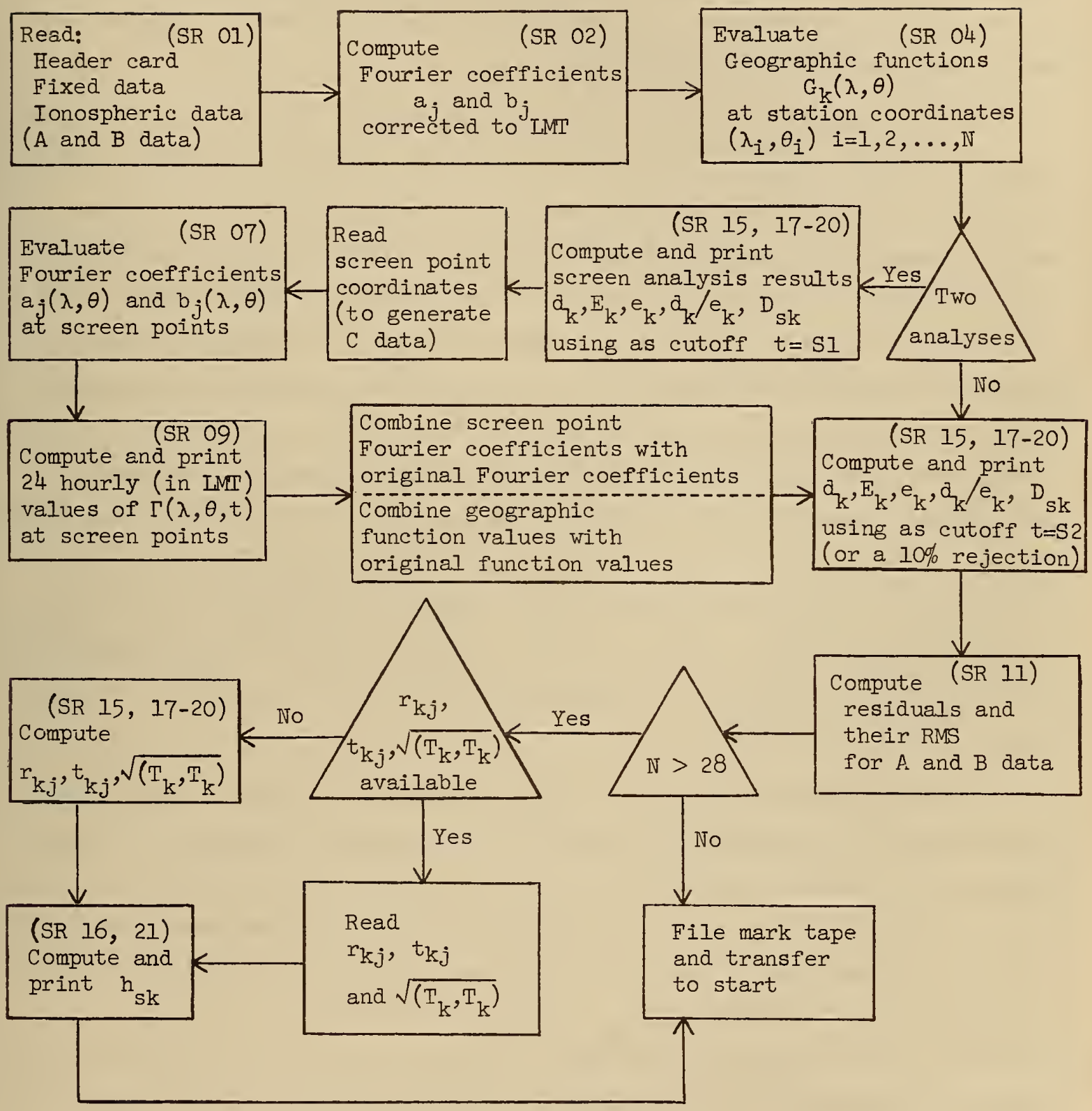


Thus, the purpose of the present paper is to fill the gap between the publications which give the scientific basis for the methods of mapping and the practical problem of producing ionospheric maps. Moreover, it is designed to complement the research papers already available by an overall treatment of the mapping processes, several of which are discussed here for the first time.

The backbone of the Numerical Map Program is an "executive program" (see section 2), which first enters the data using the routine 01 (SR OI) and then directs the operations until the final output is obtained. The main steps of the operations themselves are performed by 17 routines at the command of the executive program (see Flow Chart 1 ). 1 Each of these 17 routines forms a logical unit, which often is a relatively large problem in itself (for example, SR 17--the Gram-Schmidt Orthogonalization; see flow chart 8, second sheet). Even more, several routines are sometimes linked in a quasi-independent loop, with a loop executive program of their own (for instance, SR 20--Executive General Data Fitting). The 17 main routines are discussed in sections 3 through 9 . For the executive program and each routine, a detailed program writeup is given to describe the input, output, storage, card formats, program logic, and other necessary information. Sample printouts of input and output are given in the appendices.

Input to the Numerical Map Program consists of the 24 hourly measurements of an ionospheric characteristic from all available stations for a given month (or day) together with such basic information as station coordinates and various parameters defining the mathematical functions to be used (section $2 \cdot 3 \mathrm{a}$ ). The principal output of the program is a set of numerical coefficients $D_{\text {sk }}$, defining a function $\Gamma(\lambda, \theta, t)$, of latitude, longitude, and local mean hour angle, which represents the ionospheric characteristic, including its diurnal variation, on a world-wide scale (section $2 \cdot 3 b$ ).

${ }^{1}$ It will be noticed that in the numbering of the subroutines, numbers $3,12,13$, and 14 are missing. These subroutines are not included since they are no longer used in the Numerical Map Program. 
Although the basic theory for the methods of numerical mapping has been published [Jones and Gallet, 1962a], some essential procedures used in the Numerical Map Program have not been justified in scientific literature. In particular, the problem of the "stability" of the geographic representation in areas where no stations are available appears to be solved by a method of "screen points", which has been extensively applied and tested. While the method is described in section 2.2, further justification and illustrations will be given in a subsequent paper.

Section 9.1 describes a method for generating a special set of coefficients, $h_{s k}$, for intercomparing numerical maps from month to month or from day to day. Explanations of other new procedures and formulas are included in the text where they occur. It should also be mentioned that many of the routines in the present program were originally written for the 704 and are now retained with only slight modifications for purposes of economy. This is at no loss of program efficiency and accounts for certain differences of techniques appearing in the program.

This paper is intended for two types of users: (a) those who wish to apply the program as it stands, and (b) those who wish to use the program with modifications. For the former, a reading of only sections 2 and 3 will largely suffice. The remaining sections are included mainly for the latter. The terminology and notation used conform, whenever possible, with the reference papers [Jones and Gallet, 1962a and 1962b] so that most of the formulas and definitions are not repeated here. As a result, some knowledge of the above references will be needed for a thorough understanding of the program. 



\section{NUMERICAL MAP EXECUTIVE PROGRAM}

\subsection{Introduction}

The primary function of the numerical map executive program is to direct the operation of the various subroutines. Section 2.2 discusses the concept and application of "screen points". Section 2.3 describes input, output, intermediate output on magnetic tape, storage requirements, and subroutines used. Section 2.3 also includes: (1) a summary list of sense switch settings, (2) a storage plan for the Numerical Map Program, (3) card formats for input and output, and (4) a flow chart of the numerical map executive program. Sample printouts of input and output are contained in appendices $A$ and $B$, respectively. Before proceeding to these sections, however, it is desirable to review briefly the choice of time and geographic functions [Jones and Gallet, 1962a, chapter 3].

A number of options are available with regard to input, output, and types of analyses (section 2.3). The choice of the time and geographic functions to be used is considered here. A particular set of functions is specified by the following parameters entered on the header card (section 2.3a): (1) The total number of harmonics $\mathrm{H}$ used in the diurnal analysis. (2) The numbers $k_{0}, k_{1}$, and $k_{2}=K$ (referred to in the program by the symbols $\mathrm{PP1}, \mathrm{PP} 2$, and $\mathrm{PP} 3=\mathrm{P}$, respectively) which determine a particular set of geographic functions (table 1 , section 5). Note that $k_{0}=$ PPl must be greater than or equal zero. (3) In the geographic analyses, the residuals arrive at the noise level at a much lower degree for the high order harmonics than for the low order ones. Therefore, it is frequently necessary to truncate automatically the series of geographic functions for all harmonics of order higher than a certain value, e. g., Hl. This can be done by entering $\mathrm{Hl}$ and a special cutoff, $k=$ PH2, for the geographic series on the header card. (An example of values commonly used are $\mathrm{HI}=4$ and $\mathrm{PH} 2=4$.)

(4) Finally, a numerical code, FNCD, is used to identify the choice of time and geographic functions. 


\subsection{Screen Points}

An important modification included in the present program is the use of "screen points" for stabilizing the geographic representations in areas where few or no measurements are available. As was pointed out in chapter 5 of Jones and Gallet [1962a], the heavy grouping of stations in some regions, such as Europe, and the absence of stations in other regions tends to produce a sort of mathematical instability in the representation function--that is, unrealistic behavior in areas where no data are available. The best representation that can be expected for such a region is a smooth continuation of the variations from surrounding stations. The instability is alleviated by computing smooth continuations at "screen points" chosen inside the gaps. 1 The "screen point values" for the ionospheric characteristic are obtained from a deliberately oversmoothed geographic representation of all the data. A second analysis is then made using both the original data and the screen point values (see flow chart 2 ). ${ }^{2}$

The oversmoothed representation in the first analysis is effected by a radical truncation of the orthonormal series of geographic functions [see section 4.2 of Jones and Gallet, 1962a]. By using a rejection criterion considerably higher than 5 percent, all but the most significant terms are rejected. For example, the value $t=4.0$ or 6.0 (for the variable in Student's distribution) has been found to give a satisfactory cutoff in the first analysis, whereas $t=2.0$ is generally

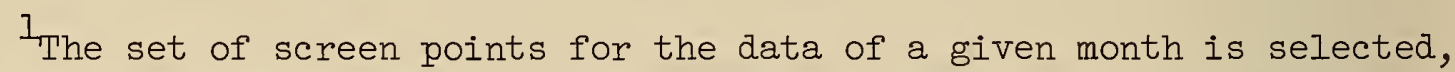
prior to using the program, in such a way as to fill all large gaps where no stations are available and where consequently unacceptable instabilities would be produced (section 2.3a, input (4)). In practice, the set of screen points remains essentially unchanged from one month to the next.

${ }^{2} \mathrm{~A}$ slight variation in the method of defining the screen analysis will be described in a later paper entitled "Representation of diurnal and geographic variations of ionospheric data by numerical methods, II. Control of instability." The screen analysis given there is made by including only the main geographic variation. 
Flow Chart 2

NUMERICAL MAP EXECUTIVE PROGRAM
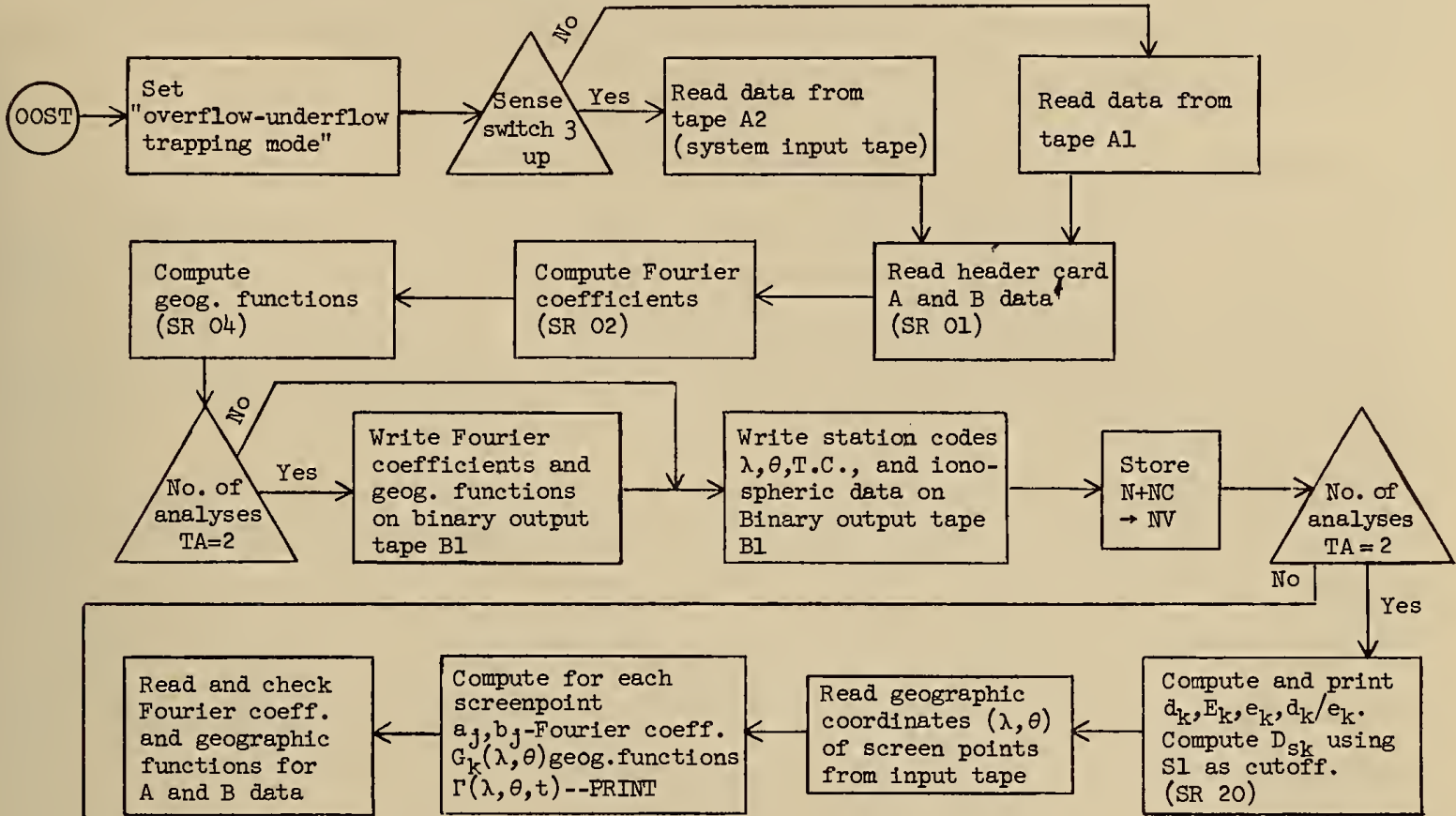

Read and check

Fourier coeff.

and geographic

functions for

$A$ and $B$ data
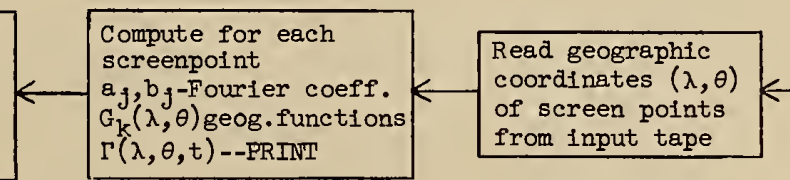

Compute and print $d_{k}, E_{k}, e_{k}, d_{k} / e_{k}$ Compute $\mathrm{D}_{\text {sk }}$ using Sl as cutoff.
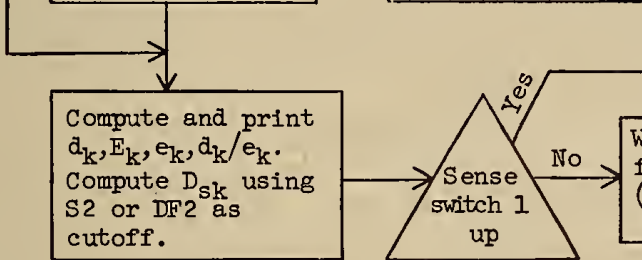

Write $\mathrm{D}_{\text {sk }}$ on $\mathrm{A} 3$ for printing

(one per card format)

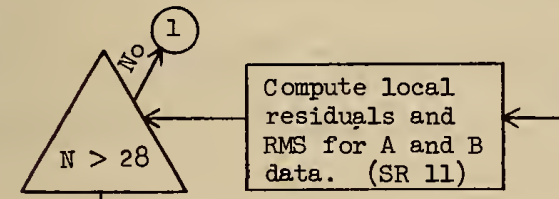
Read station code, $\lambda, \theta, T . C$. from tape Bl (SR 20)
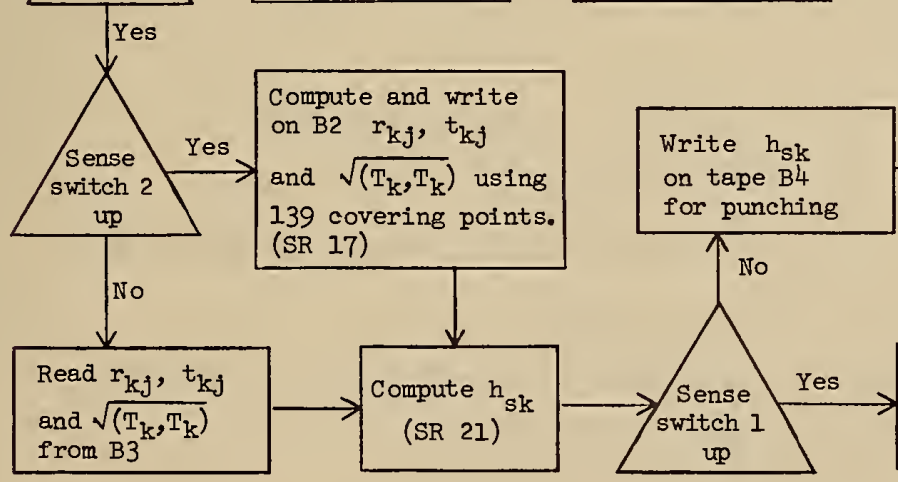

(1)

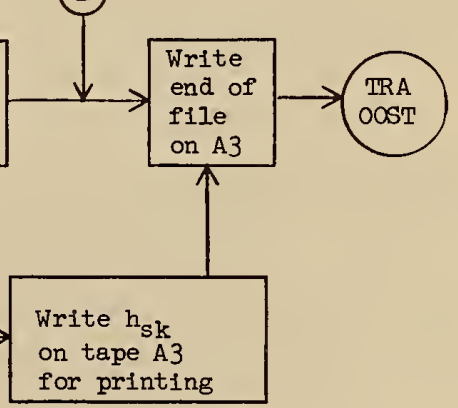


used in the second analysis. These values of $t$ are denoted in the header card by $\mathrm{SI}$ and $\mathrm{S2}$, respectively. When it is not desired to use screen points, it is possible to make only one analysis. This option is also specified in the header card.

When the number of stations $\mathbb{N}$ is so small that the number of degrees of freedom $(D F=(N-k-1)$, where $(k+1)$ is the number of geographic functions) is less than or equal 28, it is assumed that only one analysis will be made, and the value of $t$ is for a two tail, 10 percent rejection, depending on the number of degrees of freedom (see section $8.2 \mathrm{~d}$ ).

In addition to screen points described above, it has also been found helpful, in filling large gaps in the data, to use "predicted data" at certain stations for which data were not available for the given month or day being analyzed. Such "predictions" are made from correlations of measurements with a solar index. For purposes of identification in the present paper, we shall refer to measurements as $\underline{A}$ data, to predictions as $\underline{B}$ data, and to screen point values as $\underline{C}$ data.

\subsection{Program Description}

(a) Input (see sample printout, appendix A)

The following list gives the different types of input, ordered as they follow the program. Card formats and sample printouts are given for each type of card input.

(1) Header card (card format 1).

(2) Fixed data cards (card format 2)--see section 3.

A data cards precede $B$ data cards.

(3) Ionospheric data cards (card format 3)--see section 3. A data cards precede B data cards.

(4) Optional screen point coordinates on cards if a second analysis is to be made (card format 4 ). 
(5) Optional input (on binary tape 3, channel B) $r_{k j}, t_{k j}$, and $\sqrt{\left(\mathrm{T}_{\mathrm{k}}, \mathrm{T}_{\mathrm{k}}\right)}$. In this case, these numbers can be computed in the first analysis and then entered as input in tape 3, channel $B$ in each subsequent analysis by having sense switch 2 down.

The IBM 1401 is used to convert the binary program deck and the input data deck to magnetic tape.

If it is desired to use the Fortran monitor system, sense switch 3 must be up. In this case, tape 1 , channel $A$ is the system tape and the program and data are read from tape 2, channel A (the system input tape). There are two program options if the Fortran monitor system is not used: (I) if sense switch 3 is up, the self-loading program must be on tape 1 , channel $A$ and the input data must be on tape 2, channel A; (2) if sense switch 3 is down, the self-loading program followed by the input data must be on tape 1 , channel $\mathrm{A}$.

(b) Output. The following are regular and optional types of output:

(1) Tape 3, channel A, BCD output (see sample printout, appendix B).

\section{First analysis:}

$\mathrm{d}_{\mathrm{k}}, \mathrm{E}_{\mathrm{k}}, \mathrm{e}_{\mathrm{k}}, \mathrm{d}_{\mathrm{k}} / \mathrm{e}_{\mathrm{k}}, \mathrm{k}=0,1, \ldots, \mathrm{K}$ (for each Fourier coefficient).

Second analysis (optional):

$\Gamma$ values at screen points and $d_{k}, E_{k}, e_{k}, d_{k} / e_{k}$. (The following are output from analysis $I$ when there is no second analysis.) Coefficients $D_{\text {sk }}$ (if sense switch $I$ is down); residuals and their root mean square; intercomparison coefficients $h_{s k}$ (if sense switch $l$ is down).

(2) Tape 4, channel B, binary output to be punched into column binary cards by 1401 (see card formats 6 and 7). These cards contain the coefficients $D_{s k}$ and are stored for permanent records and later use in predictions. First card is binary identification followed by the coefficients $D_{\text {sk }}$. These cards are punched in absolute locations for use in prediction programs. 
(3) Optional binary output of coefficients $D_{\text {sk }}$ is obtained on tape 2, channel A, when sense switch 3 is down. This output is generally used for immediate applications such as the computation of contour maps. (Note: if sense switch 3 is up, tape 2, channel A is used for input).

(4) Optional BCD tape 4, channel B will contain the coefficients $D_{\text {sk }}$ and $h_{\text {sk }}$ when sense switch $I$ is up. These coefficients are then punched one per card for later use (see card format 5). Note: if sense switch $I$ is down, these coefficients will be included in output $I$ above.

(5) Optional binary output $r_{k j}, t_{k j}$, and $\sqrt{\left(T_{k}, T_{k}\right)}$ will be written on tape 2, channel B if sense switch 2 is up (see input 5 and also section 9).

(c) Intermediate output

(1) The geographic functions and Fourier coefficients for $\mathrm{A}$ and $B$ data are written on tape 1 , channel $B$ if two analyses are used. This is done so that corresponding screen point results can be combined for the second analysis.

(2) Geographic latitudes and longitudes, time corrections, and ionospheric data ( $A$ and $B$ data) are written on tape 1 , channel B for subsequent use in the residual subroutine (SR 1I).

(3) Tape 2, channel B is used to write the intermediate triangular matrices $a_{k j}, b_{k j}$, for use in SR 17 and SR 18 (see section 8). This tape is subsequently rewound and used for output if the option is chosen to compute the $r_{k j}, t_{k j}$ (see output 5) rather than read them from input.

(d) Storage

At most instances during the operation of the program, the computer storage capacity of $32,000+$ storage locations is used. See storage plan (h) for matrix limits and locations. 
(e) Share subroutines used

Punch B, UA-SPHI, and UA-BDCI, along with those share subroutines incorporated in each of the seventeen subroutines.

(f) Remarks

Trapping mode is set for use in controlling underflow. End of file is written on tape 3, channel A after each set of data. If consecutive months of data are to be run, push start at the program halt or return to system.

If at any time during the computation it is desired to see the off-line BCD output written on the on-line printer, put sense switch 6 down. The printing may again be suppressed by putting sense switch 6 up.

(g) Sense switch settings for Numerical Map Program

1 up writes coefficients $D_{s k}$ and $h_{s k}$ (as above) on tape 4, channel B.

down writes coefficients $D_{s k}$ and $h_{s k}$ in BCD one per card format on tape 3, channel A.

2 up computes $r_{k j}, t_{k j}$, and $\sqrt{\left(T_{k}, T_{k}\right)}$ and writes output on tape 2, channel B. Computed values are used as input to SR 21.

down assumes tape 3 , channel $B$ contains 3 binary records $r_{k j}, t_{k j}$, and $\sqrt{\left(T_{k}, T_{k}\right)}$ (see input (5)) for input to SR 21.

3 up reads data (monitor system) from tape 2, channel A. Omits writing binary record of coefficients $D_{s k}$ on tape 2, channel A.

down reads program and data from tape 1 , channel A. Writes binary record of coefficients $D_{\text {sk }}$ on tape 2, channel A. 6 up normal operating procedure.

down $B C D$ records are written on tape and the on-line printer. 
(h) Storage Plan for Numerical Map Program

\begin{tabular}{|c|c|}
\hline $\begin{array}{l}\text { 3. } \operatorname{Max}\left(\mathbb{N}_{A}+\mathbb{N}_{B}\right)=180 \\
\operatorname{Max} H=8 \text { Max } P=80\end{array}$ & is 2. $\begin{aligned} \operatorname{MAX}\left(N_{A}+\mathbb{N}_{B}+\mathbb{N}_{C}\right) & =220 \\
& \operatorname{Max} H=8 \quad \operatorname{Max} P=80\end{aligned}$ \\
\hline 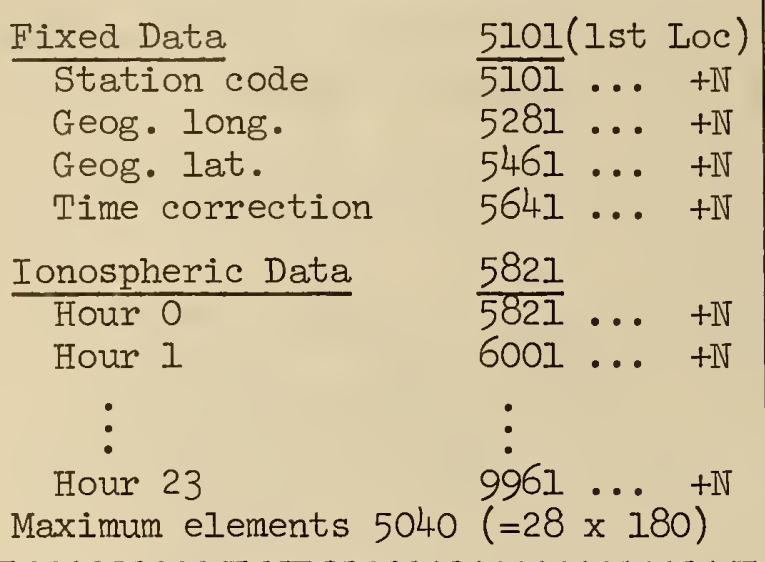 & 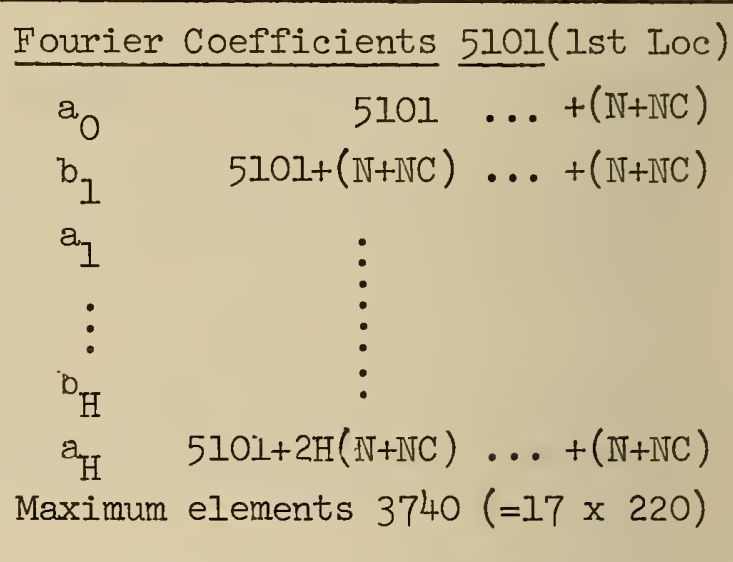 \\
\hline 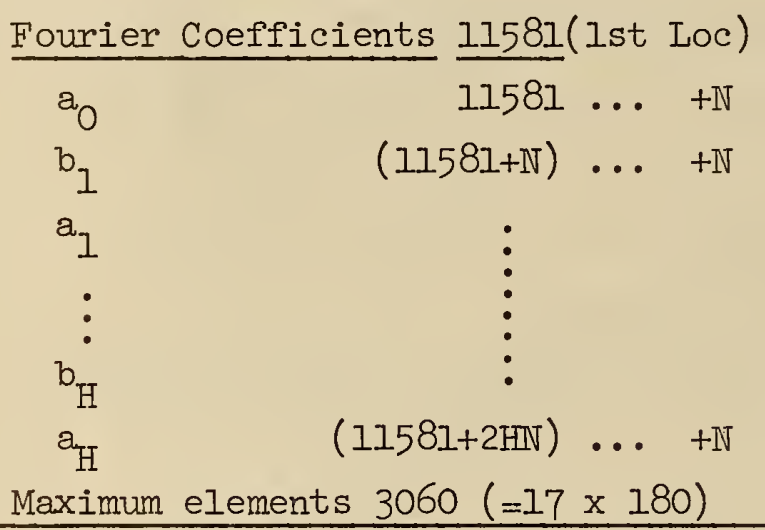 & 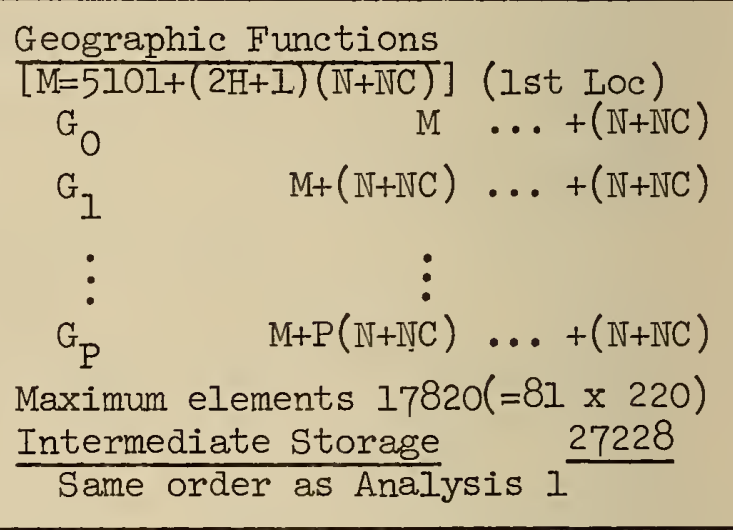 \\
\hline 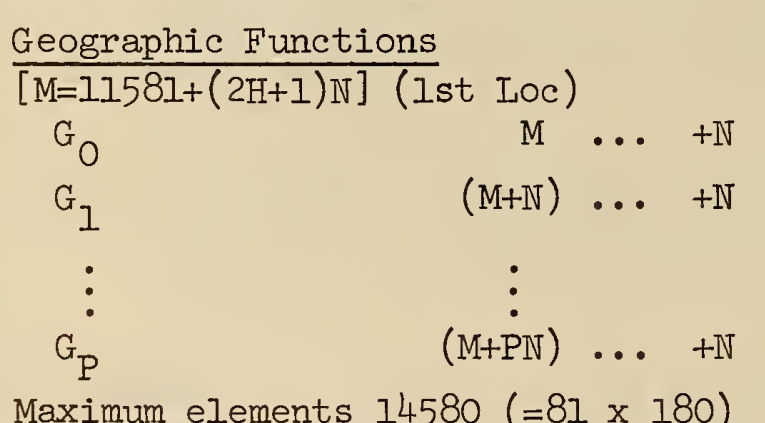 & $\begin{array}{ll}\begin{array}{l}\text { Residual Subroutine (restored } \\
\text { from tape BI as in Analysis I) } \\
\text { Fixed Data }\end{array} & 5101 \text { (Ist Ioc) } \\
\text { Station code } & 5101 \ldots+\mathbb{N} \\
\text { Geog. long. } & 5281 \ldots+\mathbb{N} \\
\text { Geog. lat. } & 5461 \ldots+\mathbb{N} \\
\text { Time correction } & 5641 \ldots+\mathbb{N} \\
\text { Ionospheric Data } & 5821 \\
\end{array}$ \\
\hline $\begin{array}{l}\frac{\text { Intermediate Storage }}{\mathrm{P}(\mathrm{P}+\mathrm{I}) / 2} \text { 27228 (Ist Loc) } \\
\text { Maximum elements } 3240 \\
\text { Coefficients } \mathrm{D}_{\text {sk }}, \quad 30468 \text { (Ist Loc) } \\
\text { Maximum elements } 1377\end{array}$ & $\begin{array}{cc}\vdots & \vdots \\
\text { Hour } 23 & 9961 \ldots+1 N \\
\text { Maximum elements } & 5040(=28 \times 180) \\
\text { Program Origin } 101\end{array}$ \\
\hline
\end{tabular}




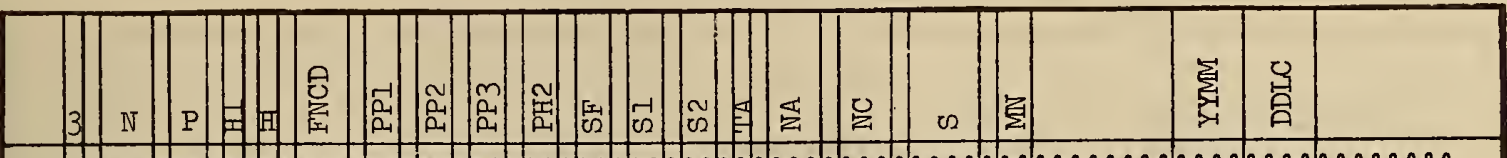

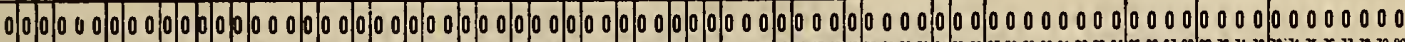

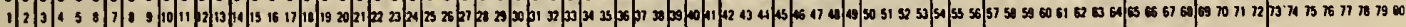

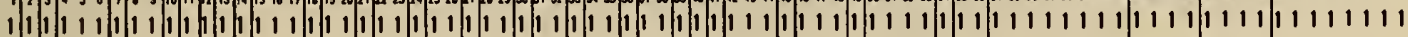

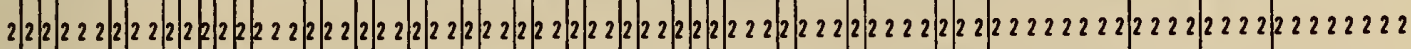

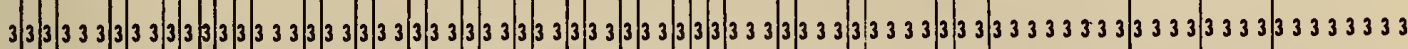

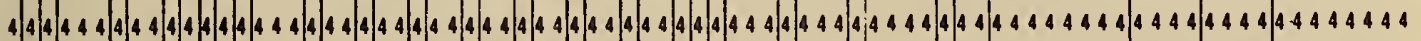

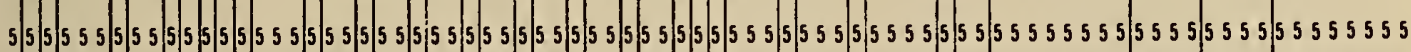

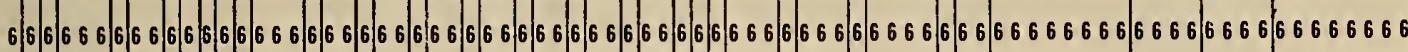

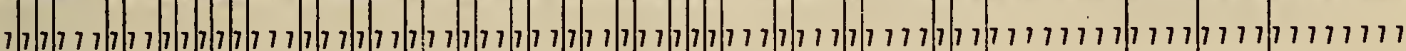

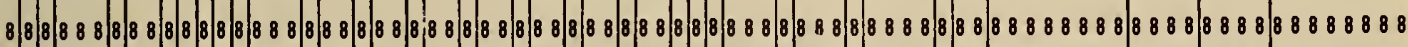

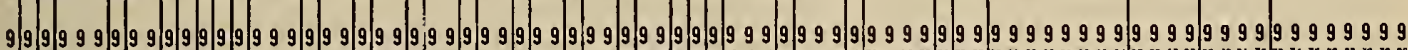

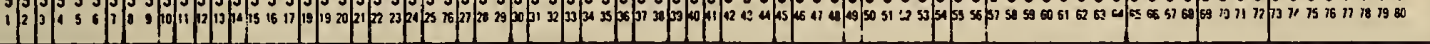

\begin{tabular}{|c|c|c|}
\hline CARD COLUMN & DESCRIPTION & REMARKS \\
\hline 2 & 3 & Header carả \\
\hline $4-6$ & $(x \times x)$ & Number of stations ( $A$ and $B$ data) \\
\hline $8-9$ & $(\mathrm{xx})$ & $\mathrm{P}+\mathrm{I}=\mathrm{K}+\mathrm{l}=$ Number of geographic functions \\
\hline 11 & $(x)$ & $\begin{array}{l}\text { Highest harmonic for which the geographic } \\
\text { analysis is made with } \mathrm{P}+1 \text { functions }\end{array}$ \\
\hline 13 & $(\mathrm{x})$ & Number of harmonics for diurnal analysis \\
\hline $15-17$ & $(\mathrm{xxx})$ & Function identification code \\
\hline $19-20$ & $(x x)$ & $\mathrm{k}_{0}:$ Highest term for main latitudinal variation \\
\hline $22-23$ & $(\mathrm{xx})$ & $\begin{array}{ll}\mathrm{k}_{1}: & \text { Highest term for first order } \\
\text { longitudinal variation }\end{array}$ \\
\hline $25-26$ & $(x x)$ & $\begin{array}{ll}\mathrm{k}_{2}=\mathrm{K}: & \text { Highest term for second order } \\
\text { longitudinal variation }\end{array}$ \\
\hline $28-29$ & $(x x)$ & $\begin{array}{l}\text { Highest term used in geographic analysis } \\
\text { of harmonics } \mathrm{Hl}<j \leqq \mathrm{H} \text {. }\end{array}$ \\
\hline $31-32$ & $( \pm n)$ & Scale factor \\
\hline $34-35$ & $(\mathrm{xx})^{1}$ & Student's $t$ cutoff in first analysis \\
\hline $37-38$ & $(x x)^{1}$ & Student's $t$ cutoff in second analysis \\
\hline 40 & $(\mathrm{x})$ & Option of 1 or 2 analyses \\
\hline $42-44$ & $(x x x)$ & Number of stations with A data \\
\hline
\end{tabular}

1 Program automatically places a decimal point between the first and second digits. 
Card Format 1 (Cont.)

NUMERICAL MAP HEADER CARD

See previous page

00000000000000000000000000000000000000000000000000000000000000000000000000000000 徒 111111111111111111111111111111111111111111111111111111111111111111111111

22222222222222222222222222222222222222222222222222222222222222222222222222222222

33333333333333333333333333333333333333333333333333333333333333333333333333333333 44444444444444444444444444444444444444144444444444444444144444444 55555555555555555555555555555555555555555555555555555555555555555555555555555555 66666666666666666666666666666666666666666666666666666666666666666666666666666666 ו 88888888888888888888888888888888888888888888888888888888888888888888888888888888 و 99999999999999999999999999999999999999999999999999999999999999999999999999999999

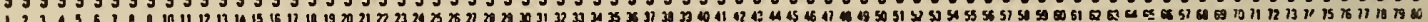

\begin{tabular}{|c|c|c|c|}
\hline CARD COLUMN & \multicolumn{2}{|c|}{ DESCRIPTION } & REMARKS \\
\hline $46-48$ & & $(x x x)$ & Number of screen points \\
\hline $50-53$ & $\mathrm{~S}$ & $(x \times x \cdot x)$ & Sunspot number \\
\hline $55-56$ & $\mathrm{MN}$ & $(x x)$ & $\begin{array}{l}\text { Order of months (or days) for use } \\
\text { in prediction program }\end{array}$ \\
\hline $65-68$ & YYMM & $(x x \times x)$ & Year and month \\
\hline $69-72$ & DDIC & $(x \times x \times x)$ & $\begin{array}{l}\text { Date, layer, and characteristic (see card format } \\
\text { for ionospheric data) }\end{array}$ \\
\hline & & & \\
\hline & & & \\
\hline & & & \\
\hline & & & \\
\hline & & & \\
\hline & & & \\
\hline & & & \\
\hline & & & \\
\hline & & & \\
\hline
\end{tabular}




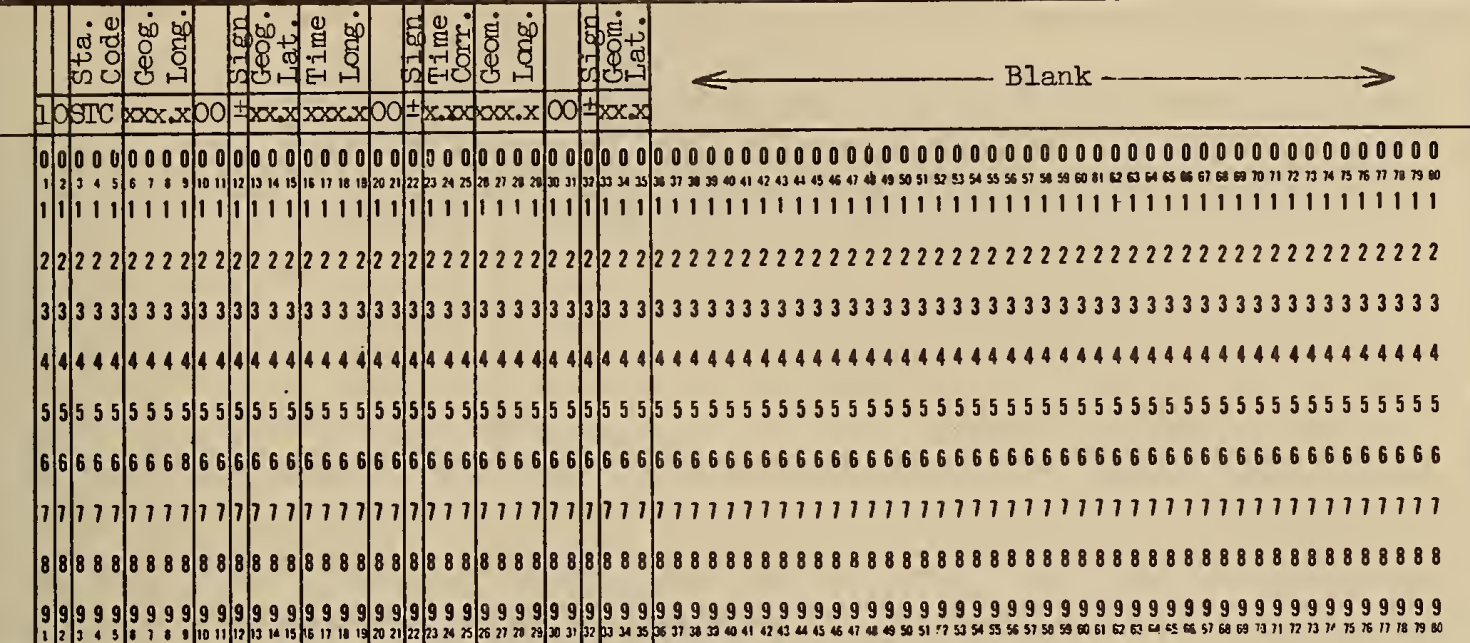

\begin{tabular}{|c|c|c|}
\hline CARD COLUMN & DESCRIPTION & REMARKS \\
\hline 1 & 1 & Ionospheric data \\
\hline 2 & 0 & Fixed station data \\
\hline $3-5$ & $\mathrm{STC}$ & Station code \\
\hline $6-9$ & $000.0 \leqq x x x \cdot x<360.0$ & $\begin{array}{l}\text { Geographic longitude }(\theta) \text { in degrees east of } \\
\text { Greenwich. }\end{array}$ \\
\hline $10-11$ & 00 & Constants \\
\hline 12 & 11 or 12 Punch & $\begin{array}{l}\text { Sign of geographic latitude. } 11 \text { indicates } \\
\text { southern latitude, } 12 \text { indicates northern latitude. }\end{array}$ \\
\hline $13-15$ & $00.0 \leqq x x \cdot x \leqq 90.0$ & Geographic latitude $(\lambda)$ in degrees \\
\hline $16-19$ & $000.0 \leqq x x x . x<360.0$ & $\begin{array}{l}\text { Reference longitude }\left(\theta_{\mathrm{R}}\right) \text { for time zone } \\
\text { See [Jones and Gallet, } 1962 a, \text { section 3.1.] }\end{array}$ \\
\hline $20-21$ & 00 & Constants \\
\hline 22 & 11 or 12 Punch & $\begin{array}{l}\text { Sign of time correction. } 11 \text { indicates negative } \\
\text { correction, } 12 \text { indicates positive correction. }\end{array}$ \\
\hline $23-25$ & $x \cdot x x$ & $\begin{array}{l}\text { Time correction (in hours). } \\
\text { T.C. }=\left(\theta-\theta_{\mathrm{R}}\right) / \mathrm{I} 5 \text {. }\end{array}$ \\
\hline $26-29$ & $000.0 \leqq x \times x . x<360.0$ & $\begin{array}{l}\text { Geomagnetic longitude: see Smithsonian Physical } \\
\text { Tables, Ninth Revised Edition, pp. } 493-501 .\end{array}$ \\
\hline $30-31$ & 00 & Constants \\
\hline 32 & 11 or 12 Punch & $\begin{array}{l}\text { Sign of geomagnetic latitude. } 11 \text { indicates } \\
\text { south, } 12 \text { indicates north. }\end{array}$ \\
\hline $33-35$ & $x x \cdot x$ & $\begin{array}{l}\text { Geomagnetic latitude: see Smithsonian Physical } \\
\text { Tables, Ninth Revised Edition, pp. 493-501. }\end{array}$ \\
\hline
\end{tabular}




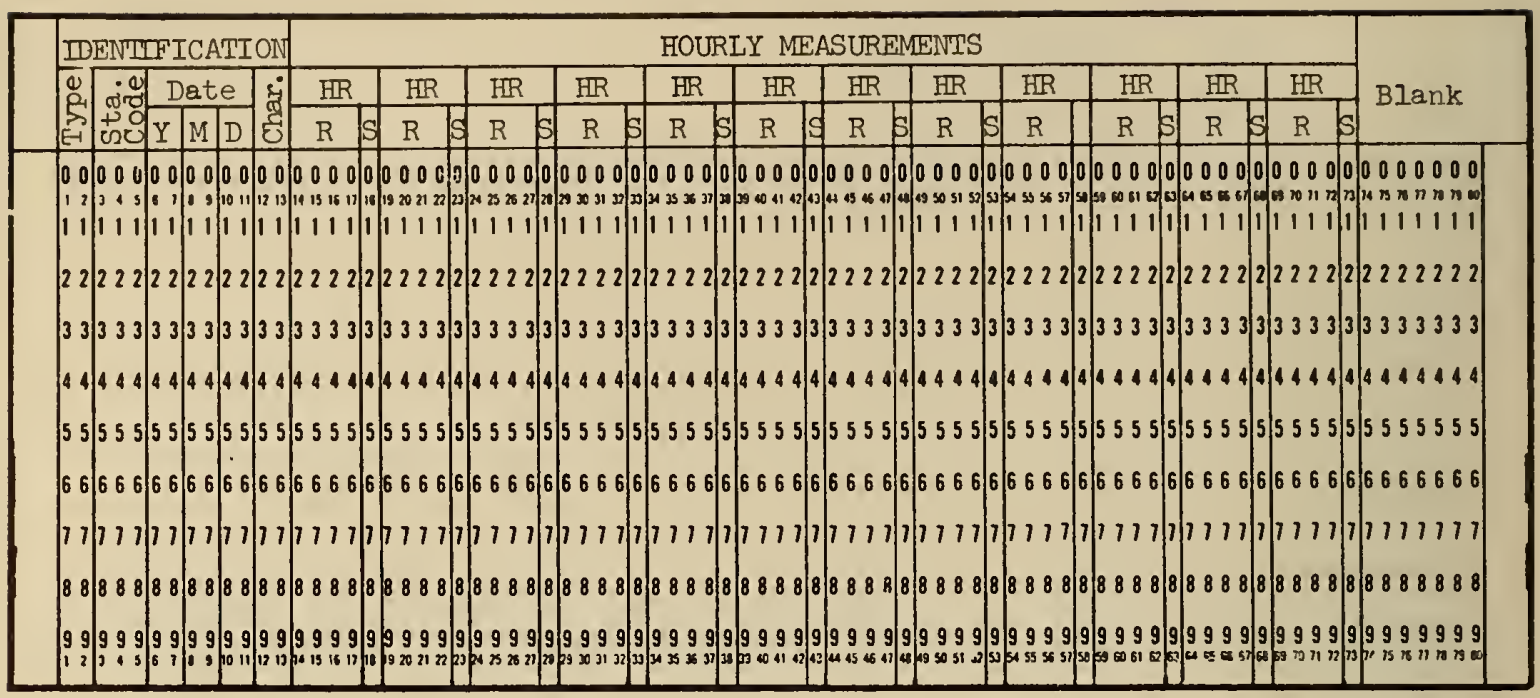

\begin{tabular}{|c|c|c|}
\hline CARD COLUMN & DESCRIPTION & REMARKS \\
\hline 1 & 1 & Ionospheric data \\
\hline 2 & 1 or 2 & $\begin{array}{l}1 \text { refers to hours from } 00: 00 \text { to } 11: 00 \\
2 \text { refers to hours from 12:00 to } 23: 00 \\
\end{array}$ \\
\hline $3-5$ & STC & Station code \\
\hline $6-7$ & $Y Y$ & Year \\
\hline $8-9$ & MM & Month \\
\hline $10-11$ & $\mathrm{DD}$ & $\begin{array}{ll}\text { Date: } & 01 \leqq D D \leqq 31 \text { indicates day of month } \\
& \mathrm{DD}=45 \text { indicates monthly median }\end{array}$ \\
\hline 12 & L & $\begin{array}{l}\text { Ionospheric layer: } L=0, F \text {-layer; } L=1 \text {, } \\
\text { Fl-layer; } L=2, E \text {-layer }\left[L=3, E_{S} \text {-layer }\right.\end{array}$ \\
\hline 13 & $\mathrm{C}$ & $\begin{array}{l}\text { Ionospheric characteristic: } \mathrm{C}=0, \text { fo; } \mathrm{C}=1 \text {, } \\
\mathrm{fx} ; \mathrm{C}=3, \mathrm{M} 3000 ; \mathrm{C}=4, \mathrm{~h} ; \mathrm{C}=5, \mathrm{~h}_{\mathrm{p}}\end{array}$ \\
\hline $14-73$ & Hourly Readings & Twelve readings of five positions each \\
\hline & & $\begin{array}{l}\text { First four positions--numerical reading }(\mathrm{R}) \\
\text { Fifth position--qualifying symbol }(\mathrm{S})\end{array}$ \\
\hline & & \\
\hline & & \\
\hline & & \\
\hline & & \\
\hline & & \\
\hline
\end{tabular}




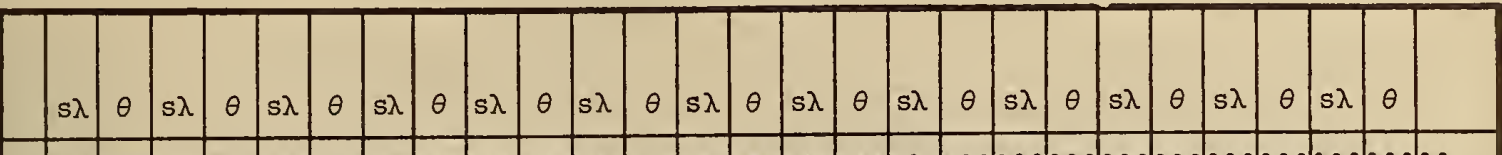

0000000000000000000000000000000000000.0000000000000000000000000000000000000000000000000

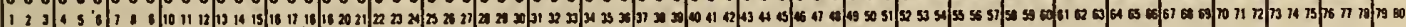

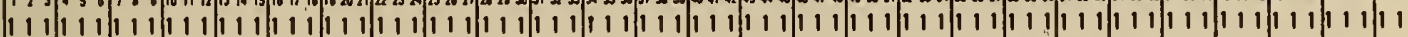

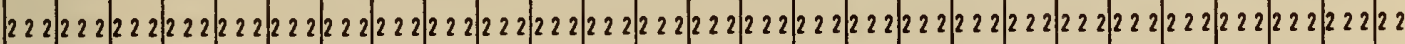

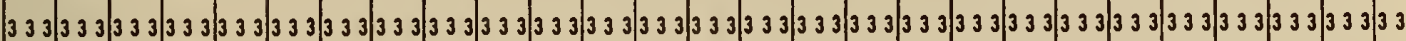

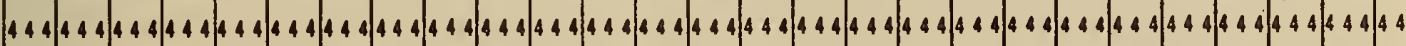
55555555555555555555555555555555555555555555555555555555555555555555555555555555

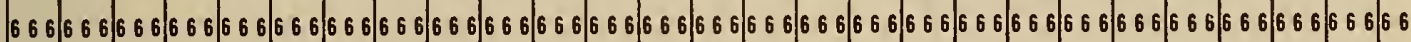

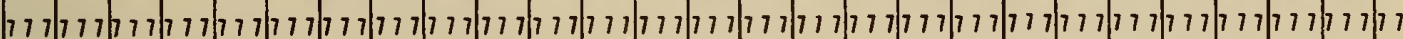

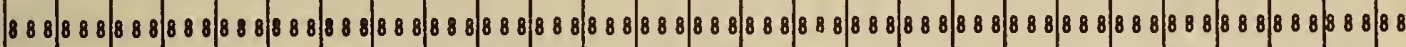

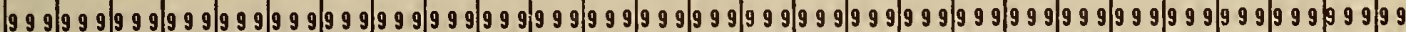

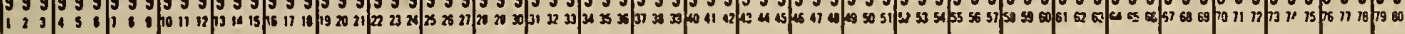

\begin{tabular}{|c|c|c|}
\hline CARD COLUMN & DESCRIPTION & REMARKS \\
\hline \multirow[t]{2}{*}{$1,7, \ldots, 73$} & s & Sign of geographic latitude \\
\hline & & (blank for plus and - for minus) \\
\hline $2-3,8-9,74-75$ & $\lambda \dot{\lambda}$ & Geographic latitude (degrees) \\
\hline $\begin{array}{r}4-6,10-12 \\
\ldots, 76-78 \\
\end{array}$ & $\theta \theta \theta$ & $\begin{array}{l}\text { Geographic longitude } \\
\text { (degrees east of Greenwich) }\end{array}$ \\
\hline & & \\
\hline & & \\
\hline & & \\
\hline & & \\
\hline & & \\
\hline & & \\
\hline & & \\
\hline & & \\
\hline & & \\
\hline & & \\
\hline
\end{tabular}


COEFFICIENTS $D_{\text {SK }}$ AND $h_{\text {SK }}$ DEFINING NUMERICAL

MAPS OF IONOSPHERIC CHARACTERISTICS

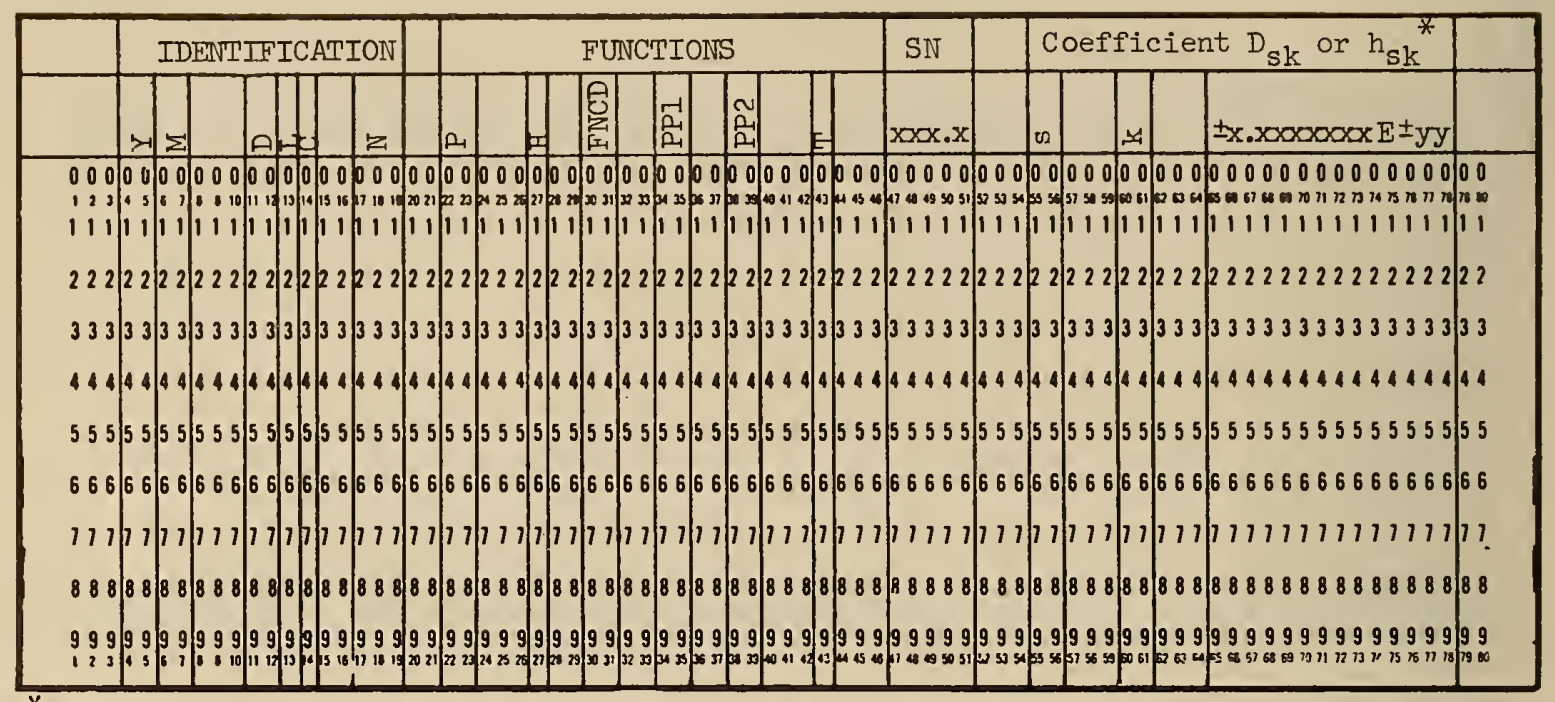

* For $D_{s k}$ or $h_{s k}$, the number given by the first eight digits and sign is multiplied by 10 raised to the power given by the last two digits and sign.

\begin{tabular}{|c|c|c|}
\hline CARD COLUMN & DESCRIPTION & REMARKS \\
\hline $4-5$ & YY & Year \\
\hline $6-7$ & MM & Month \\
\hline $11-12$ & DD & Date: See Ionospheric Data Card Format. \\
\hline 13 & $I$ & $\begin{aligned} & \text { Ionospheric layer: } \begin{array}{l}\text { See Ionospheric Data } \\
\text { Card Format. }\end{array} \\
&\end{aligned}$ \\
\hline 14 & $\mathrm{C}$ & $\begin{array}{c}\text { Ionospheric Characteristic: See Ionospheric } \\
\text { Data Card Format. }\end{array}$ \\
\hline $17-19$ & NNNN & Number of stations used in the analysis \\
\hline $22-23$ & $P$ & $\mathrm{P}+1=\mathrm{K}+\mathrm{I}=$ Number of geographic functions \\
\hline 27 & $\mathrm{H}$ & Number of harmonics for diurnal analysis \\
\hline $30-31$ & FNCD & Function identification code \\
\hline $34-35$ & $\mathrm{PP1}$ & $\mathrm{k}_{0}=$ Highest term for main latitudinal variation \\
\hline $38-39$ & PP2 & $\begin{aligned} \mathrm{k}_{1}= & \text { Highest term for first order } \\
& \text { longitudinal variation }\end{aligned}$ \\
\hline 43 & $\mathrm{~T}$ & $\begin{array}{l}T=1 \text { for coefficients } D_{s k} \\
T=2 \text { for coefficients } h_{s k}\end{array}$ \\
\hline $47-51$ & $\mathrm{xxx} \cdot \mathrm{x}$ & Sunspot number \\
\hline $\begin{array}{l}55-56 \\
60-61 \\
\end{array}$ & $\begin{array}{l}\text { ss } \\
\mathrm{kk}\end{array}$ & $\begin{array}{l}\text { Indices for coefficients } D_{\mathrm{sk}} \text { or } \mathrm{h}_{\mathrm{sk}} \\
\text { [Jones and Gallet, 1962a, chapter } 7 \text { ] }\end{array}$ \\
\hline $65-78$ & $\pm x \cdot x \times x \times x \times x \times \pm y y$ & Coefficient $D_{s k}$ or $h_{s k}$ in floating decimal form \\
\hline
\end{tabular}




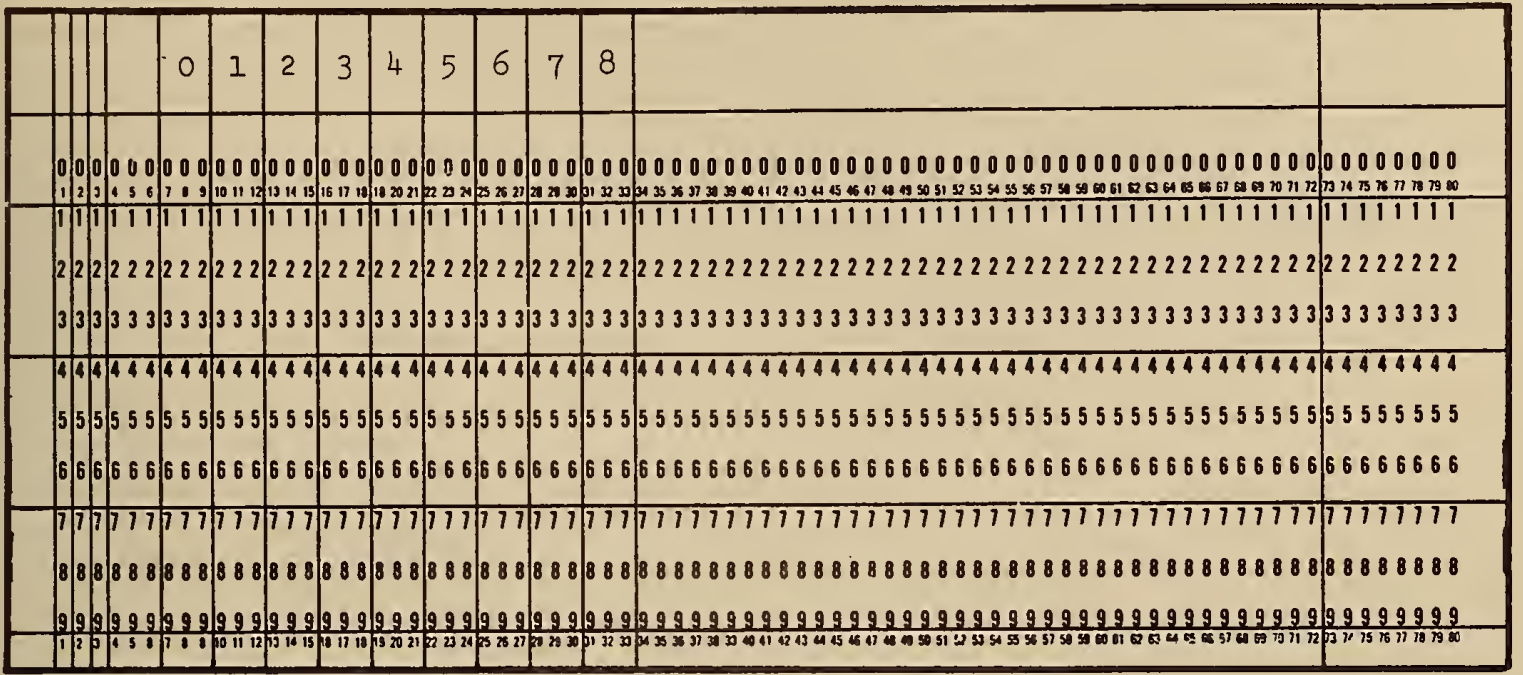

\begin{tabular}{|l|l|l|}
\hline CARD COLUMN & \multicolumn{1}{|c|}{ DESCRIPTION } & REMARKS \\
\hline 1 & 7 and 9 Punch & Column binary \\
\hline $2-3$ & & Absolute binary location (100) 10 \\
\hline $4-6$ & Check Sum & \\
\hline $7-9$ & YYMM & Year, month \\
\hline $10-12$ & DDLC & Date, layer, characteristic \\
\hline $13-15$ & N & Number of stations (A and B data) \\
\hline $16-18$ & P & P+1 = K+1 = Number of geographic functions \\
\hline $19-21$ & H & Number of harmonics for diurnal analysis \\
\hline $22-24$ & FNCD & Function identification code \\
\hline $25-27$ & PP1 & $\mathrm{k}_{0}: \begin{array}{l}\text { Highest term for main } \\
\text { latitudinal variation }\end{array}$ \\
\hline $28-30$ & PP2 & $\mathrm{k}_{1}:$ H1ghest term for first order \\
longitudinal variation
\end{tabular}





\section{DATA READ SUBROUTINE OI}

The data read subroutine (SR Ol) is employed by the numerical map executive program for reading and storing the header card, fixed data, and ionospheric ( $A$ and $B$ ) data. Although most of the necessary information concerning input is given in section 2, certain additional information is necessary, in particular, the discussion of the scale factor and the list of stops resulting from improper input (section 3g). Other topics include: output, storage, calling sequence, subroutines used, general remarks, and program logic (flow chart 3).

(a) Input (see sample printout, appendix A)

Input card formats and sample printouts were discussed in section 2. One fixed data card and two ionospheric data cards must be read for each station (for $A$ and $B$ data). All fixed data cards precede the ionospheric data cards, and the latter must be paired by stations in the same order as the fixed data. In each pair, the type 1 card (col. 2) must precede the type $2 \operatorname{card}(\operatorname{col} .2)$. Also, the stations with $A$ data must precede those with $B$ data.

For ionospheric data other than foF2, a special scale factor must be inserted in the header card. The ionospheric data are assumed to be given by four digit numbers (XXXX) (see card format 3). If no scale factor (blank) is punched on the header card, the program places a decimal point between the second and third digits (XX.XX). For other characteristics, however, (such as M3000) the position of the decimal point is specified by the scale factor. A scale factor of plus (or minus) $n(n \neq 0)$ moves the decimal point $n$ places to the right (or left) from the position at the right of the fourth digit. "Minus zero" places the decimal point to the right of the fourth digit. For example, for M3000 the scale factor is -3 so that each ionospheric reading is taken as X.XXX.

(b) Output includes: station code, geographic longitude $(\theta)$ and latitude $(\lambda)$, time correction, and ionospheric data. 
Flow Chart 3

DATA READ SUBROUTTNE OI

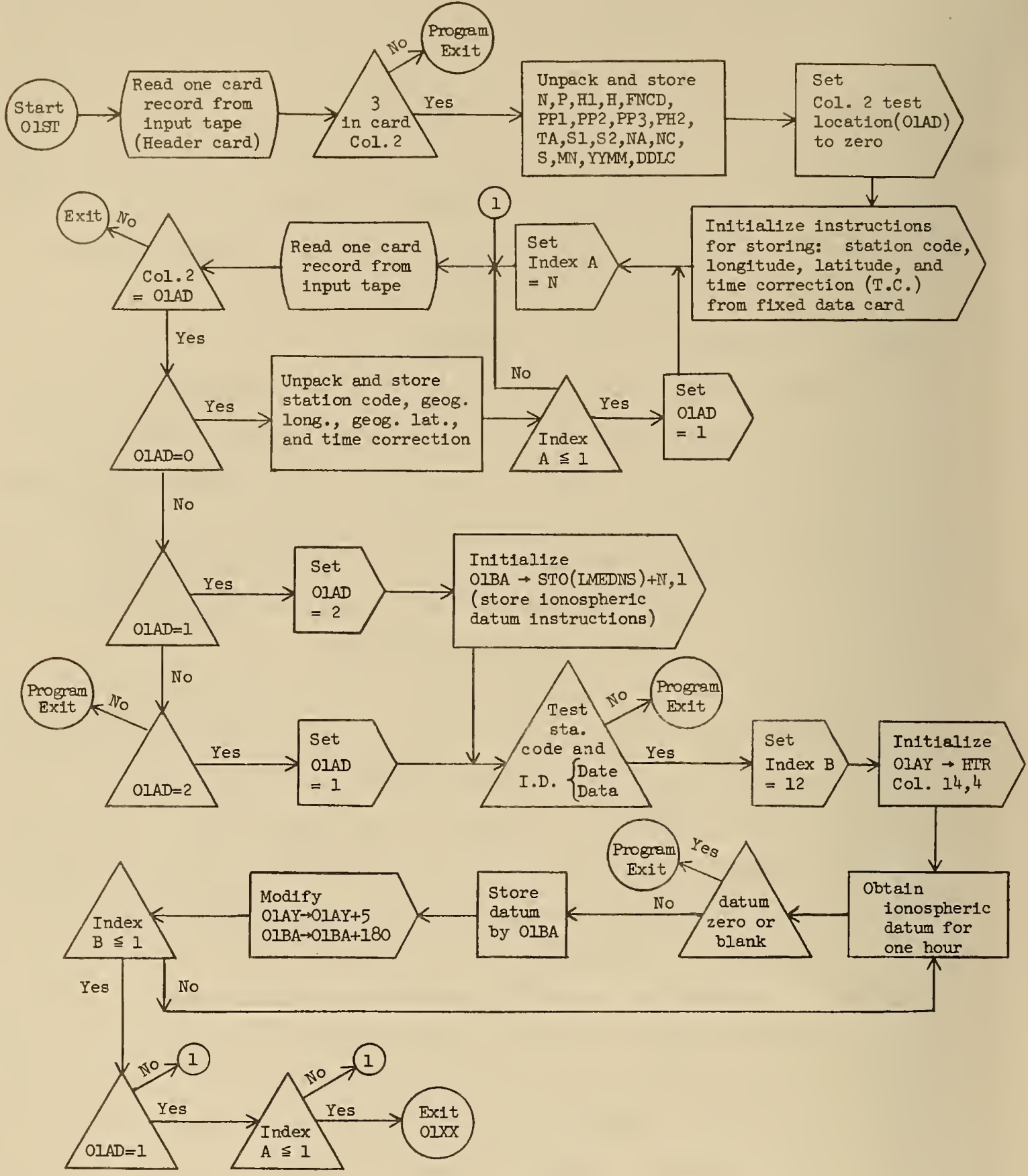


(c) Storage (see storage plan in section 2)

The input uses maximum storage of 5040 locations starting at (5101) $_{10^{\circ}}$ SR 01 itself takes 157 locations.

(d) Calling sequence

$$
\begin{array}{ccc}
\text { C I A } & \text { (EXTIN) } \\
\text { S T O } & \text { OIXX } \\
\text { T R A } & \text { OIST } \\
\text { (EXTIN) } & \text { T R A } & \text { (NEXT) }
\end{array}
$$$$
\text { (NEXT) (CONTINUE) }
$$

(e) Subroutines used

Modified share subroutine PE-CSMO, which includes: READT, FLOAT, FIXED, SCAIE, and BCDPK.

(f) Remarks

(1) Index registers $A, B$, and C are used with no provision to restore them.

(2) In order to read data on tapes other than Al or A2, a modification must be made in READT.

(g) Stops

SR Ol stops at OIAC for the following conditions:

(1) An ionospheric datum is zero or blank.

(2) Input cards not in proper order with respect to column 2. Proper order requires: (i) first card has 3 in column 2, (ii) the following $\mathbb{N}$ cards have 0 in column 2, and (iii) the following $2 \mathbb{N}$ cards have alternately 1 and 2 in column 2 .

(3) Column 2 contains a number other than 3, 0, 1, 2.

(4) Identification of ionospheric data cards does not match identification on header card or ionospheric data cards (in pairs) are in different order from fixed data cards. 



\section{FOURIER ANALYSIS SUBROUTINE 02}

SR 02 is used to compute Fourier coefficients for the diurnal analysis of the ionospheric data. The coefficients are then corrected to local mean time [Jones and Gallet, 1962a, section 3.1]. SR 02 is entered one time for each set of ( $A$ and $B$ ) ionospheric data (i.e., N times). This section gives a general description of the subroutine including the program logic (flow chart 4 ).

(a) Input

(1) Hourly values $y_{1}, y_{2}, \ldots, y_{24}$ of ionospheric data from one station.

(2) Number $\mathrm{H}$ of harmonics.

(3) Time correction T.C. (in hours).

(b) Output

Fourier coefficients $a_{0}, a_{j}$, and $b_{j}$, amplitudes $c_{j}$ and phase angles $\psi_{j}$ corrected to local mean time (I.MT) for $j=1,2, \ldots, H$ (see [Jones and Gallet, 1962a], section 3.1). Note: the $c_{j}$ and $\psi_{j}$ are merely intermediate results and hence are not permanently stored.

(c) Storage

There are $4(H+I)$ storage locations required for output: $\mathrm{AO}$ to $\mathrm{AO}+\mathrm{H}, \quad \mathrm{BO}$ to $\mathrm{BO}+\mathrm{H}, \mathrm{CO}$ to $\mathrm{CO}+\mathrm{H}$, and $\mathrm{PSIO}$ to $\mathrm{PSIO}+\mathrm{H}$. The routine itself (not including subroutines) takes 328 storage locations.

(d) Calling sequence

$$
\begin{array}{lccc} 
& \text { C L A } & \text { (EXTIN) } \\
\text { S T O } & \text { O2XX } \\
\text { (EXTIN) } & \text { T R A } & \text { (NEXT) } \\
\text { (NEXT) } & \text { (CONTINUE) }
\end{array}
$$

(e) Subroutines used

Share subroutines: UASQR 4, NAO331, UA-S + CL, and UA-SPHI 
Flow Chart 4

FOURIER ANALYSIS SUBROUIINE O2

$\left(x=\right.$ zone time hour angle; $\left.x_{1}=\left(15^{\circ} 1-180^{\circ}\right) ; 1=0,1, \ldots, 23\right)$
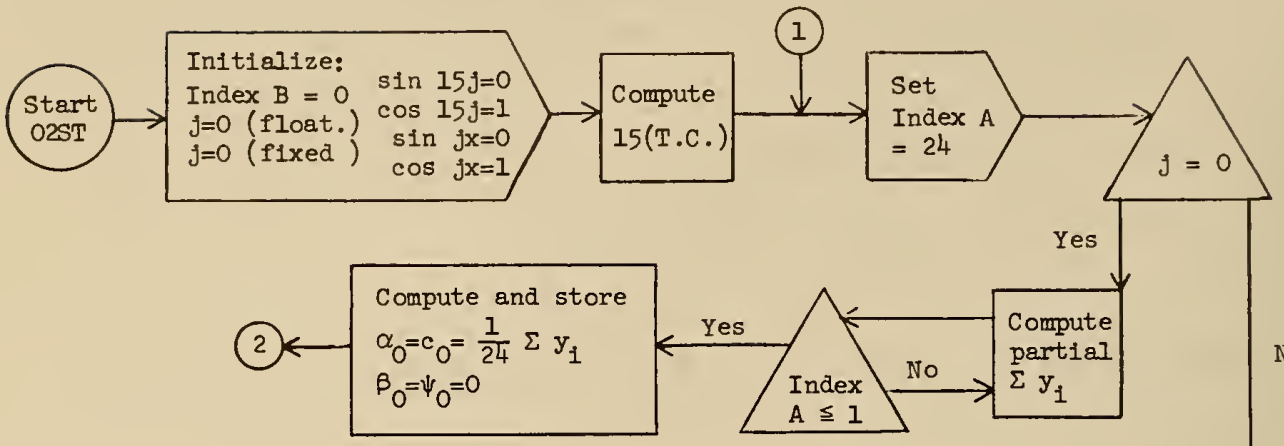

No

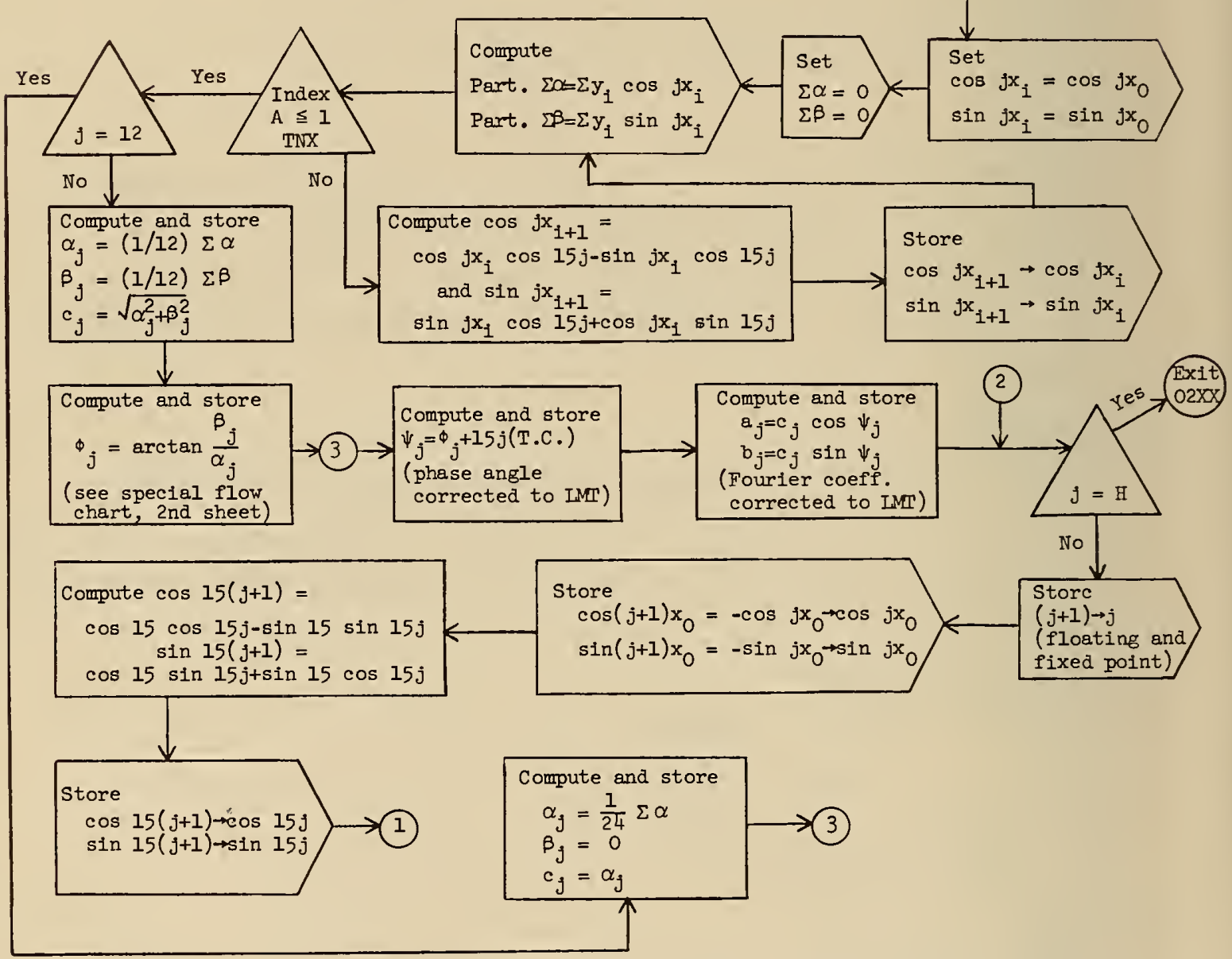


Flow Chart 4 (Cont.)

Special Flow Chart for Computing ${ }_{f}$

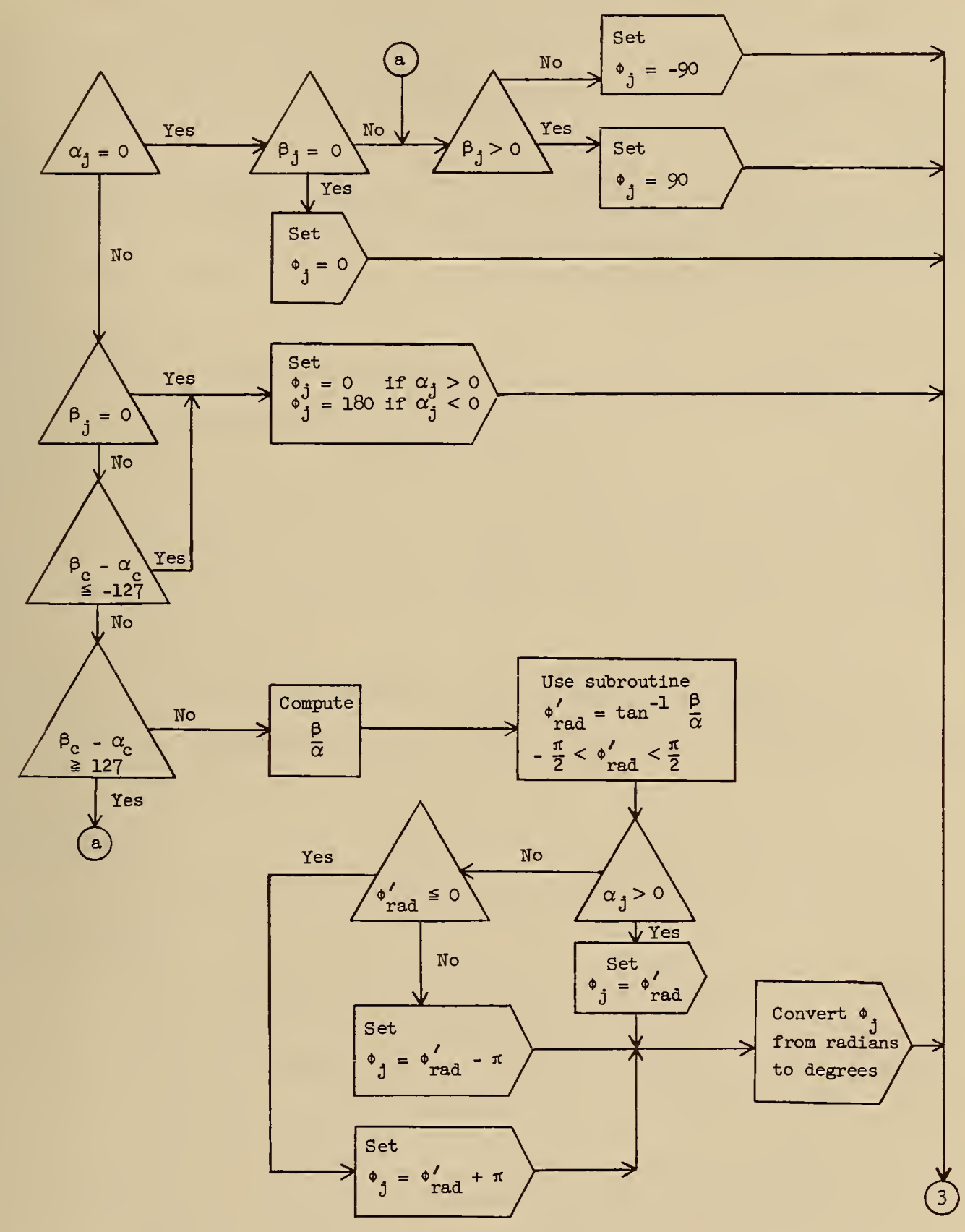


(f) Remarks

(1) The AC and MQ overflow indicators should be off at entry to SR 02 .

(2) Index registers $A, B$, and C are used with no provision to restore them.

(g) Stops

A halt will occur at 02BM +2 if an attempt is made to take the square root of a negative number. 
5. GEOGRAPHIC FUNCTIONS SUBROUTINE O4

SR 04 is used to evaluate the geographic functions $G_{k}(\lambda, \theta)$ at station coordinates and at screen point coordinates (see table 1 ). These functional values are subsequently used in the geographic analyses. For this purpose, SR 04 is entered one time for each of the $\mathbb{N}$ stations and once for each screen point. SR 04 is again entered once for each of the $\mathbb{N}$ stations for computing residuals (section 7). A general description of the subroutine is given, including the program logic (flow chart 5).

(a) Input

(1) Geographic coordinates $\left(\lambda_{i}, \theta_{i}\right)$ for one station $\left(\lambda_{i}=\right.$ latitude, $\theta_{i}=$ longitude $)$.

(2) Parameters PPI ( $\geqq 1), \quad P P 2$, and PP3 = P defining the choice of geographic functions $G_{k}(\lambda, \theta)$. If no longitude terms are desired, we set PP1 $=$ PP2 $=$ PP3 $=$ P. See table 1 (this section) and the discussion of the choice of functions in section 2.1.

(3) Function identification code FNCD (see header card).

(4) If 04ST entry is used, $\mathbb{N}, \mathbb{N}-1, \ldots, 1$ must be in index register A.

(b) Output

Geographic function values $G_{k}\left(\lambda_{i}, \theta_{i}\right), k=0,1, \ldots, k$.

(c) Storage

(1) Entry through 04ST causes the $G_{k}\left(\lambda_{i}, \theta_{i}\right)$ to be stored in matrix form involving $\mathbb{N}(\mathrm{K}+1)$ elements.

(2) Entry through 04ST2 causes the $G_{k}\left(\lambda_{i}, \theta_{i}\right)$ to be stored in consecutive locations starting at FUNCT. This involves $(\mathrm{K}+\mathrm{I})$ elements.

(3) $\mathrm{SR} 04$ (not including subroutines) itself requires 286 storage locations. 
TABLE I

GEOGRAPHIC FUNCTIONS $G_{k}(\lambda, \theta)$

\begin{tabular}{|c|c|c|}
\hline & $\mathrm{k}$ & $G_{k}(\lambda, \theta)$ \\
\hline & $\begin{array}{l}0 \\
I \\
2 \\
\ldots \\
k_{0} \\
\end{array}$ & $\begin{array}{c}1 \\
\sin \lambda \\
\sin ^{2} \lambda \\
\cdots{ }^{q} 0_{\lambda}\end{array}$ \\
\hline ت্ & $\begin{array}{l}k_{0}+1 \\
k_{0}+2\end{array}$ & $\begin{array}{l}\cos \lambda \cos \theta \\
\cos \lambda \sin \theta\end{array}$ \\
\hline 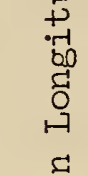 & $\begin{array}{l}k_{0}+3 \\
k_{0}+4\end{array}$ & $\begin{array}{l}\sin \lambda \cos \lambda \cos \theta \\
\sin \lambda \cos \lambda \sin \theta\end{array}$ \\
\hline $\begin{array}{l}\cdot-1 \\
4 \\
0 \\
0 \\
0 \\
0 \\
0\end{array}$ & $\begin{array}{l}\cdots \\
\cdots\end{array}$ & $\begin{array}{lll}\ldots & \ldots & \ldots \\
\ldots & \ldots & \ldots\end{array}$ \\
\hline $\begin{array}{l}+2 \\
02 \\
.1 \\
o-1 \\
i=1\end{array}$ & $\begin{array}{l}k_{1}-1 \\
k_{1}\end{array}$ & 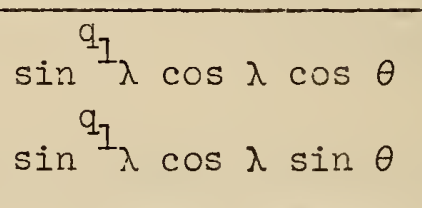 \\
\hline שี & $\begin{array}{l}k_{1}+1 \\
k_{1}+2\end{array}$ & $\begin{array}{l}\cos ^{2} \lambda \cos 2 \theta \\
\cos ^{2} \lambda \sin 2 \theta\end{array}$ \\
\hline 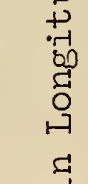 & $\begin{array}{l}k_{1}+3 \\
k_{1}+4\end{array}$ & $\begin{array}{l}\sin \lambda \cos ^{2} \lambda \cos 2 \theta \\
\sin \lambda \cos ^{2} \lambda \sin 2 \theta\end{array}$ \\
\hline 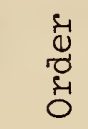 & $\begin{array}{l}\cdots \\
\cdots\end{array}$ & $\begin{array}{lll}\cdots & \cdots & \cdots \\
\cdots & \cdots & \cdots\end{array}$ \\
\hline $\begin{array}{l}\text { ro } \\
0 \\
0 \\
0 \\
0\end{array}$ & $\begin{array}{l}\mathrm{K}-\mathrm{I} \\
\mathrm{K}\end{array}$ & $\begin{array}{l}\sin ^{q_{2}} \lambda \cos ^{2} \lambda \cos 2 \theta \\
\sin ^{q_{2}} \lambda \cos ^{2} \lambda \sin 2 \theta\end{array}$ \\
\hline
\end{tabular}


Flow Chart 5

GEOGRAPHIC FUNCTIONS SUBROUTINE 04

$\left(\begin{array}{l}\text { LGK }=\text { Loc. of } G_{k}\left(\lambda_{1}, \theta_{i}\right), i=1,2, \ldots, N, k=0,1, \ldots, P . \\ \text { FUNICT }=\text { Loc. of } G_{k}(\lambda, \theta), \quad k=0,1, \ldots, P .\end{array}\right)$

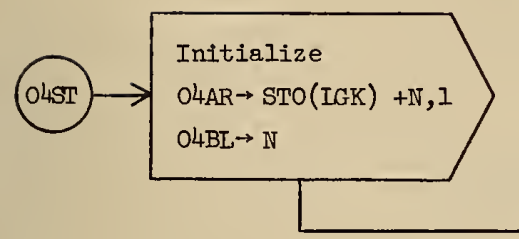

(24ST2
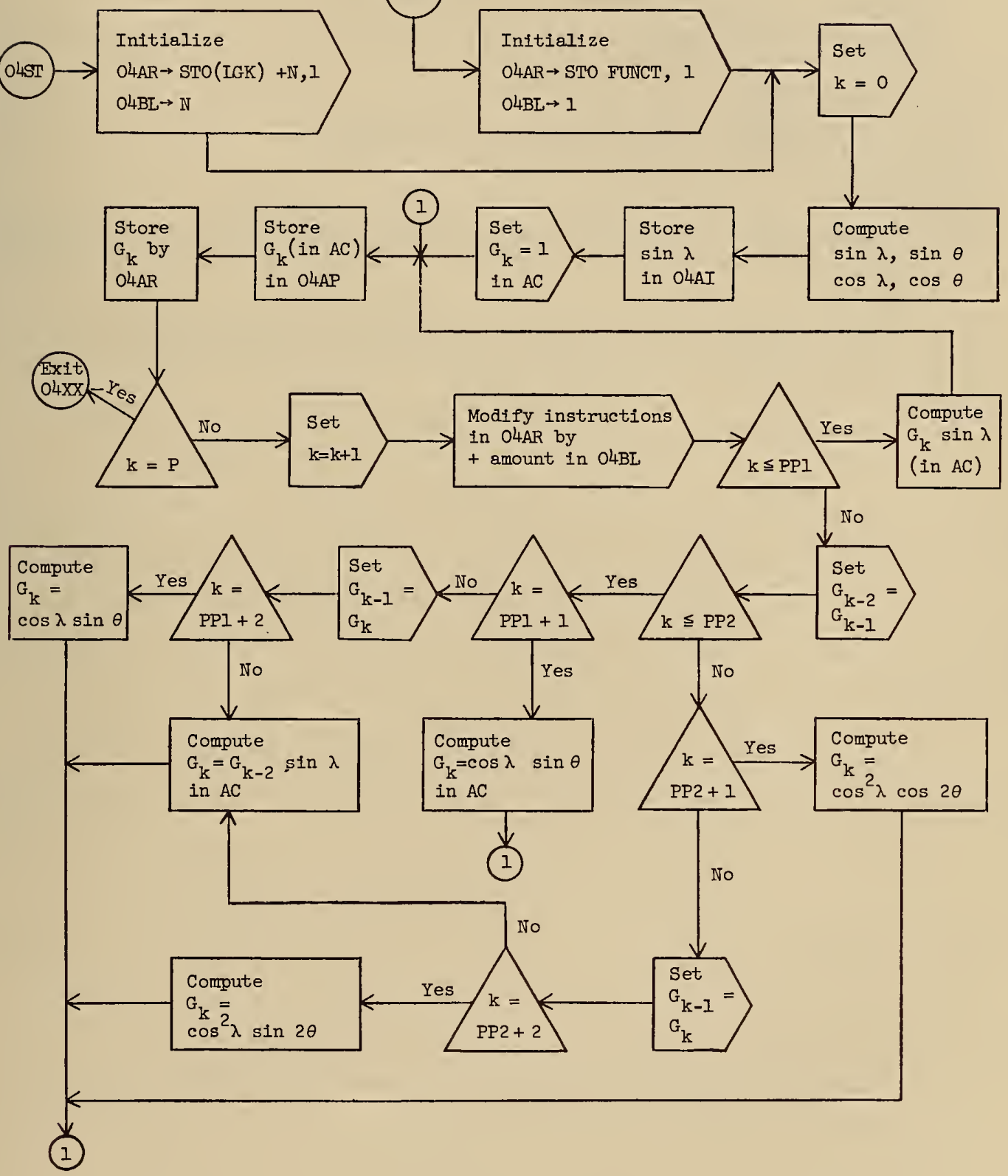
(d) Calling sequence

C I A EXTIN

S T $0 \quad 04 X X$

T R A O4ST (or 04ST2)

EXTIN T R A (NEXT)

(NEXT) (CONTINUE)

(e) Subroutines used

Share subroutines: UA-S +CL and UA-SPHI

(f) Remarks

(I) The $\mathrm{AC}$ and $\mathrm{MQ}$ overflow indicators should be off at entry to SR 04.

(2) Index registers $A, B$, and C are used with no provision to restore them. 


\section{SYMTHESIS SUBROUTINES 05-10}

\section{I Explanatory Remarks}

Six subroutines are described in the present section. These subroutines are used to compute the value of the function $\Gamma(\lambda, \theta, t)$. One frequently needs to evaluate $\Gamma(\lambda, \theta, t)$, (a) at many locations for a fixed instant of time, or (b) at a fixed location for several different instants of time. In such cases, considerable savings in computer time can be gained by use of the following subroutines. The techniques employed are described in detail in section 3.1 of [Jones and Gallet, $1962 \mathrm{~b}]$.

(a) SR 08 should be used when, for successive computations, $\Gamma$ is evaluated for a fixed $t$ and varying $\lambda$ and $\theta$. The entry for the first of such computations is 085T, and for all following 085T2 until $t$ changes.

(b) SR 09 should be used for fixed $\lambda$ and $\theta$ and varying $t$. The entry for the first of such computations is 09ST and for subsequent computations 09ST2 (until $\lambda$ and $\theta$ change).

(c) SR 10 should be used for successive computations of $\Gamma$ for fixed $T$ and $\theta$ and for varying $\lambda$. SR 10 is entered initially at IOST and then at IOST2 until $T$ and $\theta$ are changed.

The following three subroutines are used in connection with the above:

(d) SR 05 computes sin $j t$ and $\cos j t$ for $j=1,2, \ldots, H$, given $t, H$, and TRA exit instruction in 05XX.

(e) SR 06 computes $D_{k}(t)$ for $k=0,1, \ldots, K$, given the matrix of coefficients $D_{s k}$, sin $j t$ and $\cos j t(j=1,2, \ldots, H)$, $\mathrm{H}, \mathrm{K}$, and TRA exit instruction in 06XX. For an explanation of $D_{k}(t)$, see section 3.la of [Jones and Gallet, 1962b]. 
SYNTHESIS SUBROUTMNES 05-10

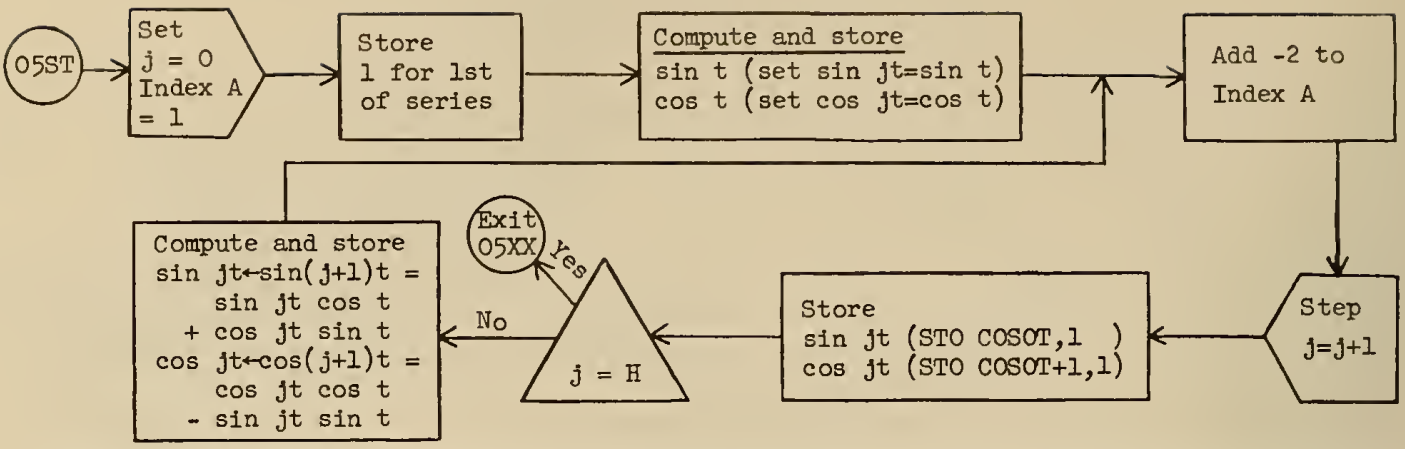

$$
\begin{aligned}
& \text { LDSK }=\text { Loc. of } D_{k}(t) \\
& \text { LDM }=\text { Loc. of } D_{s k} \text { coefficients. }
\end{aligned}
$$

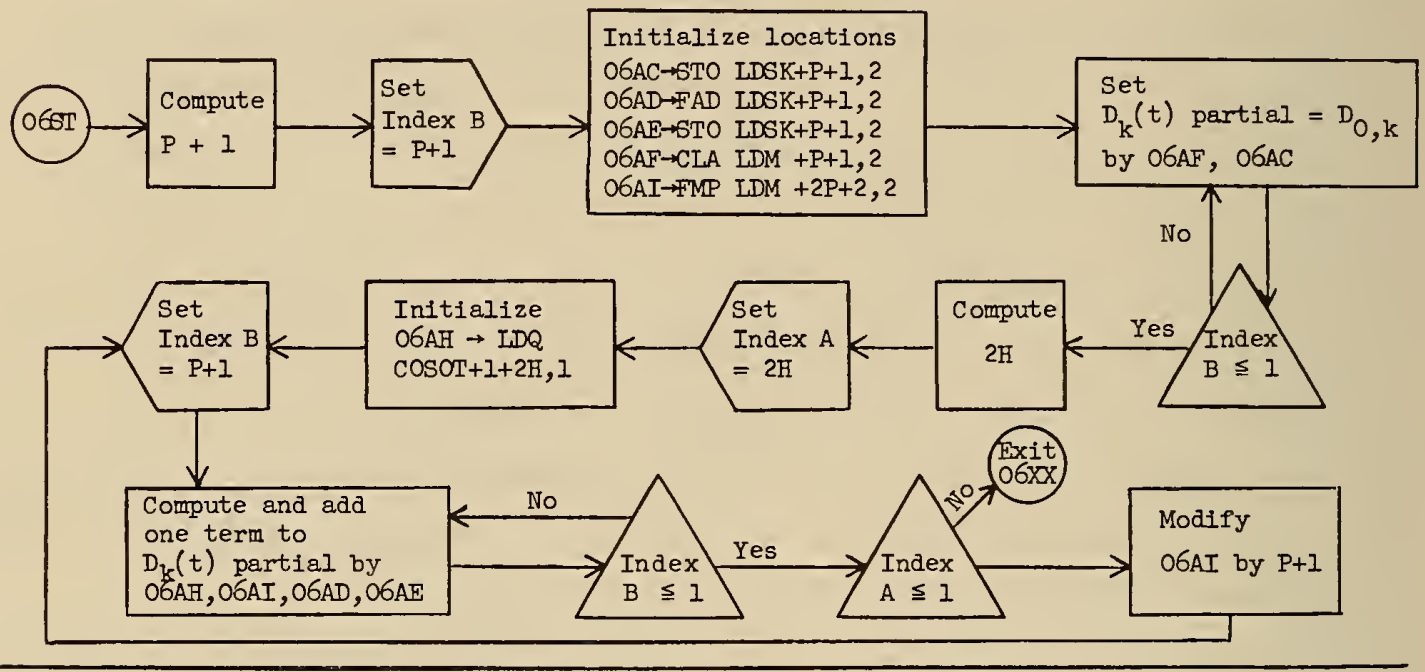

FUNCT $=$ Loc. of $G_{k}(\lambda, \theta), k=0,1, \ldots, P$.

LAIBT $=$ Loc of $a_{j}(\lambda, \theta)$ and $b_{j}(\lambda, \theta)$.

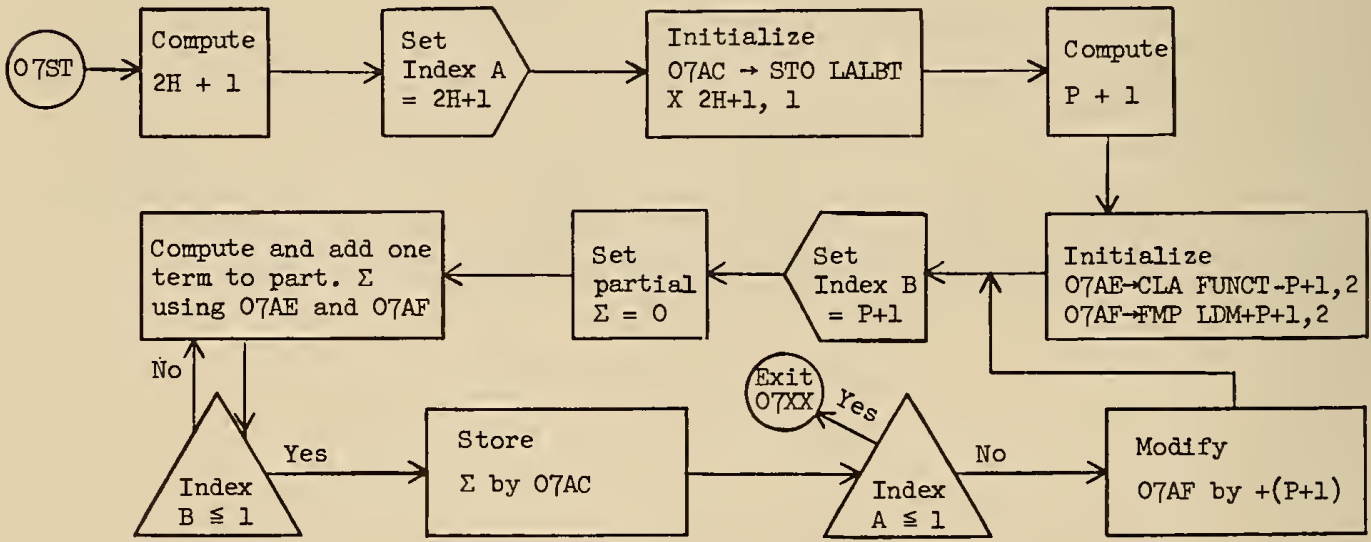


Compute $\Gamma(\lambda, \theta, t)$ for fixed $t$ and varylng $\lambda$ and $\theta$

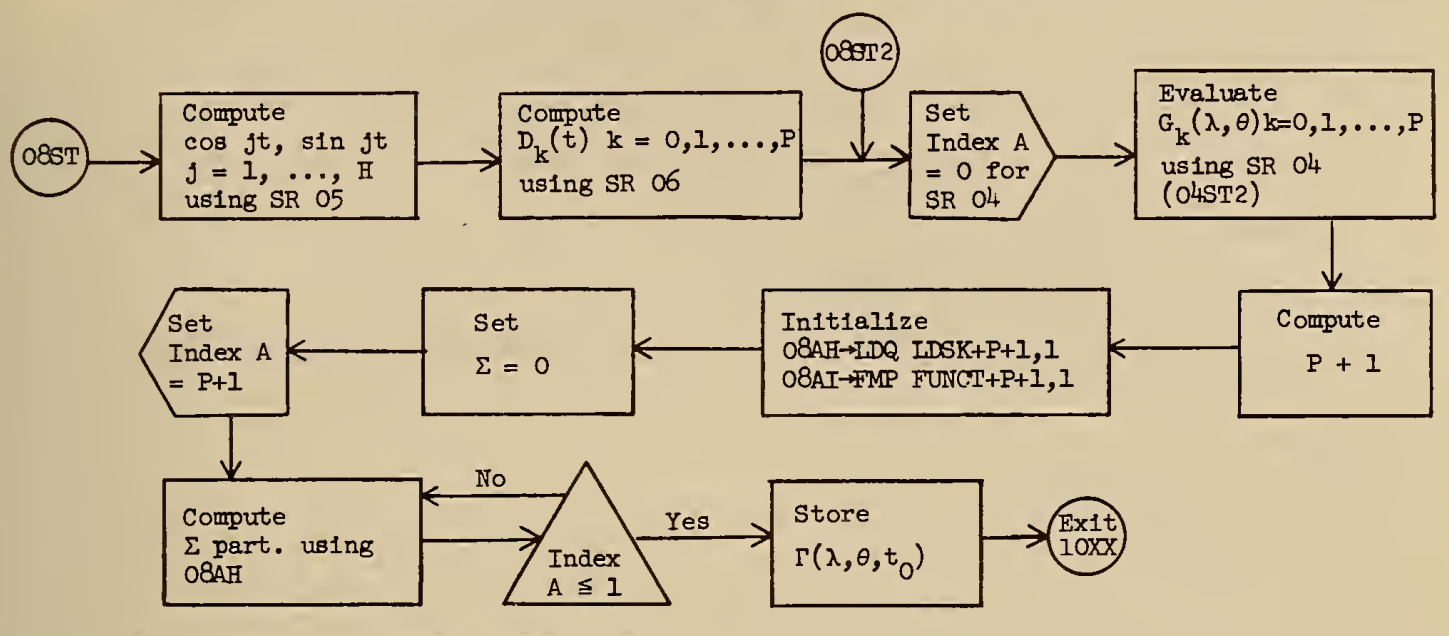

Compute $\Gamma(\lambda, \theta, t)$ for flxed $\lambda$ and $\theta$ and varylng $t$

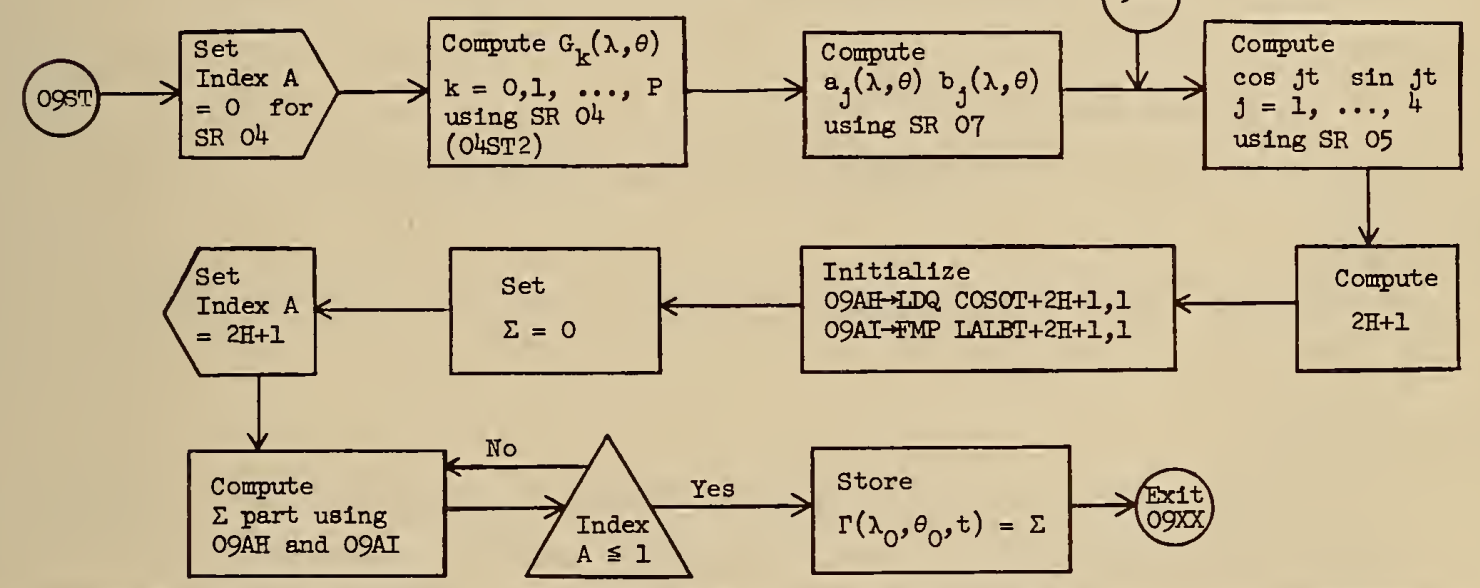

Compute $\Gamma(\lambda, \theta, t)$ for Ilxed $T=t-\theta$ and varying $\lambda$

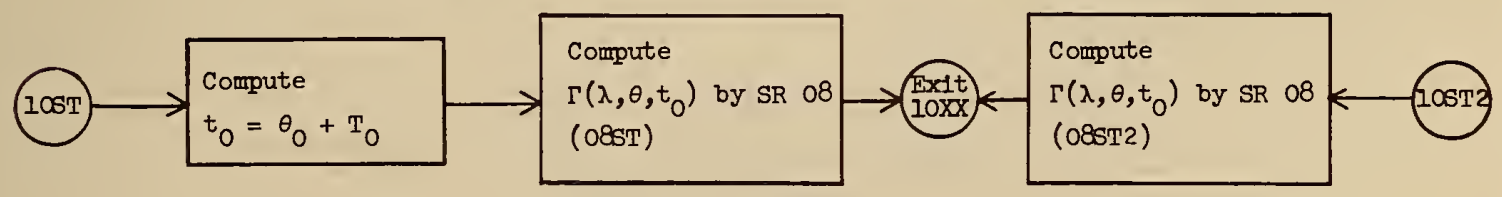


(f) SR 07 computes $a_{0}(\lambda, \theta), a_{j}(\lambda, \theta)$ and $b_{j}(\lambda, \theta) \quad(j=1,2, \ldots, H)$, given the matrix of coefficients $D_{\text {sk }}$, the functional values $G_{k}(\lambda, \theta) \quad(k=0,1, \ldots, K)$ from SR 04, $H, K$, and TRA exit instruction in $07 X X$. For an explanation of $a_{j}(\lambda, \theta)$ and $b_{j}(\lambda, \theta)$, see section 3.1c of [Jones and Gallet, 1962b]. (Entrance to SR 04 is through 04ST2.)

6.2 Program Description (for subroutines 08, 09 and 10)

(a) Input
(1) $\lambda=$ geographic latitude,
(2) $\theta=$ geographic longitude,
(3) $t=$ local mean hour angle, or
$T=$ universal hour angle.

(4) Matrix of coefficients $\mathrm{D}_{\mathrm{sk}}, \mathrm{s}=0,1, \ldots, 2 \mathrm{H}$ and $\mathrm{k}=0,1, \ldots, \mathrm{K}$.

(5) $\mathrm{PP} 1, \mathrm{PP} 2$, and $\mathrm{PP} 3=\mathrm{P}$.

(6) $\mathrm{H}=$ number of harmonics for the diurnal analysis.

(b) Output

The desired functional value, $\Gamma(\lambda, \theta, t)$ or $\Gamma(\lambda, \theta, \theta+\mathrm{T})$ where $t=\theta+T$.

(c) Storage

Subroutine 08 and 09 each take 72 storage locations, not including other subroutines used. SR 10 takes 11 storage locations in addition to the locations used in SR 08 and other subroutines.

(d) Calling sequence

C I A EXTIN

$S$ T 0 08XX (or 09XX or 10XX)

T R A 08ST (or 08ST2 or 09ST or 09ST2 or

(EXTIN) T R A (NEXT) IOST or IOST2)

(NEXT) (CONTINUE) 
(e) Subroutines used

SR 08 uses subroutines 04,05 and 06 (see remarks) and hence all subroutines used by these. SR 09 uses subroutines 04, 05, and 07 (see remarks). SR 10 uses SR 08 and all subroutines used by it.

(f) Remarks

The $A C$ and $M Q$ overflow indicators should be off at entry to subroutines 08, 09, and 10. They, along with their included subroutines, use index registers $A, B$, and $C$, making no provision to restore them. 



\section{RESIDUAL SUBROUTINE 11}

SR 11 is used to compute residuals between the original ionospheric data $(A$ and $B)$ and the values computed from $\Gamma(\lambda, \theta, t)$ and their root mean square. Examples of such results are given in the sample printout in appendix $B$. These results are used to test the "goodness of fit" of the function $\Gamma(\lambda, \theta, t)$ and to spot undue irregularities in the data. Separate results are obtained for the $A$ and $B$ data, since the residuals for the latter are in general systematically higher than for the former. The program description is followed by a logical diagram (flow chart 7).

(a) Input
(1) Matrix of coefficients $D_{\text {sk }}$,
(2) Ionospheric data ( $\mathrm{A}$ and $\mathrm{B}$ ),
(3) Station latitudes $\lambda_{i}(i=1,2, \ldots, \mathbb{N})$,
(4) Station longitudes $\theta_{i}(i=1,2, \ldots, \mathbb{N})$,
(5) Time corrections,
(6) Station codes,
(7) $N$ = number of stations ( $A$ and $B$ data),
(8) $\mathrm{PP1}, \mathrm{PP} 2$, and $\mathrm{PP} 3=\mathrm{P}$,
(9) $\mathrm{H}=$ number of harmonics for diurnal analysis, and
(10) Exit instruction TRA, in 11XX.

(b) Output (see sample printout 2, appendix B)

(1) For each station ( $A$ and $B$ data) the 24 hourly residuals (original ionospheric data minus values computed from $\Gamma(\lambda, \theta, t)$,

(2) Root mean square (RMS) of the 24 residuals from each station,

(3) RMS of residuals from A data stations taken together,

(4) RMS of residuals from $B$ data stations taken together, and

(5) RMS of residuals from all stations ( $A$ and $B$ data) taken together. 
Flow Chart 7

RESIDUAL SUBROUTINE II
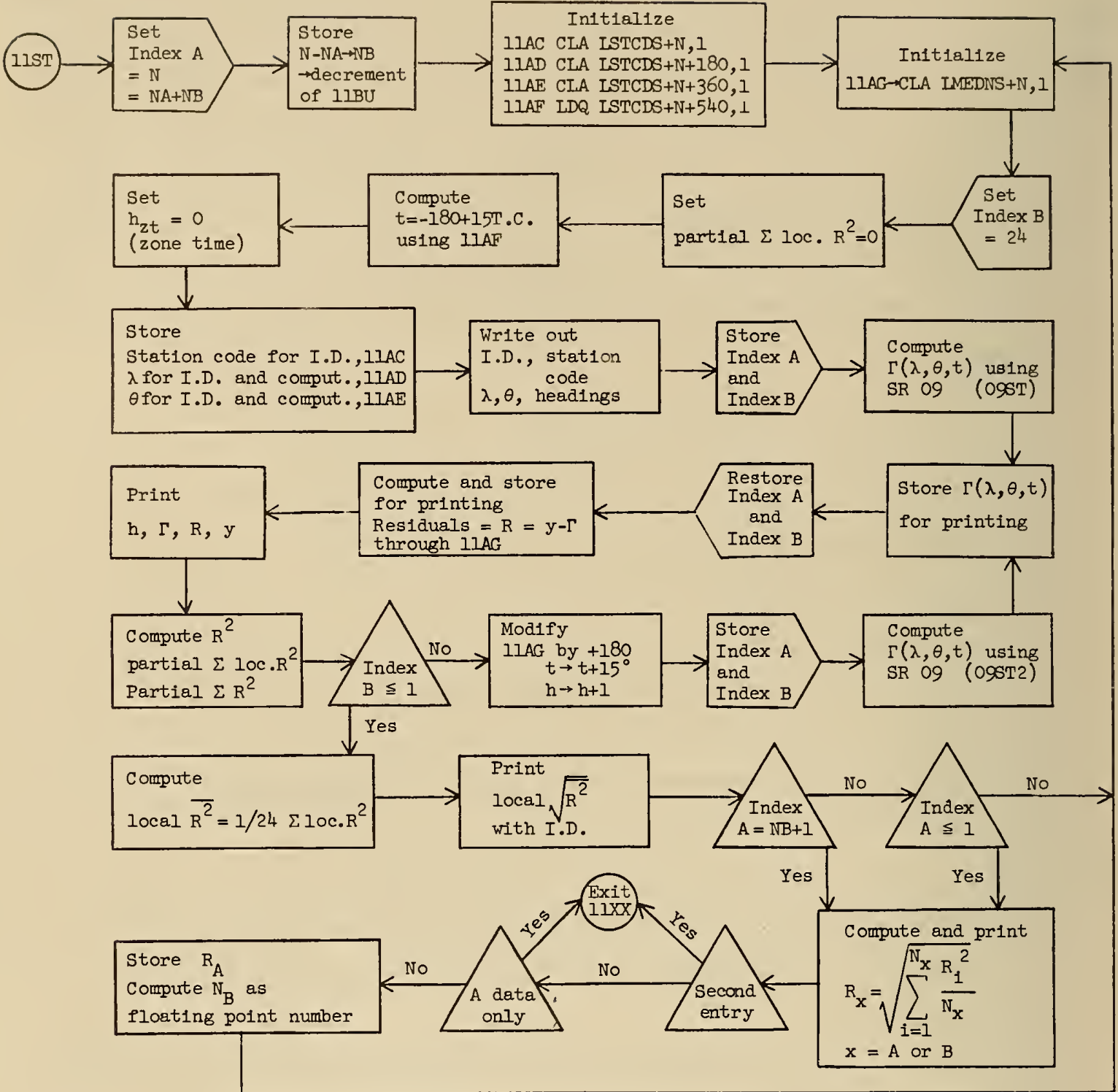
(c) Storage

SR 11 uses 185 storage locations (not including other subroutines employed).

(d) Calling sequence

$$
\begin{array}{ccc}
\text { C I A } & \text { (EXIIN) } \\
\text { S T O } & \text { IIXX } \\
\text { T R A } & \text { IIST } \\
\text { (EXIIN) } & \text { T R A } & \text { (NEXT) }
\end{array}
$$$$
\text { (NEXT) (CONTINUE) }
$$

(e) Subroutines used

Share subroutine UA-SPHI, SR 09, and all included subroutines.

(f) Remarks

(1) $\mathrm{AC}$ and $\mathrm{MQ}$ overflow indicators should be off at entry to SR 11 .

(2) Index registers $A, B$, and $C$ are used making no provision to restore them.

(g) Stops

(1) IIBM -4 \} if an attempt is made to take the square root

(2) $I I B Q-4$ ) of a negative number 


\subsection{Explanatory Remarks}

The general data fitting method described in chapters 2 and 6 of Jones and Gallet [1962a] is performed in the present program by five subroutines:

SR 20 Executive general data fitting,

SR 15 Inner products,

SR 17 Gram-Schmidt orthogonalization,

SR 19 Least squares fitting, and

SR 18 Coefficients $D_{\text {sk }}$.

SR 20 sets up the necessary requirements for input, output, storage, and number of entries to each of the other subroutines, and restores all index registers. Input, output, storage and calling sequences for SR 20 are included in section 8.2. The descriptions of the other subroutines are given in section $8.2 \mathrm{e}$. The program logic for each of the five subroutines is given in flow chart 8.

\subsection{Program Description}

(a) Input (to SR 20)

(I) First of $\mathbb{N}(K+I)$ consecutive storage locations used successively to store the functional values $G_{k}\left(\lambda_{i}, \theta_{i}\right)$, $A_{k}\left(\lambda_{i}, \theta_{i}\right)$, and $B_{k}\left(\lambda_{i}, \theta_{i}\right), \quad i=1,2, \ldots, N$, and $\mathrm{k}=0,1, \ldots, \mathrm{K}$.

(2) First of $\mathrm{N}(2 \mathrm{H}+\mathrm{I})$ consecutive storage locations used for the $(2 \mathrm{H}+\mathrm{I})$ sets of $\mathrm{N}$ Fourier (time series) coefficients for geographic analysis.

(3) First of $K(K+I) / 2$ consecutive storage locations used successively to store the triangular matrices of coefficients $a_{k j}, b_{k j}, b_{k j}, I_{k j}(k=1,2, \ldots, K$ and $j=0,1, \ldots, k-1$ ). 
SR 20 Executive General Data-Fitting

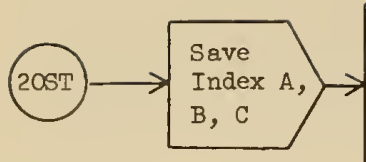

Set up calling sequence for orthogonalization SR 17.

Put address of matrix to be used in address \& decrement $20 \mathrm{AB}, 2 \mathrm{OAH}$.
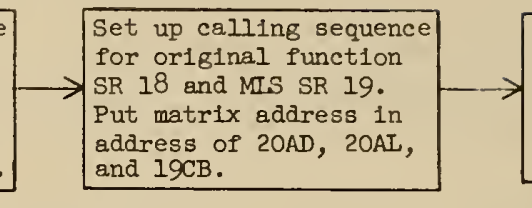

Set up storage area for $\mathrm{P}(\mathrm{P}+\mathrm{I}) / 2$ locations $a_{k j}, b_{k j}, L_{q k}, l_{q k}$

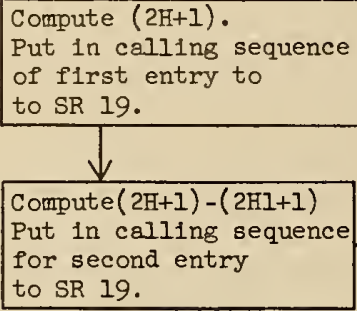

\section{$\downarrow$ \\ Compute $(2 \mathrm{H}+1)-(2 \mathrm{H} I+1)$ \\ Put in calling sequence for second entry to SR 19.}

Place $\mathrm{SI}$ or $\mathrm{S} 2$

In $\mathrm{KI}$

for $N>28$
Set up locations for Fourler coeff.

input to SR 19
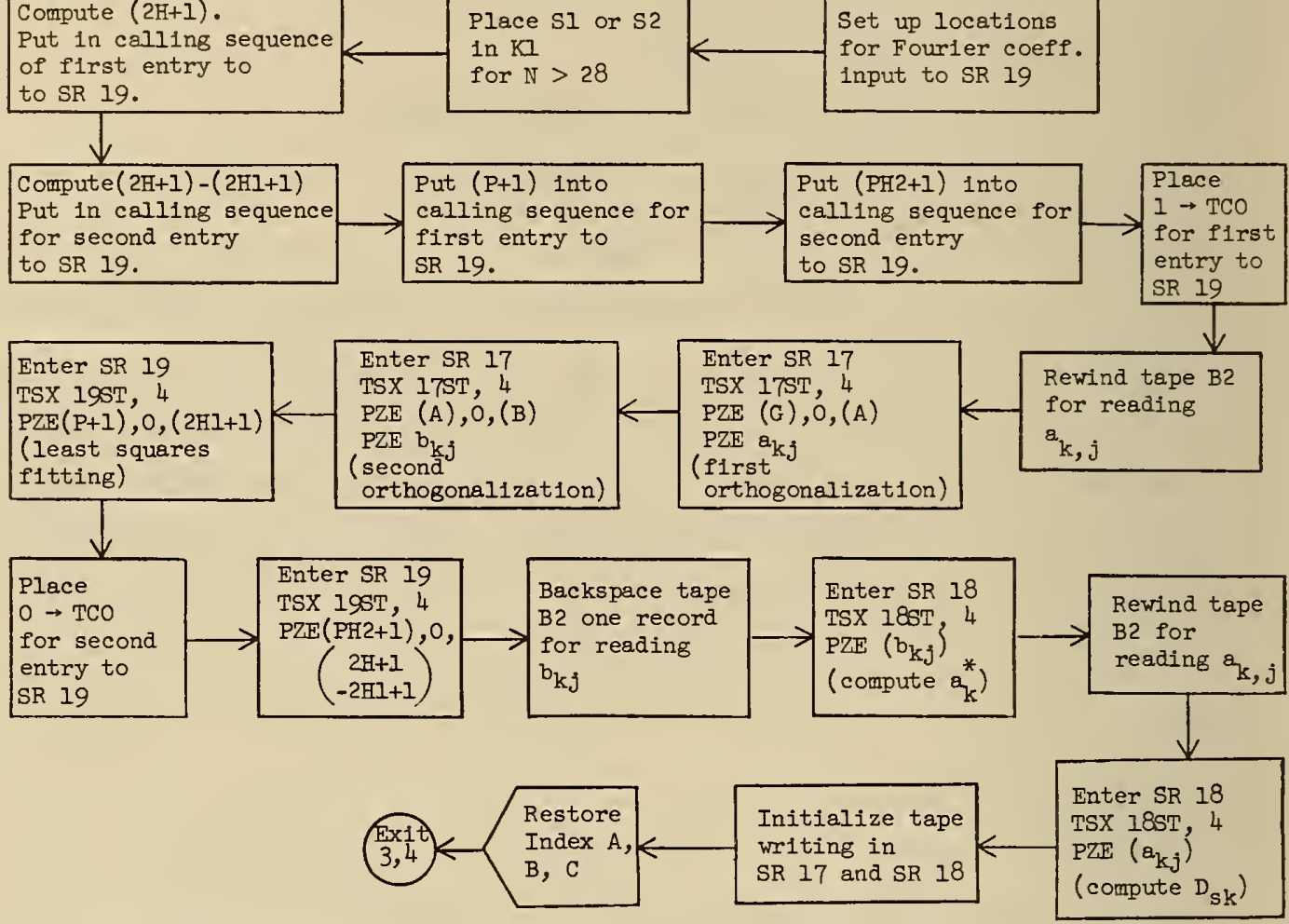

SR 15 Inner Products

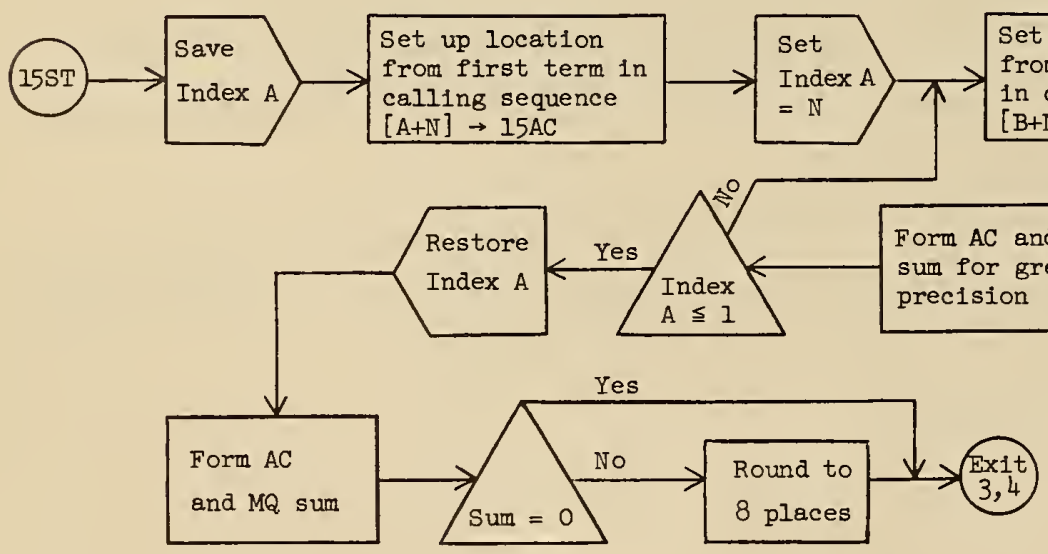


SR 17 Gram-Schmidt Orthogonalization

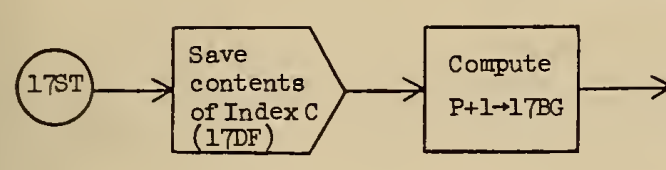

Set up locations
of matrices obtained
from the calling
sequence
(A and B)

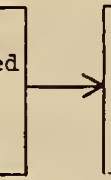

Set up location for triangular matrix $a_{k, j}$ or $b_{k, j}$ to be computed and written on binary tape B2

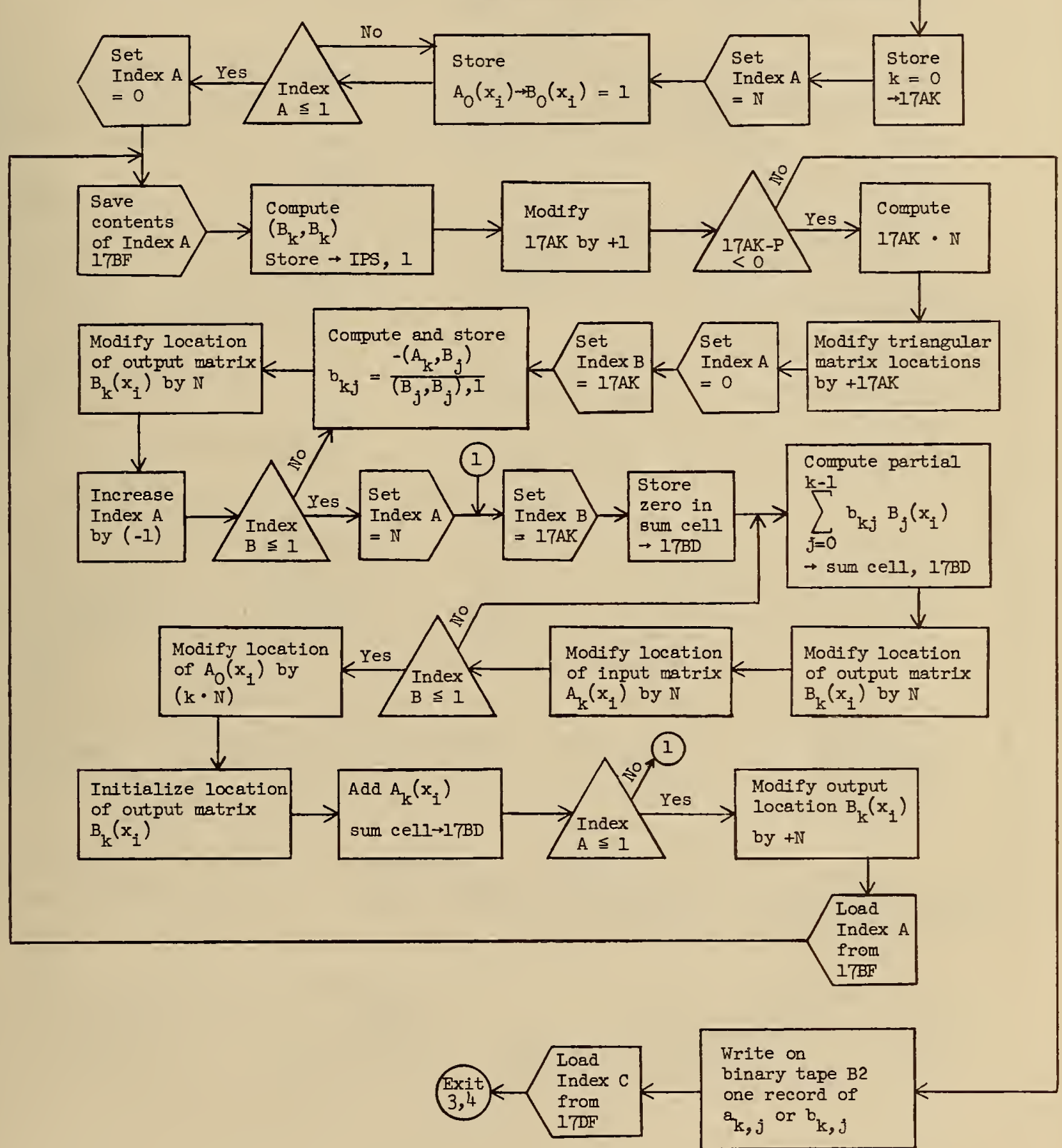


SR 19 Least Squares Fitting

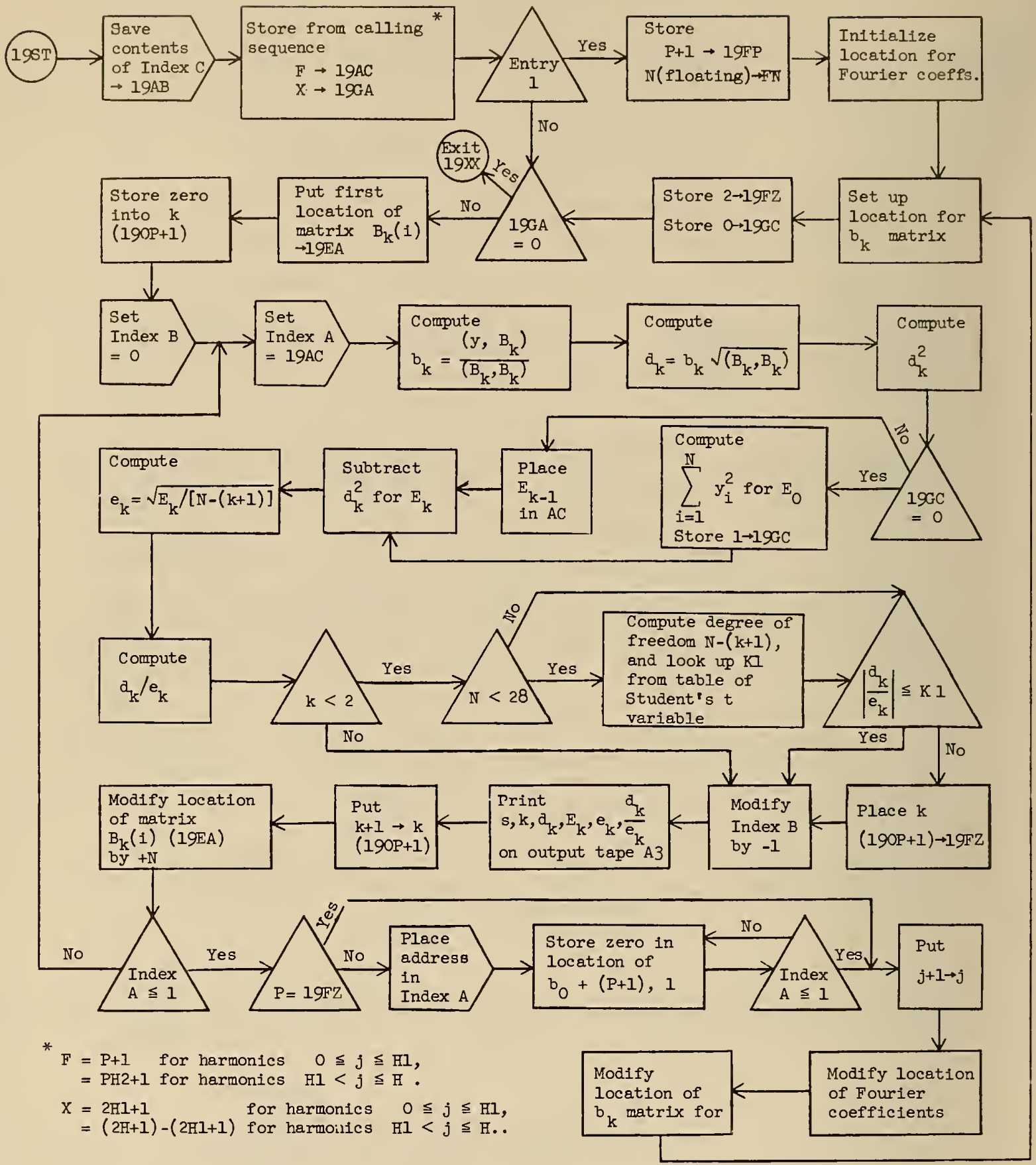


SR 18 Obtaining $Y_{P}$ in terms of $\Sigma D_{k} G_{k}$

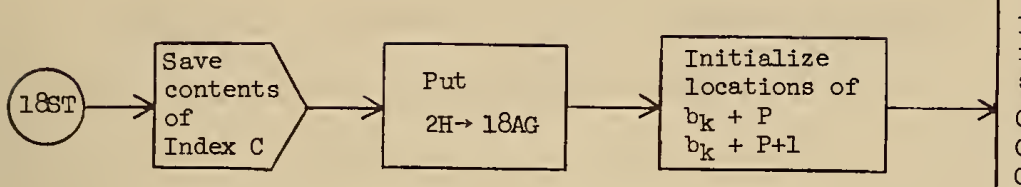

Initialize location 1 for intermediate storage of $\ell_{\mathrm{qk}}$ or $\mathrm{L}_{\mathrm{qk}}$ ORC $\rightarrow 18 \mathrm{CA}$ $\mathrm{ORC}+\mathrm{P} \rightarrow 18 \mathrm{CF}$ $\mathrm{ORC}+\mathrm{P}+\mathrm{I} \rightarrow 18 \mathrm{CD}$

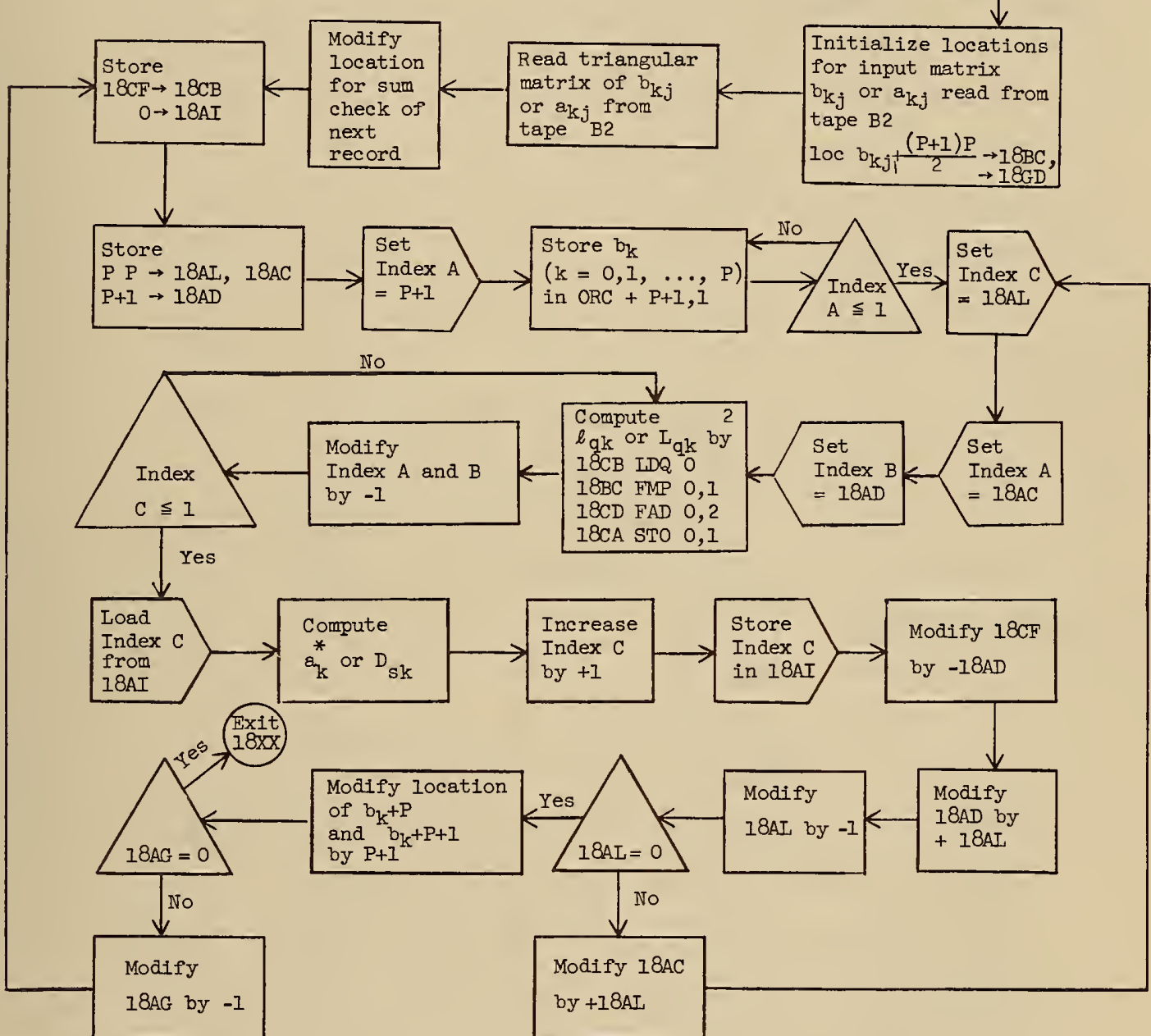

${ }^{1}$ ORC $+\mathrm{k}=$ location of $\ell_{0, \mathrm{k}}, \mathrm{k}=0,1, \ldots, \mathrm{P}$. ORC- $(k+1)=$ location of $\ell_{1, k} k=0,1, \ldots, P-1$. ORC $-\sum_{j=2}^{q}(P+2-\ell)-(k+1)=$ location of $\ell_{q}, k, k=0,1, \ldots, P-q$, for $2 \leqq q \leqq P$.

2 Computation starts with $\ell_{1, P-1}$ (or $I_{1, P-1}$ ) followed by $\ell_{1, P-2}, \ell_{1, P-3}, \ldots$, etc. 
Note: The matrix $\ell_{k j}$ is used after second orthogonalization to transfer $\sum b_{k} B_{k}$ to the form $\sum a_{k}^{*} A_{k}$, see section 6.2 of Jones and Gallet [1962a]. Then the matrix $L_{k j}$ is used to transfer $\Sigma a_{k}^{*} A_{k}$ to the form $\Sigma D_{s k} G_{k}$ (see section 2.2 [Jones and Gallet, 1962a]).

(b) Output (for each of the $(2 \mathrm{H}+1$ ) sets of Fourier coefficients written on tape 3 , channel A) (see printout in appendix $B$ )

(1) Orthonormal coefficients $a_{k}, k=0,1, \ldots, k$.

(2) Sums of squares of residuals $E_{k}, k=0,1, \ldots, K$.

(3) Root mean squared residual $e_{k}, k=0,1, \ldots, k$.

(4) Ratios $a_{k} / e_{k}, k=0,1, \ldots, k$.

(5) Coefficients $D_{\text {sk }}, k=0,1, \ldots, K$.

(c) storage

(I) $N(K+I)$ locations for input (I) above.

(2) $K(K+I) / 2$ location for input (3) above.

(3) $(2 \mathrm{H}+\mathrm{I})(\mathrm{K}+\mathrm{I})$ locations for the coefficients $\mathrm{D}_{\mathrm{sk}}$ $(\mathrm{s}=0,1, \ldots, 2 \mathrm{H}$ and $\mathrm{k}=0,1, \ldots, \mathrm{K})$.

(d) Calling sequence

$$
\begin{array}{ll}
\text { T S X } & \text { 2OST, } 4 \\
\text { P Z E } & (G), 0,(\text { ADFC) } \\
& \text { (IFC), O, (KI) }
\end{array}
$$

Note: $K I$ denotes the value of Student's $t$ variable used for truncating the orthonormal series $\Sigma \mathrm{d}_{\mathrm{k}} \mathrm{F}_{\mathrm{k}}$. All terms are rejected after the last term for which $\left|\mathrm{d}_{\mathrm{k}} / \mathrm{e}_{\mathrm{k}}\right| \geqq \mathrm{KI}$. The number $\mathrm{KI}$ is either $\mathrm{SI}$ or $\mathrm{S} 2$ (see header card) for the first or second analysis, respectively. Kl could also be the value of $t$ for a two tail, 10 percent rejection depending upon the number of degrees of freedom

$$
\mathrm{DF}=\mathrm{N}-(\mathrm{k}+\mathrm{I}) \text {, }
$$


Table 2

$$
\begin{gathered}
\text { STUDENT'S } t \text { VARIABLE FOR } \\
\text { TWO TAIL IO\% REJECTION }{ }^{1} \\
\text { [Degrees of Freedom } \left.\left(\mathrm{D} . \mathrm{F}_{\cdot}\right)=\mathrm{N}-(\mathrm{k}+\mathrm{l}) .\right]
\end{gathered}
$$

\begin{tabular}{|c|c|}
\hline D.F. & $t$ \\
\hline $\begin{array}{l}1 \\
2 \\
3 \\
4 \\
5 \\
6 \\
7 \\
8 \\
9 \\
10 \\
11 \\
12 \\
13 \\
14 \\
15 \\
16 \\
17 \\
18 \\
19 \\
20 \\
21 \\
22 \\
23 \\
24 \\
25 \\
26 \\
27 \\
28\end{array}$ & $\begin{array}{l}6.314 \\
2.920 \\
1.353 \\
2.132 \\
1.015 \\
1.943 \\
1.895 \\
1.860 \\
1.833 \\
1.812 \\
1.796 \\
1.782 \\
1.771 \\
1.761 \\
1.753 \\
1.746 \\
1.740 \\
1.734 \\
1.729 \\
1.725 \\
1.721 \\
1.717 \\
1.714 \\
1.711 \\
1.708 \\
1.706 \\
1.703 \\
1.701\end{array}$ \\
\hline
\end{tabular}

1 Reference: [C.R.C., 1957]. 
where $\mathbb{N}$ is the number of Fourier coefficients being analyzed and $k+1$ is the number of functions used at this point in the analysis (see section 2.I). Table 2 contains the values of $t$ for a 10 percent cutoff.

A different percent can be used for the rejection criterion by replacing the values of $t$ in table 2 by a different set, as follows. The program must be reassembled with the new table of values in locations DF2 to DF2 + 27. The following card format should be used.

Table 3

Carc Format for Change in the Rejection Criterion

Card Column $\begin{array}{lll}8 & 12 & 18\end{array}$ 72

DF2 DEC X.XXX $, X . X X X, \ldots, X . X X X, \ldots$

DEC $X . X X X, X \cdot X X X, \ldots, X \cdot X X X, \ldots$

DEC $X . X X X, X . X X X$,

Note: No columns after 72 can be used. A blank after column 11 causes all remaining information on that card to be ignored.

(e) Description of subroutines used

(1) SR 15 is used to form inner products of two $\mathbb{N}$ dimensional vectors. Suppose $U$ is a vector whose components are stored in locations $A, A+1, \ldots, A+\mathbb{N}-1$ and $V$ is a vector with corresponding components in $\mathrm{B}, \mathrm{B}+1, \ldots, \mathrm{B}+\mathbb{N}-1$. Then given $\mathbb{N}$ and the locations $A+\mathbb{N}$ and $B+N$, $S R \quad 15$ computes the inner product $(U, V)$ and leaves it in the accumulator. The calling sequence is:

$\begin{array}{ll}\text { T S X } & 15 S T, 4 \\ \text { P Z E } & (A+N), O,(N) \\ \text { P Z E } & (B+N)\end{array}$


(2) SR 17 is used to orthogonalize a set of $\mathrm{K}+\mathrm{I}$ linear $\perp \mathrm{y}$ independent vectors of dimension $\mathbb{N}$. The method employed is the Gram-Schmidt orthogonalization and reorthogonalization process described in sections 2.2 and 6.2 by Jones and Gallet, [1962a]. SR 17 forms the orthogonal functions $B_{k}(\lambda, \theta)$ from the geographic functions $G_{k}(\lambda, \theta)$ (table 1 ). Given the locations for input (1) and input (3), SR 17 first computes the values $A_{k}\left(\lambda_{i}, \theta_{i}\right)$ and stores them in place of the $G_{k}\left(\lambda_{i}, \theta_{i}\right)$. Following this, it computes the values $B_{k}\left(\lambda_{i}, \theta_{i}\right)$ (from the second orthogonalization process) and stores them in place of the $A_{k}\left(\lambda_{i}, \theta_{i}\right)$. The intermediate coefficients $a_{k j}$ and $b_{k j}$ are also computed, the $b_{k j}$ being stored in place of the $a_{k j}$. (Note: in order to conserve storage space the input and output locations determined by SR 20 are the same as used here). The triangular matrices of coefficients $a_{k j}$ and $b_{k j}$ are written on tape 2 , channel B for later use in SR 18. The same storage locations are also used by SR 18 for intermediate storage of matrices $\ell_{k j}$ and $I_{k j}$. The calling sequence is:

$$
\begin{aligned}
& \text { T S X 17ST, } 4 \\
& \text { P Z E }(C+W), O,(C+N) \\
& \text { P Z E (D) }
\end{aligned}
$$

where $C$ is input ( $I$ ) and $D$ is input (3) above.

(3) SR 19 is used to fit successively, by least squares, the orthogonal functions generated by SR 17 to each of the $2 \mathrm{H}+1$ sets of $\mathbb{N}$ Fourier coefficients (input (2)). Output from SR 19 includes output (1), (2), (3), and (4) listed above. The orthonormal coefficients $\mathrm{a}_{\mathrm{k}}$ are set equal to zero for all $k$ greater than the last $k$ for which $\left|a_{k} / e_{k}\right| \geqq K I$. When fitting Fourier coefficients for harmonics less than or equal $\mathrm{Hl}$, the calling sequence is:

$$
\begin{aligned}
& \text { T S X } 19 S T, 4 \\
& \text { P Z E }(P+1), 0,(2 \mathrm{HI}+1) .
\end{aligned}
$$


For harmonics $j$ such that $H l<j \leqq H$, the calling sequence is:

$$
\begin{array}{ll}
\text { T S X } & \text { 19ST, } 4 \\
\text { P Z E } & (\mathrm{PH} 2+\mathrm{I}), 0,2(\mathrm{H}-\mathrm{HI}) \text {. }
\end{array}
$$

(4) SR 18 is used to compute the coefficients $D_{\text {sk }}$ (output (5) above). Input to SR 18 are the orthonormal coefficients $\mathrm{d}_{\mathrm{k}}$ from SR 19, and the triangular matrices of coefficients $a_{k j}$ and $b_{k j}$ on tape 2, channel B. SR 20 determines the number of entries to SR 18 and the position of tape 2, channel B. The calling sequence for SR 18 is:

$$
\begin{array}{ll}
\text { T S X I8ST, } 4 \\
\text { P Z E (IGK), O, O }
\end{array}
$$

Note: location IGK which was used in SR 17 for storage of the matrices of orthogonal values is now free to be used for the storage of the triangular matrices $b_{k j}$ and $a_{k j}$ as they are read from tape 2, channel $B$. 


\subsection{Summary of Method and Formulas}

For intercomparing numerical maps of ionospheric characteristics from month to month, it is desirable to use series of orthonormal functions, since the terms in such series are independent. The orthonormal functions $F_{k}(\lambda, \theta)$ used for a given month (or day) depend, for their construction, on the particular set of stations available [Jones and Gallet, 1962a, chapter 2]. Therefore, since the set of available stations changes from day to day and month to month, one cannot use the orthonormal coefficients $\mathrm{a}_{\mathrm{k}}$ for intercomparison purposes. For this reason we have made use of a special set of orthonormal functions $H_{k}(\lambda, \theta)$, constructed relative to a fixed set of 139 points which cover the globe approximately uniformly. The coordinates of these points are given in table 4. Thus, it is possible to represent the function $\Gamma(\lambda, \theta, t)$ in terms of a fixed set of orthonormal functions, and the resulting coefficients $h_{\text {sk }}$ can be intercompared from one month (or day) to the next. ${ }^{1}$

The construction of the functions $H_{k}(\lambda, \theta)$ is completely analogous to the construction of the orthonormal functions $F_{k}(\lambda, \theta)$ [Jones and Gallet, 1962a, chapters 2 and 6]. One begins with the same set of geographic functions $G_{k}(\lambda, \theta)$, with the station coordinates $\left(\lambda_{i}, \theta_{i}\right)$ replaced by the set of 139 covering points in table 4 . The first orthogonalization provides:

$$
\begin{aligned}
& R_{0}=G_{0} \\
& R_{k}=\sum_{j=0}^{k-1} r_{k j} R_{j}+G_{k} \quad k=1,2, \ldots, k
\end{aligned}
$$

INote: The index $\mathrm{s}$ in $\mathrm{h}_{\mathrm{sk}}$ is used here in the same sense as (56) in [Jones and Gallet, 1962a]. 
COORDINATES OF THE 139 COVERING POINTS

\begin{tabular}{|l|c|}
\hline \multicolumn{1}{|c|}{$\lambda=$ Latitude } & $\theta=$ Longitude \\
\hline $\pm 90^{\circ}$ & $0^{\circ}$ \\
\hline $\pm 80^{\circ}$ & $25^{\circ}+90^{\circ} i, \quad i=0,1,2,3$ \\
\hline $\pm 70^{\circ}$ & $10^{\circ}(1+6 i), \quad i=0,1,2,3,4,5$ \\
\hline $\pm 10^{\circ}(1+2 \mathrm{k}), \quad \mathrm{k}=0,1,2$ & $20^{\circ}(1+2 i), \quad i=0,1, \ldots, 8$ \\
\hline $\pm 20^{\circ} \mathrm{k}$, & $40^{\circ} i, \quad i=0,1, \ldots, 8$ \\
\hline
\end{tabular}


where

$$
r_{k j}=-\frac{\left(G_{k}, R_{j}\right)}{\left(R_{j}, R_{j}\right)} \cdot I
$$

A second orthogonalization yields:

$$
\begin{aligned}
\mathrm{T}_{0} & =\mathrm{R}_{0} \\
\mathrm{~T}_{\mathrm{k}} & =\sum_{j=0}^{\mathrm{k}-1} t_{k_{j}} \mathrm{~T}_{j}+\mathrm{R}_{\mathrm{k}} \quad \mathrm{k}=1,2, \ldots, \mathrm{K}, \\
t_{k j} & =-\frac{\left(\mathrm{R}_{k}, \mathrm{~T}_{j}\right)}{\left(\mathrm{T}_{j}, \mathrm{~T}_{j}\right)} .
\end{aligned}
$$

The orthogonal functions $\mathrm{T}_{k}(\lambda, \theta)$ are then normalized by

$$
\mathrm{H}_{\mathrm{k}}=\frac{\mathrm{T}_{\mathrm{k}}}{\sqrt{\left(\mathrm{T}_{\mathrm{k}}, \mathrm{T}_{\mathrm{k}}\right)}} \quad \mathrm{k}=0, \mathrm{l}, \ldots, \mathrm{K} \text {. }
$$

Consider now the problem of transforming the expression

$$
\mathrm{Y}_{\mathrm{k}}=\sum_{\mathrm{k}=0}^{\mathrm{K}} \mathrm{D}_{\mathrm{k}} \mathrm{G}_{\mathrm{k}}
$$

to the form

$$
\mathrm{Y}_{\mathrm{k}}=\sum_{\mathrm{k}=0}^{\mathrm{K}} \mathrm{h}_{\mathrm{k}} \mathrm{H}_{\mathrm{k}}
$$

The first step is:

$$
\mathrm{Y}_{\mathrm{k}}=\sum_{\mathrm{k}=0}^{\mathrm{K}} \mathrm{r}_{\mathrm{k}} \mathrm{R}_{\mathrm{k}}
$$

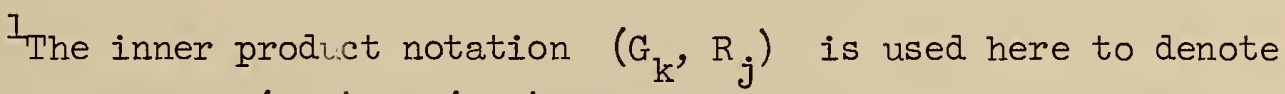
a summation $\Sigma G_{k}(\lambda, \theta) R_{j}(\lambda, \theta)$ over the set of 139 covering points (table 4). 
which from (9.1) and (9.6) provides:

$$
\begin{aligned}
& r_{k}=D_{k}-\sum_{j=k+1}^{K} r_{j k} D_{j}, \quad k=0,1, \ldots, K-1 \text {, and } \\
& r_{K}=D_{K} .
\end{aligned}
$$

This gives

$$
\mathrm{Y}_{\mathrm{k}}=\sum_{\mathrm{k}=0}^{\mathrm{K}} \mathrm{t}_{\mathrm{k}} \mathrm{T}_{\mathrm{k}} \text {, }
$$

where from (9.3) and (9.8)

$$
\begin{aligned}
& t_{k}=r_{k}-\sum_{j=k+1}^{K} t_{j k} r_{j}, \quad k=0,1, \ldots, K-1 \text {, and } \\
& t_{K}=r_{K}=D_{K} .
\end{aligned}
$$

Finally, the desired coefficients in (9.7) are obtained from

$$
h_{k}=t_{k} \sqrt{\left(T_{k}, T_{k}\right)}, \quad k=0,1, \ldots, k \text {. }
$$

Two subroutines are described in this section. SR 21 is an executive subroutine which employs SR 16 to compute the coefficients $r_{k}$ and $t_{k}$, the numbers $r_{k j}, t_{k j}$ and $\sqrt{\left(T_{k}, T_{k}\right)}$ being obtained from the numerical map executive program (see input 5, section 2.3). The program description is given in section 9.2.

\subsection{Program Description}

(a) Input

(1) Triangular matrices $r_{k j}$ and $t_{k j}, k=1,2, \ldots, k$ and $j=0,1, \ldots, k-1$ defining orthogonal functions for the 139 covering points. (Note: these numbers are either computed by the numerical map executive program (section 2) or else read in from tape 3, channel $B$. See input 5 and output 5, section 2.3). 
Flow Chart 9

INTERCOMPARISON COEFFICIENTS SUBROUTINES 16 AND 21

SR 21 Intercomparison Coefficients Executive Subroutine

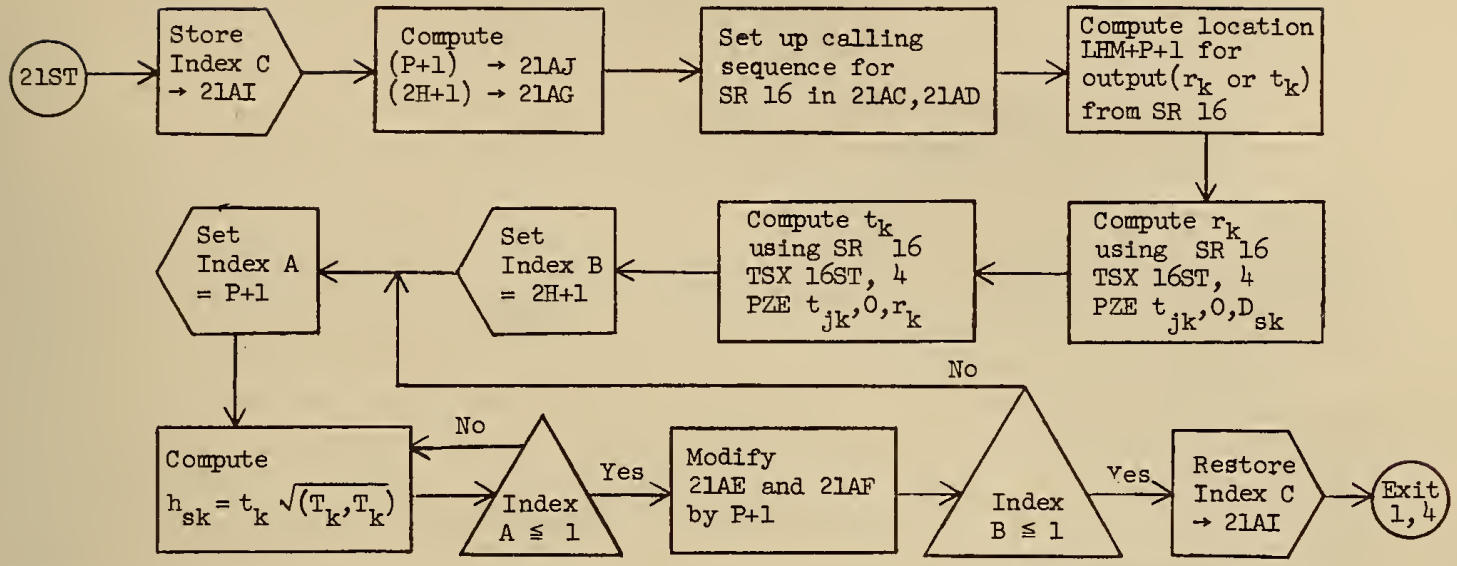

SR 16 (Computes $r_{k}$ or $t_{k}$ )
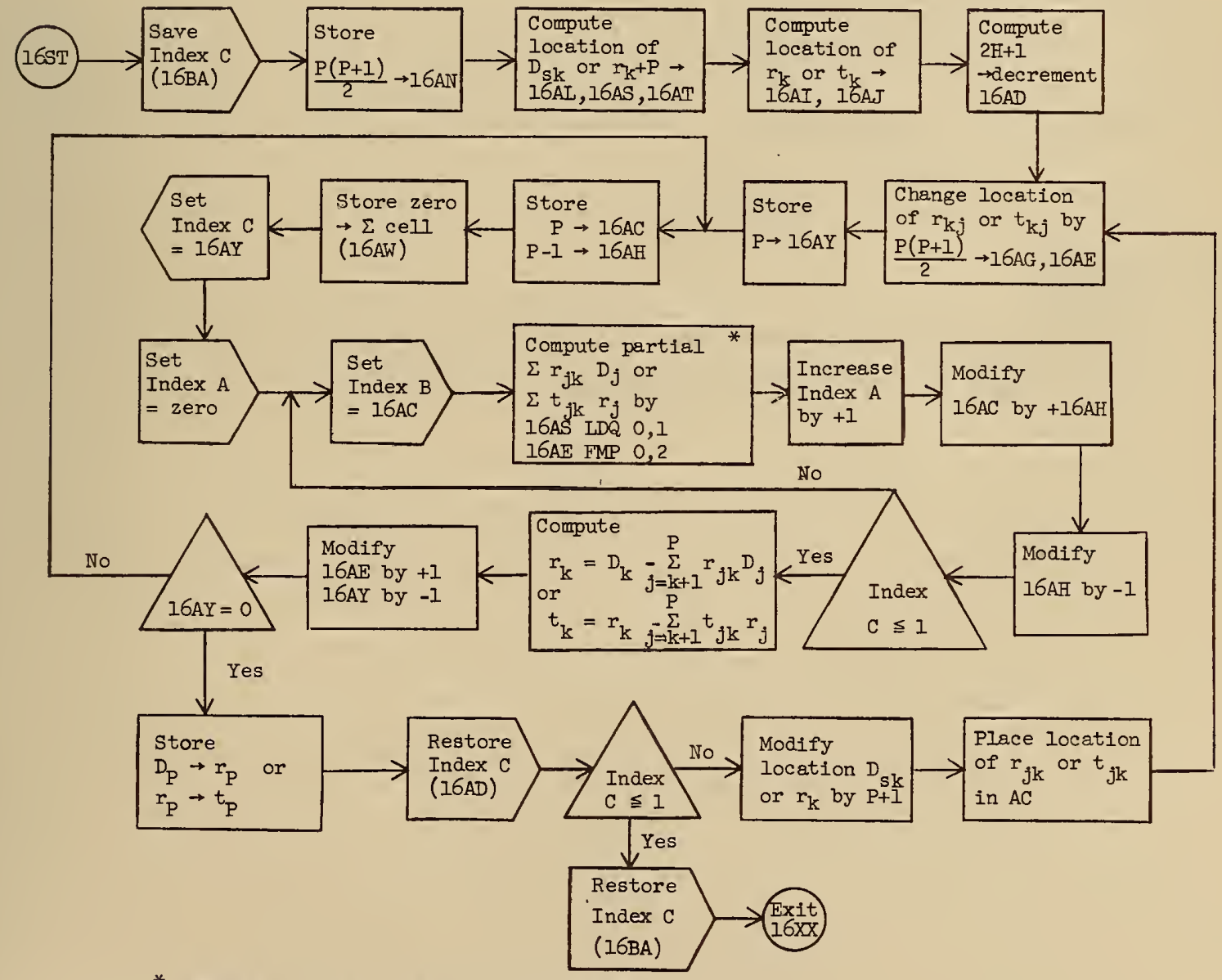

* Compute $r_{0}$ first, starting with the term $r_{P O} D_{P}$. 
(2) Square roots of inner products $\left.\sqrt{\left(T_{k}\right.}, T_{k}\right), k=0,1, \ldots, K$. (Note: these numbers are also either computed by the numerical map executive program (section 2) or else read in from tape 3, channel B.

(3) Matrix of coefficients $\mathrm{D}_{\mathrm{sk}}, \mathrm{k}=0,1, \ldots, \mathrm{K}$, $\mathrm{s}=0,1, \ldots, 2 \mathrm{H}$.

(b) Output

Matrix of intercomparison coefficients $h_{s k}, s=0,1, \ldots, 2 \mathrm{H}$ and $\mathrm{k}=0,1, \ldots, \mathrm{k}$.

(c) Calling sequence

T S X 2IST, 4

(d) Subroutines used

SR 16 computes the coefficients $r_{k}$ and $t_{k}$. The $r_{k}$ are computed when entering SR 16 by

$$
\begin{aligned}
& \text { T S X I6ST, } 4 \\
& \text { (ITI), } 0,0
\end{aligned}
$$

The $t_{k}$ are computed when entering SR 16 by

T S X 16ST, 4

$$
\text { (IT2), } 0,0
$$

(e) Remarks

(1) The index registers are restored after they are used.

(2) Underflow is checked internally in the code. 


\section{ACKNOWLEDGEMENTS}

The authors gratefully acknowledge the assistance they received from a number of persons. A significant contribution to the work described here was given by Mrs. G. Anne Hessing who was responsible for the program development using the IBM 650 computer and for the initial programming on the IBM 704. Valuable assistance in correcting the flow charts and the program description was rendered by Mr. Ronald P. Graham. Computer services were obtained from the operators in the Computer Laboratories of the National Bureau of Standards (in Washington, D. C., and in Boulder, Colorado). Able assistance in typing the manuscript and assembling the material for this paper was given by Mrs. Anna von Kreisler. 



\section{REFERENCES}

C.C.I.R. (1959), Report No. 162 and Study Programme No. 149, Documents of the Plenary Assembly, Los Angeles (Published by the International Telecommunication Union, Geneva).

C.R.C. Standard Mathematical Tables (1957), 12th Ed., p. 244 (Chemical Rubber Publish. Co., Cleveland, Ohio).

Central Radio Propagation Laboratory Ionospheric Predictions (Jan. 1963), No. 1 (U. S. Dept. of Commerce, National Bureau of Standards).

Hinds, M., and W. B. Jones (Dec. 1962), Computer program for ionospheric mapping by numerical methods, Unpublished Report (National Bureau of Standards, Boulder, Colorado).

Jones, W. B., and R. M. Gallet (Dec. 1960), Ionospheric mapping by numerical methods, $\mathrm{J}$. of the International Telecommunication Union, No. $12,260-264$.

Jones, W. B., and R. M. Gallet (May 1962a), The representation of diurnal and geographic variations of ionospheric data by numerical methods, Telecommunication J. 29, No. 5, 129-149; and (July-Aug. 1962a)

J. Res. INBS 66D (Radio Prop.), No. 4, 419-438.

Jones, W. B., and R. M. Gallet (Nov.-Dec. 1962b), Methods for applying numerical maps of ionospheric characteristics, J. Res. NBS 66D (Radio Prop.), No. 6, 649-662.

Ostrow, S. M. (Dec. 21, 1962), Handbook for the Central Radio Propagation Laboratory ionospheric predictions based on numerical methods of mapping, National Bureau of Standards Handbook 90. 

SAMPLE PRINTOUT OF INPUT TO NUMERICAL MAP PROGRAM

$\begin{array}{llllllllllll}3 & 154 & 52 & 4 & 8 & 100 & 12 & 36 & 52 & 4 & -2 & 60\end{array}$

$2 \begin{array}{lllll}2 & 142 & 59 & 1868 & 4\end{array}$

58064500

$10687219900+868210000+066201000+790$ $10483141700+823045000+645191000+700$ $10982243900+799285000-274239000+810$ $10 J 82297400+826285000+083 \cdot 170000+850$ $10280058000+806045000+087$

$10980274100+800285000-073235000+860$ $10178015700+782015000+005012900+744$ $10 J 76291300+766285000+042355000+870$ $10974265100+747270000-033289400+830$ $10373080400+735105000-164162000+640$ $10771203200+713210000-045241200+685$ $10 J 70291400+705285000+043000700+819$ $10169019000+697015000+027116200+669$ $10 J 69306500+693315000-057032700+798$ $10168033000+690030000+020126000+630$ $10167020300+678015000+035115700+652$ ? $10166026600+674030000-023120000+640$ $10266066700+665060000+045148000+570$ $10165022100+656015000+047114700+629$ $10164018800+646015000+025111000+630$ $10664186600+644180000+044237000+680$ $10764212200+649210000+015256600+646$ $10964264000+643270000-040315500+737$ $10 A 64338200+641345000-045071100+701$ $10 J 63291400+638285000+043360000+750$ $10462129600+620135000-036194000+510$ $10761210100+612210000+001258200+609$ $10 J 61314600+612315000-003036900+712$ $10160030700+600030000+005$

$10059011100+600015000-026100000+595$ $10159024600+605030000-036113000+560$ $10158017600+598015000+017106000+585$ $10958265800+588270000-028322800+687$ $10056355800+574360000-028083400+607$ $10156044300+561045000-005126000+502$ $10256061100+567060000+007140800+484$ $10356084900+565090000-034159700+459$ $10055013400+546015000-011099000+550$ $10155037300+555030000+049120600+508$ $10855246700+546255000-055301000+620$ $10053005200+521000000+035089500+537$ $10052014600+500000000+097097500+500$ $10352104000+525105000-007174000+410$ $10452113500+520120000-043182100+405$ $10051359400+515360000-004083300+543$ $10651183400+519180000+023240100+472$ $10050010100+516015000-033093900+521$ $10049004600+501000000+031088000+520$ $10149039700+472045000-035120000+420$ $10949262600+499270000-049322900+588$ $10048007600+481000000+051090000+494$ $10848236600+484240000-023294300+533$ $10147019200+474000000+128101000+470$ $10547143000+470150000-047208500+370$

5806

5806

5806

5806

5806

5806

5806

5806

5806

5806

5806

5806

5806

5806

5806

5806

5806

5806

5806

5806

5806

5806

5806

5806

5806

5806

5806

5806

5806

5806

5806

5806

5806

5806

5806

5806

5806

5806

5806

5806

5806

5806

5806

5806

5806

5806

5806

5806

5806

5806

5806

5806

5806

5806 

$10210047500-188045000+017112500-237$

$1011 R 017700-192015000+018083000-180$

1051R146700-193150000-022219000-284

$1072 J 200200-212195000+035273800-209$

$10 J 2 L 313500-235315000-010022500-128$

$10120028100-262030000-013091400-269$

$10 J 20294600-269300000-036004000-160$

$1052 P 152900-275150000+019227100-357$

$10430115900-303120000-027185800-417$

$1013 M 018300-341030000-078079700-327$

$10 \mathrm{~J} 3 \mathrm{M} 301500-345300000+010009500-231$

$1053 N 149000-353150000-007224400-439$

$10 \mathrm{~J} 30287000-366285000+013356000-250$

$1054 K 147200-429150000-019224500-516$

$1064 \mathrm{~L} 172800-436180000-048252800-480$

$10 \mathrm{~J} 4 \mathrm{~L} 294700-432300000-035003000-320$

$1024 R 070300-494075000-031$

$10 \mathrm{~J} 5 \mathrm{~J} 302200-517300000+015009300-403$

$1065 K 169200-525165000+028253300-572$

$1055 M 159000-545150000+060243300-610$

$10 J 6 L 299300-630315000-105006100-515$

$10 J 6 M 296500-648300000-023004000-533$

$10360093000-665090000+020146000-780$

$10460110500-662105000+037179000-780$

$10560140000-667135000+033$

$10170023300-704030000-045063000-068$

$1067 \mathrm{~K} 170300-72316500,0+035277000-750$

$10 A 70333400-755330000+023017500-675$

$10 A 7 P 318900-777315000+026147000-670$

$1 C 670166800-778165000+012295000-790$

$10770197800-782195000+019312000-740$

$10880240000-800240000+000336000-710$

$10090000000-900000000+000000000-780$

$10471128900+716128900+000$

$10919260500+193260500+000000000+000$

$10513144900+136144900+000213000+040$

$10111043200+116043200+000114000+069$

$10411125000+110125000+000193800-001$

$10705197900+059197900+000265900+051$

$10701202700+019202700+000271400+022$

$1050 R 147100-094147100+000$

$10610178200-180178200+000251200-220$

$1062 R 182100-292182100+000257800-322$

Ionom

$1016 R 039600-690039600+000780000-700$

spheric

$1047 P 106900-784106900+000129000-880$

$\begin{array}{llllllllllll}11687580645000590 & 0600 & 0600 & 0590 & 0590 & 0550 & 0570 & 0560 & 0550 & 0550 & 0560 & 0550\end{array}$

$12687580645000540 \quad 0530 \quad 0500 \quad 0500 \quad 055010500 \quad 05100500 \quad 0530 \quad 0560 \quad 05600590$

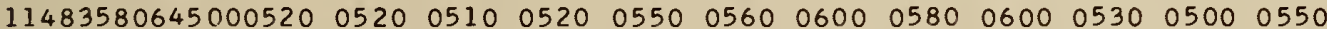

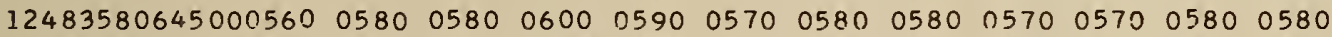

$\begin{array}{llllllllllll}11982580645000570 & 0560 & 0580 & 0585 & 0585 & 0560 & 0550 & 0550 & 0560 & 0540 & 0550 & 0550\end{array}$

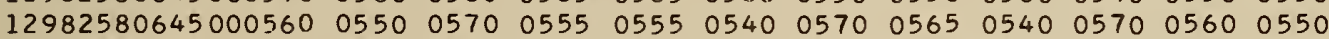

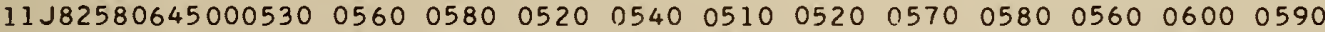

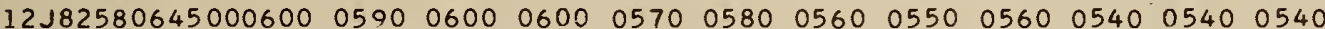

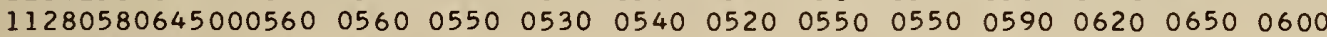
$12280580645000580 \quad 0570 \quad 0600 \quad 0600 \quad 0600 \quad 0600 \quad 0600 \quad 0600 \quad 0600 \quad 0600 \quad 0600 \quad 0600$

5806

5806

5806

5806

5806

5806

5806

5806

5806

5806

5806

5806

5806

5806

5806

5806

5806

5806

5806

5806

5806

5806

5806

5806

5806

5806

5806

5806

5806

5806

5806

5806

5806

5806 


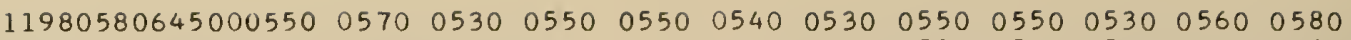

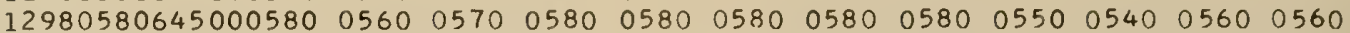

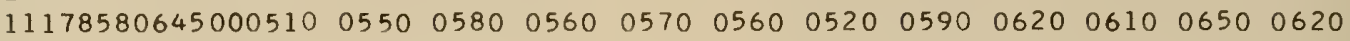

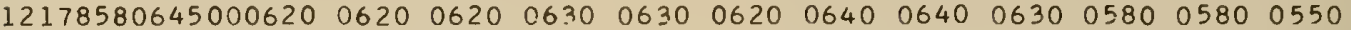

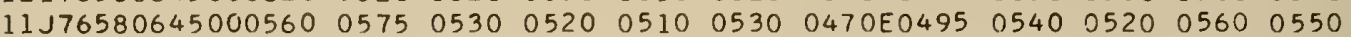

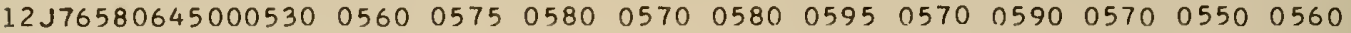

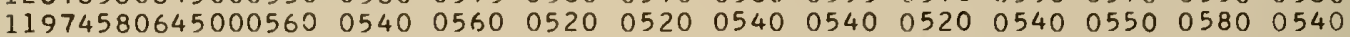

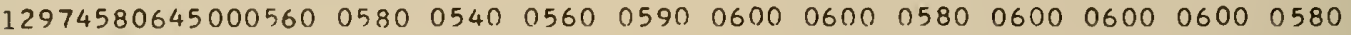

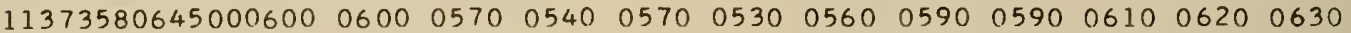

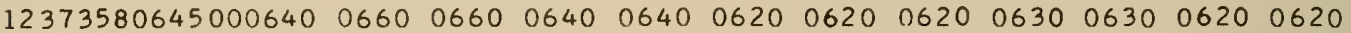

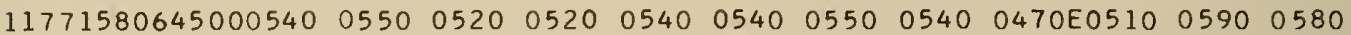

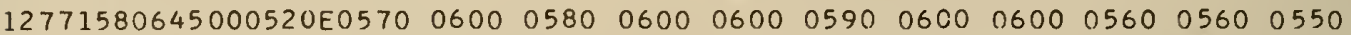

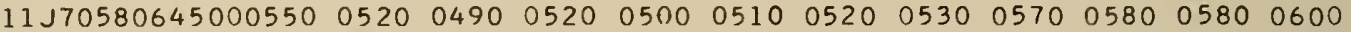

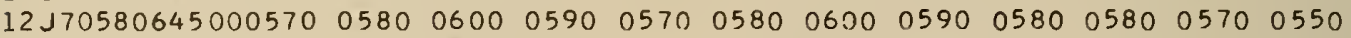

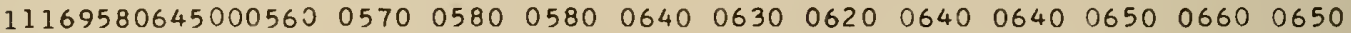

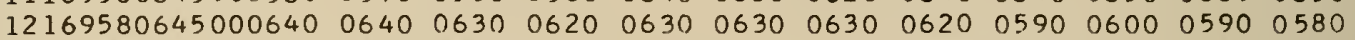
$11 J 695806450005250520 \cup 0520 U 0500 \quad 050 n \cup 04850475 \cup 0480 \quad 0530 U 0560 \quad 0555 \cup 0620 U$ $12 J 69580645000610 \cup 0600 \quad 0590 \cup 0560 \cup 0580 \quad 0575 \cup 0580 \quad 061000590 U 0590 \quad 05550520$ $\begin{array}{lllllllllllll}11168580645000620 & 0620 & 0630 & 0620 & 0620 & 0640 & 0630 & 0650 & 0640 & 0660 & 0680 & 0680\end{array}$

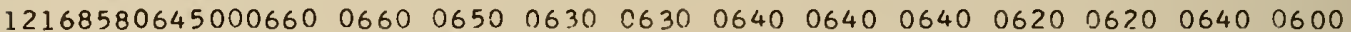

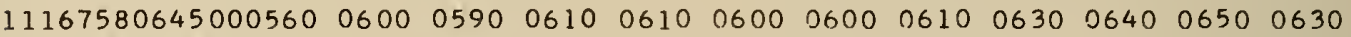

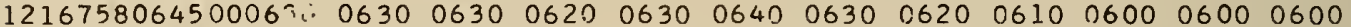
$11166580645000640 \quad 0620 \cup 0630 \cup 060040660 \quad 0640 \quad 0630 \quad 0650 \quad 0650 \quad 0690 \quad 0680 \quad 0660$

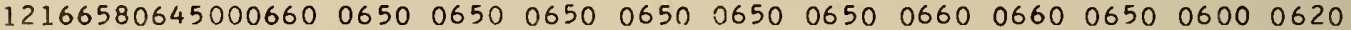

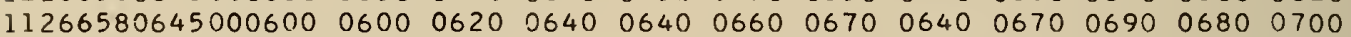
$\begin{array}{lllllllllllll}12266580645000700 & 0710 & 0700 & 0680 & 0660 & 0670 & 0670 & 0680 & 0660 & 0650 & 0660 & 0620\end{array}$

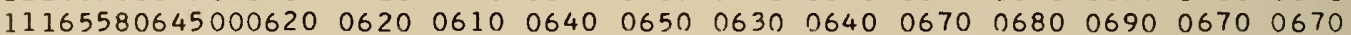
$\begin{array}{lllllllllllll}12165580645000670 & 0660 & 0660 & 0650 & 0650 & 0660 & 0660 & 0650 & 0660 & 0640 & 0620 & 0630\end{array}$

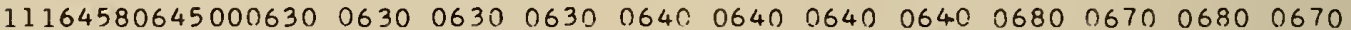
$\begin{array}{lllllllllllll}12164580645000670 & 0660 & 0670 & 0650 & 0670 & 0660 & 0670 & 0650 & 0670 & 0650 & 0620 & 0630\end{array}$

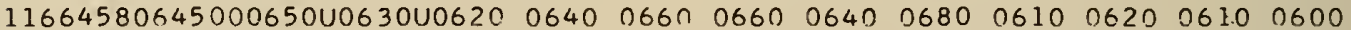
$12664580645000600 \quad 0600 \quad 06200620 \quad 0630 \quad 0630 \quad 0640 \quad 0630 \quad 06400640 \quad 0620 \quad 0650$

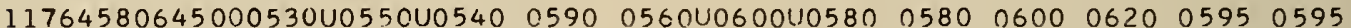

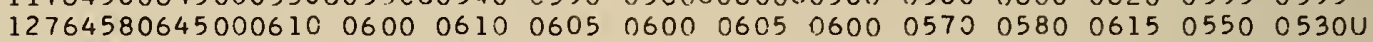

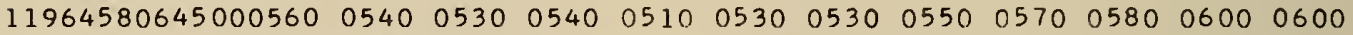

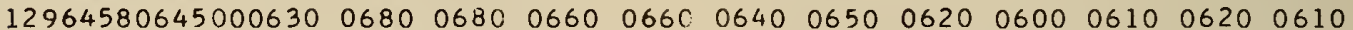
11 A64580645000500D0540U0520U0530U0530 $0560 \quad 0560 \quad 0560 \quad 0580 \quad 0600 \quad 06200630$ $12 A 64580645000640 \quad 0650 \quad 0670 \quad 0650 \quad 0640 \quad 0630 \quad 0630 \quad 0590 \quad 0580 D 0580 U 0550 U 0530 U$

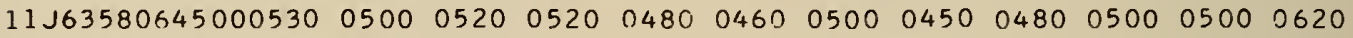

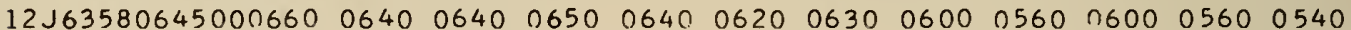
$\begin{array}{llllllllllllll}11462580645000820 & 0780 & 0700 & 0720 & 0710 & 0720 & 070 \cap & 0720 & 0720 & 0720 R O 720 R 0720 R\end{array}$ $12462580645000730 R 0730 R 0740 R \cap 740 U \cap 76010740 \quad 0740 \quad 0760 \quad 0760 \quad 078008000800$ $\begin{array}{llllllllllllll}11761580645000530 & 0520 & 0540 & 0550 & 0580 & 0610 & 0640 & 0630 & 0640 & 0620 & 0600 & 0600\end{array}$ $\begin{array}{llllllllllllll}12761580645000600 & 0620 & 0620 & 0610 & 0600 & 0600 & 0620 & 0600 & 0610 & 0600 & 0590 & 0540\end{array}$ $11 J 61580645000480 \cup 0500 \cup 0470 \cup 0465 \cup 0490 \quad 0470 \quad 0520 \quad 0570 \quad 0585 \quad 0620 \quad 0630 \quad 0640$

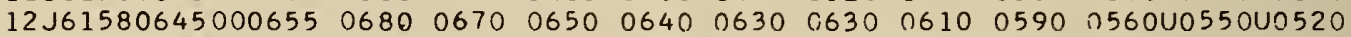

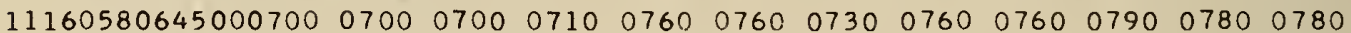

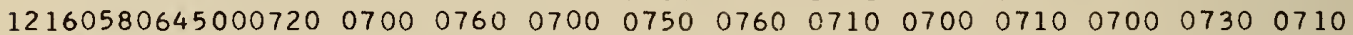

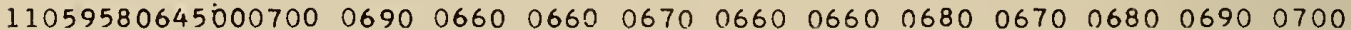
$\begin{array}{lllllllllllll}12059580645000690 & 0690 & 0690 & 0680 & 0690 & 0720 & 0700 & 0700 & 0690 & 0680 & 0650 & 0640\end{array}$

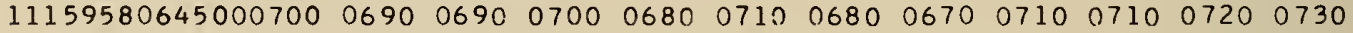
$12159580645000710 \quad 0700 \quad 0690 \quad 0690 \quad 068 \cap 0680 \quad 0700 \quad 0700 \quad 0700 \quad 0700 \quad 07000700$ $11158580645000680 \quad 0640 \quad 0650 \quad 0660 \quad 0670 \quad 0670 \quad 0680 \quad 0690 \quad 0690 \quad 0710 \quad 0720 \quad 0700$ $12158580645000700 \quad 0700 \quad 0680 \quad 0690 \quad 0700 \quad 0700 \quad 0700 \quad 0760 \quad 0700 \quad 0700 \quad 0700 \quad 0700$ $11958580645000560 \quad 0520 \quad 0500 \quad 0500 \quad 0500 \quad 0490 \quad 0500 \quad 0530 \quad 0570 \quad 0600 \quad 0620 \quad 0630$ 
$\begin{array}{llllllllllll}12958580645000650 & 0690 & 0720 & 0700 & 0690 & 0670 & 0640 & 0610 & 0600 & 0580 & 0570 & 0560\end{array}$

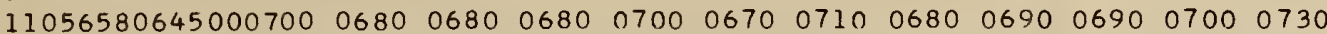

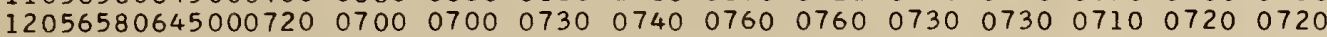
$\begin{array}{lllllllllllll}11156580645000700 & 0690 & 0680 & 0680 & 0690 & 0690 & 0740 & 0760 & 0740 & 0750 & 0790 & 0790\end{array}$

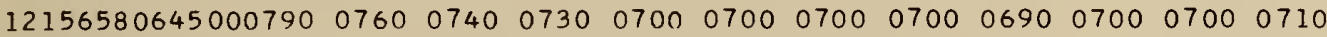

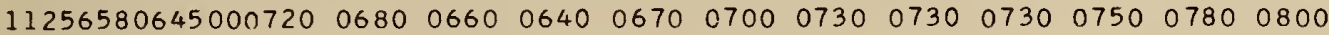

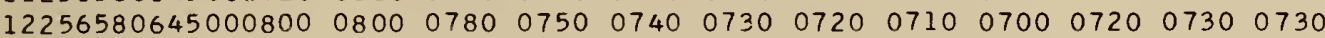

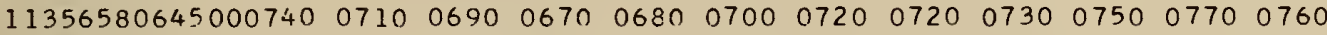
$\begin{array}{lllllllllllll}12356580645000790 & 0810 & 0800 & 0780 & 0760 & 0740 & 0740 & 0750 & 0720 & 0740 & 0770 & 0770\end{array}$ $\begin{array}{llllllllllllll}11055580645000770 & 0700 & 0690 & 0680 & 0700 & 0720 & 0710 & 0730 & 0740 & 0730 & 0730 & 0770\end{array}$ $\begin{array}{lllllllllllll}12055580645000760 & 0740 & 0750 & 0730 & 0740 & 0750 & 0780 & 0780 & 0780 & 0770 & 0770 & 0780\end{array}$

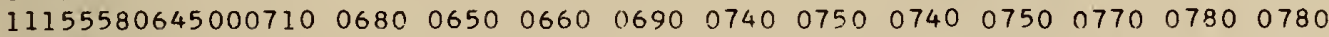

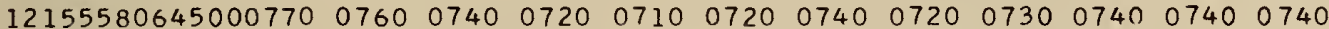

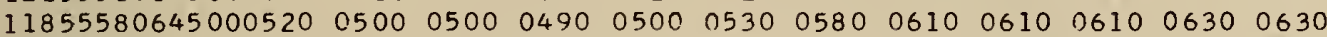

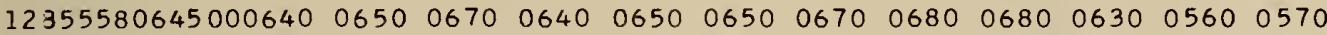

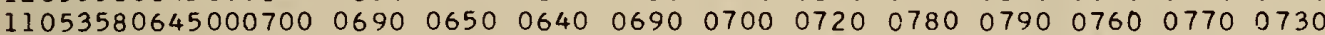

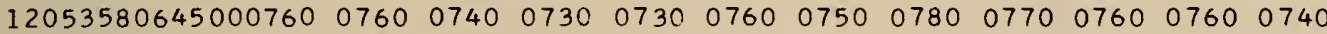

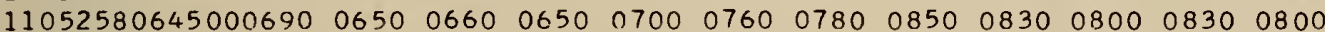
$\begin{array}{lllllllllllll}12052580645000810 & 0800 & 0800 & 0780 & 0800 & 0780 & 0800 & 0790 & 0780 & 0750 & 0720 & 0700\end{array}$

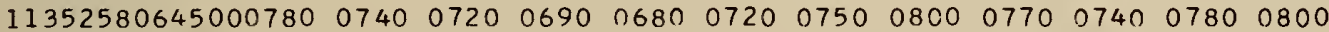
$\begin{array}{llllllllllllll}12352580645000790 & 0790 & 0810 & 0790 & 0780 & 0770 & 0750 & 0780 & 0790 & 0820 & 0820 & 0810\end{array}$ $\begin{array}{llllllllllllll}11452580645000820 & 0780 & 0730 & 0690 & 0700 & 0760 & 0760 & 0770 & 0780 & 0760 & 0740 & 0750\end{array}$ $\begin{array}{lllllllllllll}12452580645000760 & 0770 & 0770 & 0780 & 0780 & 0780 & 0780 & 0770 & 0790 & 0820 & 0820 & 0820\end{array}$

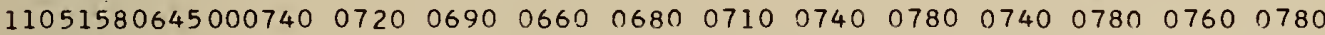
$\begin{array}{lllllllllllll}12051580645000800 & 0780 & 0770 & 0780 & 0780 & 0810 & 0800 & 0820 & 0800 & 0800 & 0830 & 0820\end{array}$

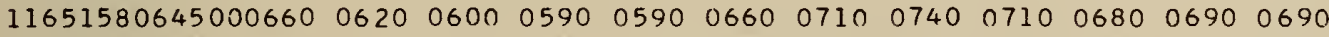
$\begin{array}{lllllllllllll}12651580645000680 & 0660 & 0650 & 0650 & 0630 & 0650 & 0670 & 0680 & 0690 & 0680 & 0700 & 0680\end{array}$ $\begin{array}{llllllllllllll}11050580645000765 & 0706 & 0690 & 0660 & 0655 & 0707 & 0730 & 0756 & 0786 & 0785 & 0758 & 0775\end{array}$ $\begin{array}{lllllllllllll}12050580645000778 & 0768 & 0769 & 0764 & 0760 & 0768 & 0779 & 0824 & 0796 & 0798 & 0793 & 0792\end{array}$

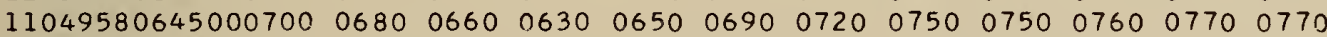

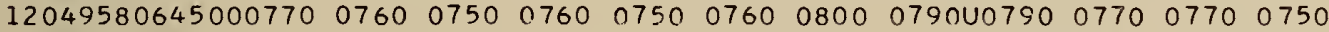

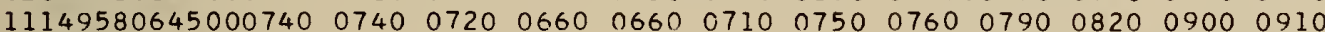
$\begin{array}{lllllllllllll}12149580645000920 & 0900 & 0860 & 0830 & 0810 & 0800 & 0790 & 0820 & 0800 & 0800 & 0770 & 0770\end{array}$ $\begin{array}{llllllllllll}11949580645000570 & 0510 & 0500 & 0480 & 0460 & 0500 & 0540 & 0560 & 0600 & 0600 & 0620 & 0630\end{array}$ $\begin{array}{llllllllllllll}12949580645000650 & 0660 & 0650 & 0680 & 0680 & 0680 & 0700 & 0700 & 0700 & 0700 & 0690 & 0600\end{array}$ $\begin{array}{llllllllllllll}11048580645000700 & 0690 & 0660 & 0640 & 0680 & 0750 & 0790 & 0810 & 0810 & 0800 & 0810 & 0880\end{array}$

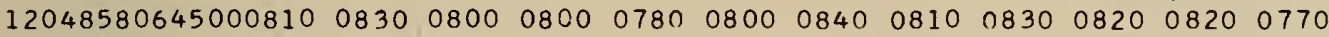

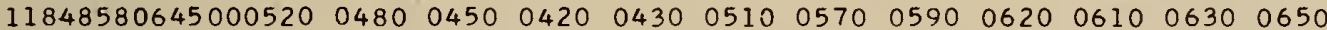

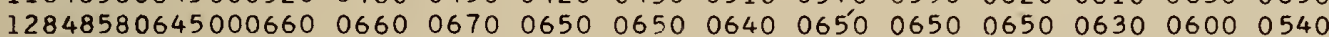
$\begin{array}{lllllllllllll}11147580645000720 & 0690 & 0670 & 0680 & 0740 & 0790 & 0770 & 0860 & 0900 & 0900 & 0870 & 0870\end{array}$

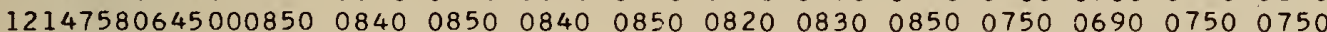

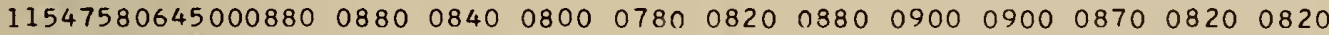

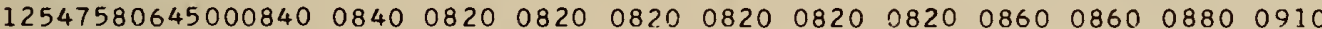

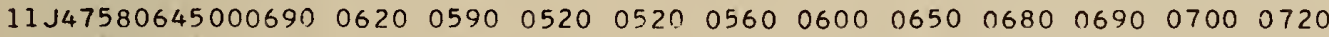
$12 J 47580645000700 \quad 0720 \quad 0740 \quad 0760 \quad 0760 \quad 0760 \quad 0800 \quad 0800 \quad 0800 \quad 0820 \quad 0780 \quad 0710$ $11046580645000800 \cup 0780 \cup 0720 \cup 0680 \cup 0680 \quad 0740 \quad 0800 \cup 0800 \quad 0800 \quad 0.830 \quad 0870 \quad 0870$ $\begin{array}{llllllllll}12046580645000880 & 0870 & 0860 & 0860 & 0860 & 0850 & 0860 \cup 0870 U 0880 & 0850 D 0860 U 0860\end{array}$ $\begin{array}{lllllllllllll}11045580645000790 & 0720 & 0700 & 0670 & 0650 & 0670 & 0740 & 0790 & 0810 & 0850 & 0820 & 0850\end{array}$ $\begin{array}{llllllllllllll}12045580645000830 & 0850 & 0820 & 0840 & 0800 & 0790 & 0790 & 0820 & 0800 & 0790 & 0790 & 0780\end{array}$

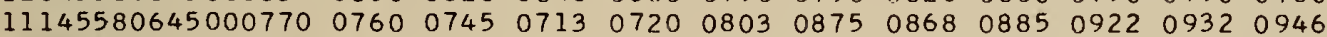
$\begin{array}{lllllllllllll}12145580645000900 & 0930 & 0912 & 0874 & 0876 & 0878 & 0873 & 0871 & 0834 & 0823 & 0802 & 0792\end{array}$

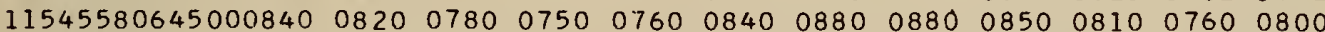

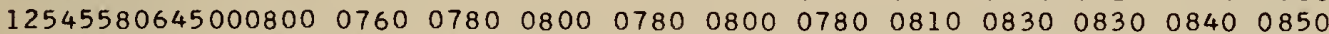

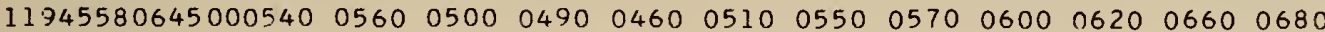
$12945580645000680 \quad 0690 \quad 0700 \quad 0710 \quad 0720 \quad 0720 \quad 0750 \quad 0800 \quad 0800 \quad 0800 \quad 0730 \quad 0660$ 


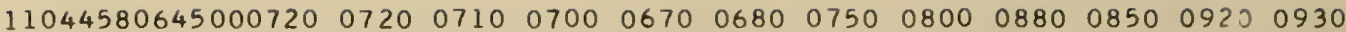
$12044580645000940 \quad 0910 \quad 0900 \quad 0870 \quad 0870 \quad 0860 \quad 0850 \quad 084040730 \quad 0690 \quad 0720 \quad 0730$

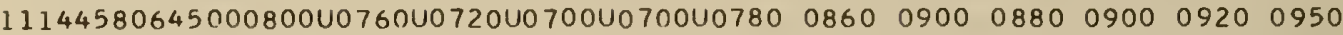
$12144580645000950 \quad 0910 \quad 0880 \quad 0880 \quad 0840 \quad 0830 \quad 0860 \quad 0840 \quad 0840 \cup 083040820 \quad 0820 U$

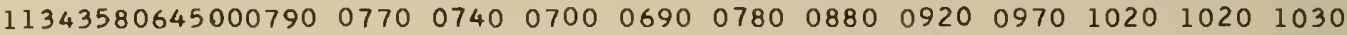
$\begin{array}{llllllllllllll}12343580645001040 & 1010 & 1000 & 0960 & 0910 & 0870 & 0860 & 0850 & 0840 & 0830 & 0830 & 0820\end{array}$

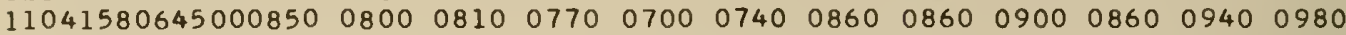
$\begin{array}{lllllllllllll}12041580645001000 & 0950 & 0970 & 0930 & 0890 & 0880 & 0880 & 0900 & 0870 & 0870 & 0860 & 0880\end{array}$

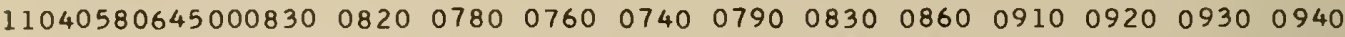

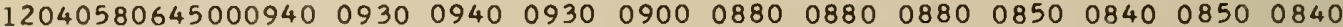

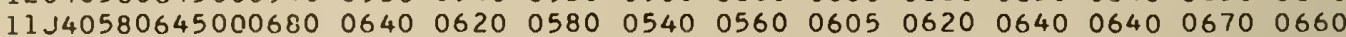

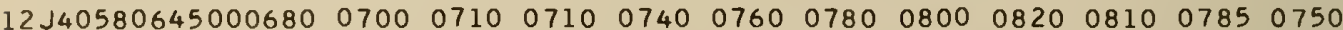

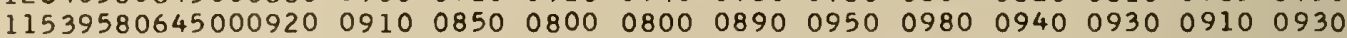
$\begin{array}{llllllllllll}12539580645000930 & 0930 & 0930 & 0920 & 0900 & 0880 & 0870 & 0860 & 0860 & 0870 & 0900 & 0910\end{array}$ $\begin{array}{llllllllllll}11938580645000700 & 0650 & 0620 & 0560 & 0530 & 0550 & 0600 & 0620 & 0670 & 0690 & 0690 & 0690\end{array}$ $\begin{array}{lllllllllllll}12938580645000710 & 0710 & 0720 & 0720 & 0730 & 0740 & 0760 & 0760 & 0800 & 0800 & 0770 & 0740\end{array}$ $11237580645000820 R 0810 R 0780 \quad 0740 \quad 0700 \quad 0750 \quad 0860 \quad 0940 \quad 0970 R 1000 R 1040 \quad 1070 R$ 12237580645001080 I080R1080 1040R0990R0940R0910R0870R0860 0840R0840R0830

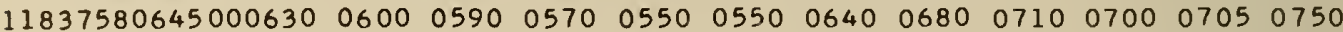
$\begin{array}{lllllllllllll}12837580645000780 & 0780 & 0790 & 0770 & 0750 & 0750 & 0720 & 0700 & 0680 & 0670 & 0650 & 0620\end{array}$

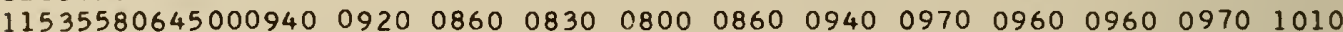
$\begin{array}{lllllllllllll}12535580645001020 & 1030 & 1020 & 1000 & 0970 & 0940 & 0920 & 0890 & 0840 & 0880 & 0920 & 0940\end{array}$ $110345806450009,040950 \quad 091040900 \quad 08300770 \quad 0800 \quad 0900 \quad 0900 \quad 0900 \quad 0920 \quad 1000$ $12034580645001030 \quad 1040 \quad 1030 \quad 1020 \quad 1020 \quad 0960 \quad 1000 \quad 0980 \quad 0900 \quad 090040920 U 0950 U$ $\begin{array}{lllllllllllllll}11832580645000670 & 0660 & 0660 & 0610 & 0600 & 0575 & 0650 & 0710 & 0770 & 0800 & 0850 & 0880\end{array}$

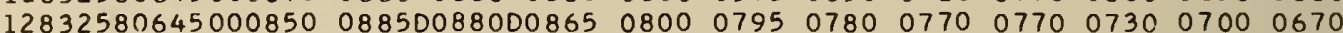
$\begin{array}{llllllllllll}11431580645000980 & 0980 & 0900 & 0860 & 0830 & 0830 & 0900 & 0930 & 0920 & 0930 & 0960 & 1040\end{array}$ $\begin{array}{lllllllllllll}12431580645001060 & 1100 & 1100 & 1130 & 1120 & 1120 & 1060 & 1000 & 0940 & 0900 & 0940 & 0970\end{array}$

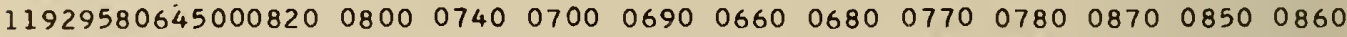
$\begin{array}{llllllllllllll}12929580645000900 & 0920 & 0900 & 0890 & 0880 & 0860 & 0860 & 0850 & 0850 & 0820 & 0800 & 0800\end{array}$ $11328580645000940 R 0920 R 0880 R 0840 R 0800 R 0820 R 0900 \quad 0950 \quad 0990 R 10201080 \quad 1160$ $12328580645001240 R 1300 R 1320 \quad 1320 R 1310 R 1270 R 1190 R 111$ OR 1030R0980R0960RO950R $11426580645001075 \quad 104509500895 \quad 0840 \quad 0785 \quad 08300865 \quad 0870 \quad 0910 \quad 0970 \quad 1040$ $\begin{array}{llllllllllll}12426580645001110 & 1150 & 1210 & 1260 & 1275 & 1265 & 1210 & 1150 & 1080 & 1000 D 1020 & 1080\end{array}$ $\begin{array}{llllllllllll}11926580645000860 & 0830 & 0780 & 0760 & 0725 & 0685 & 0735 & 0800 & 0840 & 0875 & 0925 & 0950\end{array}$ $\begin{array}{llllllllllll}12926580645000950 & 0960 & 0950 & 0930 & 0935 & 0900 & 0915 & 0890 & 0880 & 0860 & 0840 & 0830\end{array}$

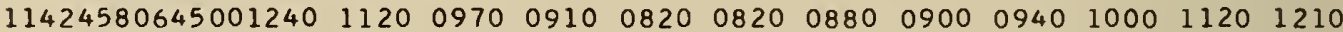

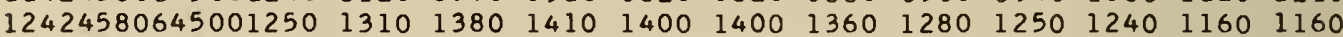
$11223580645000900 R 0840 \quad 0760 R 0710 R 0700 \quad 0710 \quad 0780 \quad 0930 \quad 0950 \quad 1000 \quad 1080 \quad 1220$ $12223580645001300 R 1400 R 1480 R 1530 R 1500 R 1440 R 1380 R 1290 R 1160110009600920$ $1102258064500120001090 R 0950 \quad 082000750 \quad 0820 \quad 0900 \quad 0930 \quad 0950 \quad 1060 \quad 1150 \quad 1240$ $12022580645001350 \quad 1400 \quad 1440 \quad 1470 R 1490 \quad 1470 R 142001360 R 130001310 D 1280 R 1240 D$ $\begin{array}{lllllllllllll}11422580645001300 & 1280 & 1120 & 0990 & 0810 & 0730 & 0800 & 0880 & 0920 & 1000 & 1080 & 1200\end{array}$

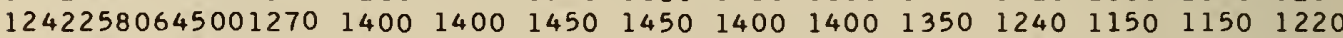

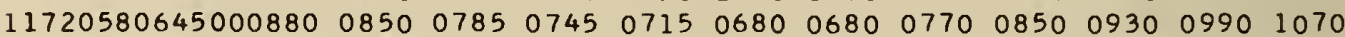
$\begin{array}{llllllllllllll}12720580645001125 & 1155 & 1170 & 1225 & 1260 & 1210 & 1145 & 1100 & 1065 & 1020 & 0930 & 0910\end{array}$ $11219580645000970 R 0940 R 0890 R 0830 R 0770 R 0690 R 0760 R 0970 R 1010 I 1040 \quad 1120 \quad 1210$ 12219580645001250 1290 1340 1360R 1360R 1350R 1330R 1290R 1240R1180R 1110R1050R

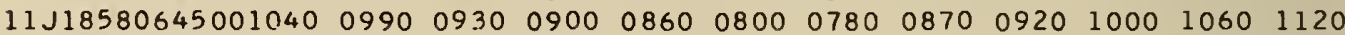

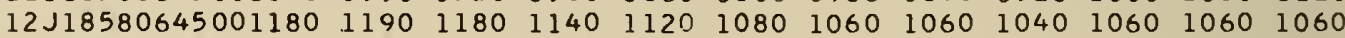

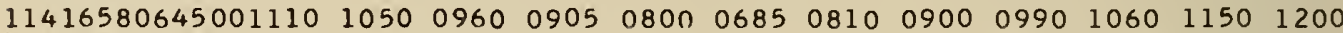
$\begin{array}{llllllllllll}12416580645001250 & 1300 & 1320 & 1305 & 1295 & 1250 & 1235 & 1195 & 1100 & 1100 & 1100 & 1125 U\end{array}$ 11A14580645000740R0720R0680R0630R0590R0570RO550R0700 0860 0950 $1050 \quad 1140$ I2A14580645001220 l290R1350R1380R1390R 1370R1330R 1240U111 OUO980RO 870R0790R $11313580645000900 \cup 0850$ U0830U0750U0700R0730RO910U109OR1150 $1220 \quad 1150 \quad 1150$ 
$12313580645001140116011701180 U 1180 U 1170 U 1100 U 1050$ U0950U0900U0970U0900U $11311580645000990 R 0940 R 0860 R 0770 R 0680 R 0660 \quad 0930 \quad 11201170 \quad 1200 \quad 1160 \quad 1120$ $123115806450011101110116011601180 \quad 1180 R 1160 R 110 O R 1020 R 1050 R 105$ ORIO3OR $11310580645000920 R 0900 R 0870 R 0830 R 0720 \quad 0600 \quad 0880 \quad 1100 \quad 1150 \quad 1190 \quad 1200 \quad 1100$ $12310580645001080 \quad 1090 \quad 1110 \quad 1120 \quad 1140 \quad 11601160 \quad 1060 \quad 0940 \quad 0910 R 0940 R 0960 R$

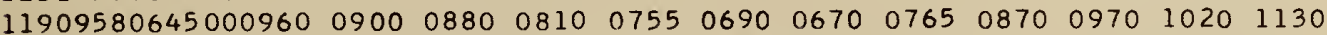
$12909580645001180 \quad 1200 \quad 1230 \quad 1220 \quad 1180 \quad 1140 \quad 1100 \quad 1030 \quad 0970 \quad 1000 \quad 0990 \quad 0990$ $11308580645001010 R 0980 R 0940 R 0890 R 0810 R 0660 R 0870 R 1130 \quad 1230 \quad 1270 R 1220 R 1130$ $12308580645001110 R 11401150 \quad$ l13OR1150R 1160R1150R1100RO980RO980D1000D1020D $11007580645000520 J 0520 J 0560 J 0570 J 0500 U 0400 \quad 0840 \quad 1130 \quad 1290 \quad 1360 \quad 1330 \quad 1230$ 12007580645001160112011201110112011101070 Uo910U0740U0680J0650J0560J

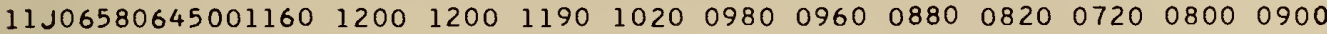
$\begin{array}{llllllllllllll}12 J 06580645001000 & 1090 & 1190 & 1200 & 1260 & 1270 & 1260 & 1200 & 1170 & 1130 & 1100 & 1060\end{array}$

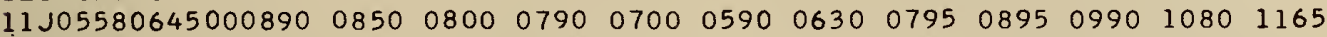
12J05580645001210 $1270 \quad 1320 \quad 1345 \quad 1295 \quad 1260 \quad 1215 \quad 1150 \quad 1100 \quad 1130 \quad 1135 \quad 1000$ $11104580645001170 R 1080 R 0930 R 0770 R 0640 R 0540 \quad 0860 \quad 125013801440 \quad 14201400$ $12104580645001400 \quad 1310 \quad 1250 \quad 1280 \quad 1240 \quad 1250 \quad 1200 \quad 1150 R 1110 R 1120 R 1140 R 1160 R$ $11102580645001120 R 0950 R 0840 R 0710 R 0860 R 1260 R 1410 R 1420 R 1420 R 142014001360$ 1210258064500134 OR1320 1340 1340 1340R1320R1320R1240R1180R1150R1120R1090R $11301580645001230 R 1100 R 0950 R 0810 R 0690 \quad 0560 \quad 0700 \quad 1140 \quad 1360 \quad 1500 \quad 1510 \quad 1480$ $12301580645001400 R 1360 R 1310 \quad 1280 \quad 1280 \quad 1290 \quad 1310 R 1320 \quad 1350 R 1360 R 1350 R 1310 R$ $1110 K 580645001560 R 1400 R 1180 R 1030 R 0860 R 0730 R 0780 \quad 1220 R 1420 R 1390 R 1370 \quad 1410$ $1210 K 580645001460 \quad 1430 \quad 1390 \quad 1410 \quad 1430 \quad 1450 R 1490 R 1540 R 1590 R 1630 R 1640 R 1620 R$ $1150 K 580645001320 \quad 1330 \quad 1360 U 1340 \quad 1350 U 1320 \quad 1340 \quad 1320 \quad 1370 \quad 1300 \quad 1360 \quad 1320$ $1250 K 580645001350 \quad 1350 \quad 1260 \quad 1160 \quad 0900 \quad 0840 \quad 0800 \quad 0730 \quad 0650 \quad 0980 \quad 1300 \quad 1350$ $1110 M 580645001270 R 1040 R 0900 R 0720 R 0490 R 0670 R 1110 R 12801300134013301360$ $1210 M 580645001400 \quad 1410 \quad 1460 \quad 1440 \quad 1450 \quad 1510 \quad 1580 R 1620 R 1640 R 1630 R 1590 R 1520$

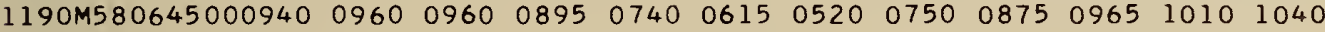
$1290 M 580645001060 \quad 1080 \quad 1090 \quad 1070 \quad 1070 \quad 1060 \quad 1040 \quad 1005 \quad 0990 \quad 1000 \quad 1015 \quad 0995$ 11 AON580645000510R0500R0490R0480R047CR0460R0450RO840U1120U1260R1320U1310U 12AON580645001300U1250U1200U1210R1210R1200R1100RO910R0780R0630RO560RO520R $\begin{array}{llllllllllll}1190 P 580645000860 & 0880 & 0885 & 0820 & 0700 & 0595 & 0560 & 0760 & 0890 & 0980 & 1030 & 1020\end{array}$ $1290 P 5806450010301050 \quad 10351010 \quad 1000 \quad 1010 \quad 0955 \quad 0900 D 0860 \quad 0895 D 0895 D 0860 D$ $1190 R 580645000820 \quad 0840 \quad 08200725^{\circ} 06300590 \quad 0550 \quad 07800925 \quad 1050 \quad 1050 \quad 1040$

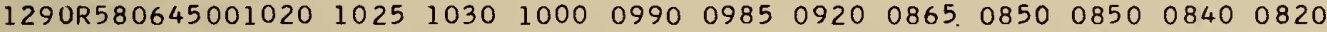

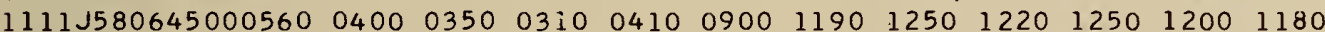

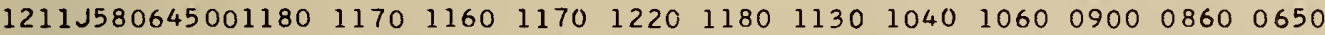

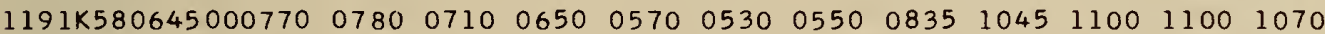

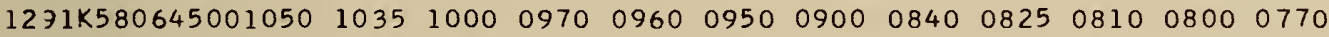

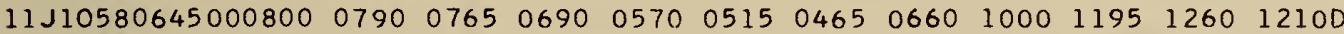

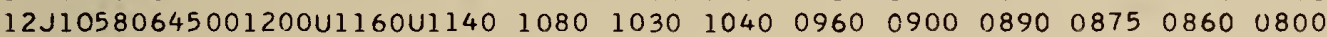

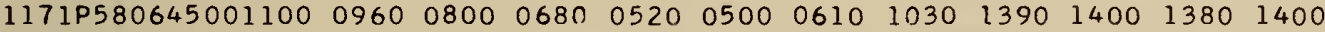

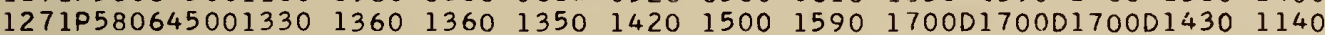

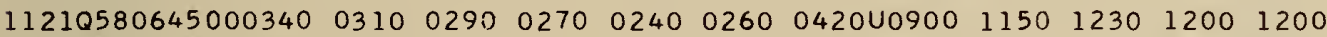
$12210580645001160 \quad 1120 \quad 1110 \quad 1100 \quad 1060 \quad 1070 \quad 0940 \quad 0780 \quad 0600 \quad 0560 \quad 051040420$

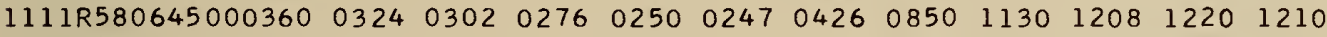
$\begin{array}{lllllllllllll}1211 R 580645001178 & 1177 & 1161 & 1166 & 1159 & 1165 & 1065 & 0854 & 0707 & 0616 & 0489 & 0430\end{array}$ $1151 R 580645000610 R 0580 R 0530 R 0470 R 0420 R 0400 R 0420$ 0840R1190R1360R1320U1260R 1251R580645001250R1230R1220R1200 1160R1060R0960RO850RO780R0760R0720RO670R $1172 J 580645000700 \quad 0620 R 0550 R 0480 R 0420 R 0440 \quad 0650 \quad 1090 U 1350 \quad 1440 \quad 1330 \quad 1290$ $1272 J 58064500126012701300 \quad 1300 \quad 1280$ U1320U1340R1290R1180R105ORO920ROBOOR

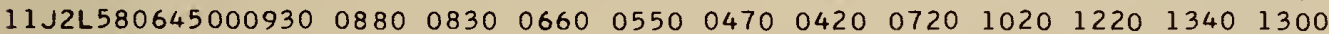
$12 J 2 L 580645001310 \quad 1340 \quad 1340 \quad 1380 \quad 1400 \quad 1420 U 1340 U 1130 \quad 1140 \quad 112 C \quad 1110 \quad 0980$

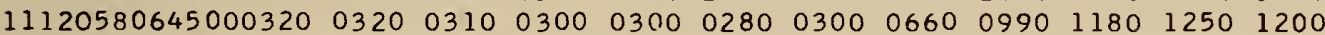
$12120580645001200 \quad 1180 \quad 1180 \quad 1140 \quad 1160 \quad 1100 \quad 10100780 \quad 06200500 \quad 03800330$ 
$11 \mathrm{~J} 20580645001050 R 0950 R 0920 \quad 0740 R 0600 R 0450 R 0420 \quad 0580 R 1080 U 1270 R 1410 R 1390 R$ 12J20580645001390R1420R1430R1450R1460R1440R1350R1290R1260R1270R 1270R1170R

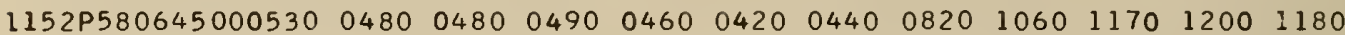
$1252 P 580645001180 \quad 1160 \quad 1120 \quad 1120 \quad 1070 \quad 1050 \quad 0890 \quad 0760 \quad 0660 \quad 0630 \quad 0560 \quad 0500$ $11430580645000430 \quad 0420 \quad 0420 \quad 0420$ U0420 $0400 \quad 0400 R 0500 R 0850 D 1070 R 1190 R 1210 R$ $12430580645001220 R 1220 R 1210 R 1210 R 1190 R 1130 R 1000 R 0820 R 0700 R 0580 R 0510 R 0450 R$

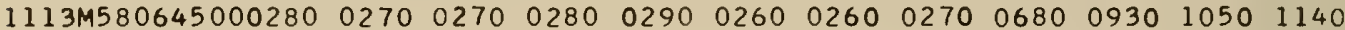
$1213 M 580645001240 \quad 1220 \quad 1220 \quad 1180 \quad 1210 \quad 1180 \quad 1030 \quad 0810 \quad 0570 \quad 0360 \quad 0310 \quad 0260$ $11 J 3 M 580645000770 R 0740 R 0680 R 0610 R 0540 \quad 0440 R 0370 R 0680 R 100011201200 \quad 1200 R$

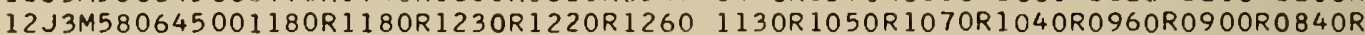
$1153 N 580645000500 \cup 0490 U 0480 \quad 0490 \quad 0480 \quad 0430 \quad 0420 \quad 0580 \cup 0940 U 1100 \quad 1180 \quad 1230 U$ $1253 N 580645001200 \quad 1200 \quad 1200 \quad 1180 \quad 1150 \quad 1100 \quad 0900 D 078 C D 0720$ UO 590 UO 520 U0 $500 U$

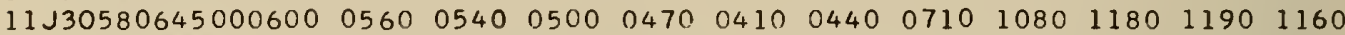

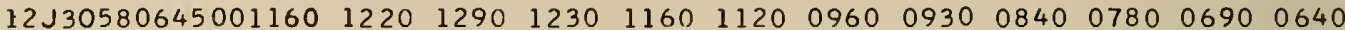
$1154 K 580645000420 \cup 0420 \quad 0400 R 0410 \quad 0390 \quad 0370 R 0360 R 0370 R 0700 D 0950 R 1100 R 1170 R$ $1254 K 580645001200 R 1200 D 1200 D 1180 R 1120 R 1030 R 090000760 D 0620 R 0520$ U0460U0440R $1164 L 580645000530 \quad 0490 \quad 0470 \quad 0460 \quad 0470 \quad 0470 \quad 0430 \quad 0400 \quad 0640 \quad 0930 R 1080 R 1180 R$ $1264 L 580645001220 R 1220 R 1190 R 1160 R 1140 \quad 1060 \quad 0890 R 0790 \quad 0700 \quad 0590 \quad 05600530$ $11 \mathrm{~J} 4 \mathrm{~L} 580645000580 \mathrm{DO} 5$ 70D0550R0530RO510 0490RO460RO470 0800R1000D1100D1100D $12 \mathrm{~J} 4 \mathrm{~L} 580645001100 D 1100 D 110001090 D 1060 D 1000 D 0890 R 0790 R 0700 R 0660 R 0620 R 0590$ $1124 R 580645000270 R 0270 R 0260 R 0250 R 0740 \quad 0230 \quad 0260 \quad 0300 \quad 050040780 \quad 0900 \quad 1050$ $1224 R 580645001210130014001300 \quad 1190 U 1030 R 0850 R 0640 R 0480 R 0350 \quad$ O29ORD270R

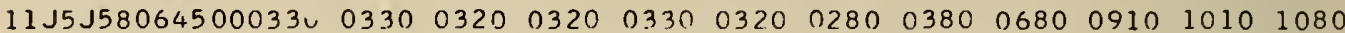

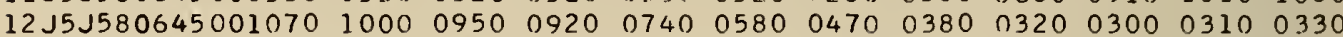

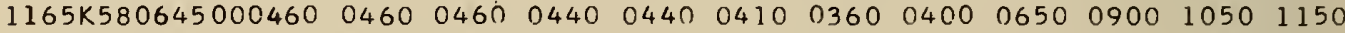
$1265 K 580645001220 \quad 1160 \quad 1210 \quad 1120 R 1000 \quad 0820 R 0690 R 0600 \quad 0570 \quad 0550 \quad 0490 \quad 0470$ 1155M580645000410R0410R0420R0420R04 IOR 0420R0390R0450R0660RO840R1000R1120R I255M580645001180R1190R1150R1030R0830R065ORO56 ORO5OORO460RO44ORO430R0420R

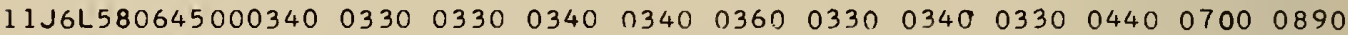

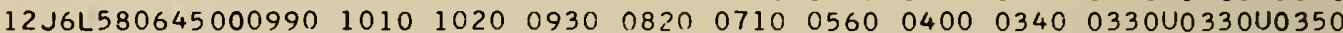

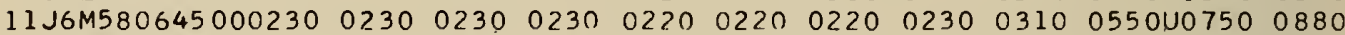

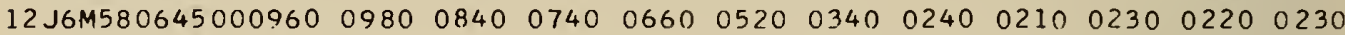
$11360580645000410 \quad 0340 \quad 0350 \quad 0340 \quad 036 n \quad 0390 \quad 0380 \quad 0380 \quad 0420 \quad 0520 R 0630 R 0710$ $12360580645000760 R 0780 R 0750 \quad 0700 R 0650 R 0610 \quad 0600 \quad 0570 R 0520 R 0470 \quad 0410 \quad 0390$ $11460580645000400 R \cap 390 R 0380 R \cap 37 \cap R \cap 36 \cap R \cap 370 R 038 \cap R 0410 R \cap 470 R 0600 R 0750 R 081$ OR $12460580645000830 R 0820 R 0790 R 0720 R \cap 69 \cap R 07 \cap 0 R \cap 670 R \cap 64$ OR 059ORO53 ORO $470 R 0420 R$

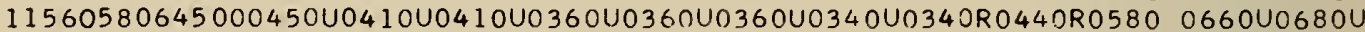
12560580645000710 U0730R0 750R0750R0740R0730U0670RO

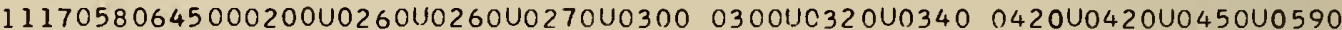

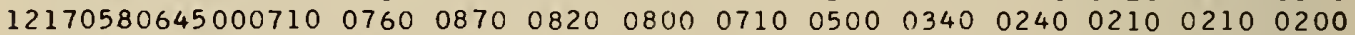

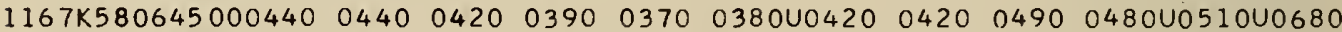

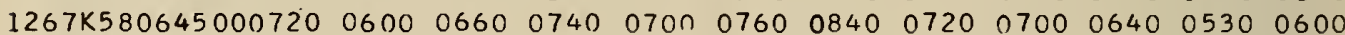
IIA70580645000200 0240R0270 $0320 R 037 n \quad 0400 \quad 0400 \quad 0420 \quad 0370 \quad 037040400 \quad 0480$

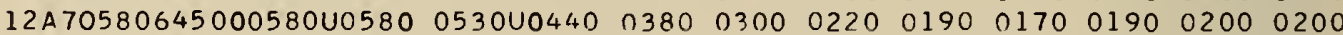

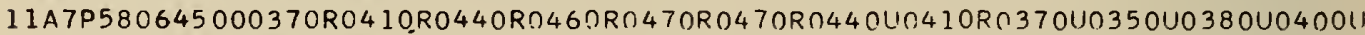
$12 A 7 P 5806450004600480 \quad 0450 \cup 0375$ Un $340102601023 n \quad 0230 R 0230 R 0250 R 0280 R D 320 R$

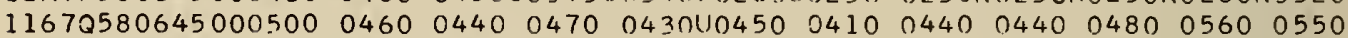

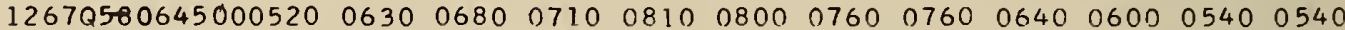
$11770580645000520 \cup 0500 \cup 0490 \cup 0430 \cup 043$ UU0 $430 \cup 0400 \cup n 385$ Un $380 \cup 0335 \cup 0390 \cup 0400 U$

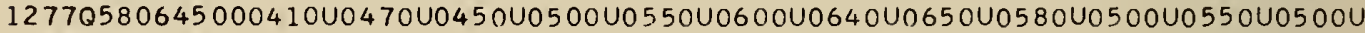
11880580645000620 U $0630 R 0610 R 0600 R 0580 R 051$ ORO440R0350 0320R0300U0320R0340R $12880580645000370 R 0360 R 0370 R 0380 R 0420 R 0430 R 0430 R 0500 R 0580$ U $620 R 0620$ U062OR

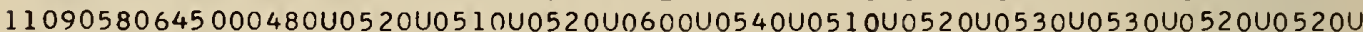
$12090580645000500 \cup 0490 \cup 0520$ U0 490 U 5 ONU0550U0470U0440U0450U0470I $0480 \cup 0500 U$ $11471580645000640 P 0640 P 0640 P 0630 P 061 C P 0590 P 0580 P 0580 P 0580 P 0580 P 0590 P 0600 P$ 
$12471580645000600 P 0610 P 0620 P 0640 P 0650 P 0660 P 0670 P 0670 P 0660 P 0650 P 0650 P 0640 P$ $11919580645000960 \mathrm{P} 0910 \mathrm{P} 0850 \mathrm{P} 0810 \mathrm{P} 0760 \mathrm{P} 0700 \mathrm{P} 0760 \mathrm{P} 0860 \mathrm{P} 0940 \mathrm{P} 1020 \mathrm{P} 1080 \mathrm{P} 1140 \mathrm{P}$ $12919580645001190 \mathrm{P} 1230 \mathrm{P} 1240 \mathrm{P} 1220 \mathrm{P} 1190 \mathrm{P} 1160 \mathrm{P} 1130 \mathrm{P} 1090 \mathrm{P} 1040 \mathrm{P} 1000 \mathrm{P} 0980 \mathrm{P} 0960 \mathrm{P}$ $11513580645000970 P 0930 P 0890 P 0830 P 0760 P 0700 P 0830 P 0940 P 0990 P 1030 P 1090 P 1150 P$ $12513580645001190 P 1230 P 1260 P 1290 P 1310 P 1330 P 1300 P 1230 P 1150 P 1080 P 1040 P 1010 P$ $11111580645000800 \mathrm{P} 0760 \mathrm{P} 0720 \mathrm{P} 0680 \mathrm{P} 0630 \mathrm{P} 0570 \mathrm{P} 0790 \mathrm{P} 0980 \mathrm{P} 1090 \mathrm{P} 1130 \mathrm{P} 1150 \mathrm{P} 1140 \mathrm{P}$ $12111580645001150 P 1170 P 1200 P 1220 P 1240 P 1240 P 1210 P 1150 P 1050 P 0960 P 0890 P 0850 P$ $11411580645000990 \mathrm{P} 0950 \mathrm{P} 0890 \mathrm{P} 0800 \mathrm{P} 0700 \mathrm{P} 0610 \mathrm{P} 0840 \mathrm{P} 1030 \mathrm{P} 1120 \mathrm{P} 1160 \mathrm{P} 1160 \mathrm{P} 1160 \mathrm{P}$ $12411580645001180 \mathrm{P} 1190 \mathrm{P} 1190 \mathrm{P} 1190 \mathrm{P} 1190 \mathrm{P} 1190 \mathrm{P} 1180 \mathrm{P} 1120 \mathrm{P} 1030 \mathrm{P} 0990 \mathrm{P} 0990 \mathrm{P} 1000 \mathrm{P}$ $11705580645001160 P 1110 P 1040 P 0950 P 0810 P 0630 P 0710 P 0890 P 0990 P 1060 P 1100 P 1130 P$ $12705580645001150 \mathrm{P} 1170 \mathrm{P} 1200 \mathrm{P} 1210 \mathrm{P} 1200 \mathrm{P} 1180 \mathrm{P} 1150 \mathrm{P} 1080 \mathrm{P} 1050 \mathrm{P} 1080 \mathrm{P} 1130 \mathrm{P} 1160 \mathrm{P}$ $11701580645001090 P 1050 P 0990 P 0900 P 0780 P 0590 P 0700 P 0870 P 0990 P 1050 P 1090 P 1120 P$ $12701580645001130 \mathrm{P} 1150 \mathrm{P} 1160 \mathrm{P} 1180 \mathrm{P} 1170 \mathrm{P} 1140 \mathrm{P} 1090 \mathrm{P} 1050 \mathrm{P} 1020 \mathrm{P} 1030 \mathrm{P} 1070 \mathrm{P} 1100 \mathrm{P}$ $1150 R 580645000850 P 0750 P 0600 P 0460 P 0370 P 0320 P 0530 P 0960 P 1190 P 1270 P 1230 P 1190 P$ $1250 R 580645001160 \mathrm{P} 1160 \mathrm{P} 1130 \mathrm{P} 1080 \mathrm{P} 1060 \mathrm{P} 1040 \mathrm{P} 1040 \mathrm{P} 1050 \mathrm{P} 1010 \mathrm{P} 0920 \mathrm{P} 0880 \mathrm{P} 0860 \mathrm{P}$ $11610580645000770 \mathrm{P} 0690 \mathrm{P} 0580 \mathrm{P} 0510 \mathrm{P} 0440 \mathrm{P} 0400 \mathrm{P} 0530 \mathrm{P} 1040 \mathrm{P} 1280 \mathrm{P} 1360 \mathrm{P} 1370 \mathrm{P} 1360 \mathrm{P}$ $12610580645001340 \mathrm{P} 1310 \mathrm{P} 1290 \mathrm{P} 1270 \mathrm{P} 1280 \mathrm{P} 1260 \mathrm{P} 1190 \mathrm{P} 1080 \mathrm{P} 0960 \mathrm{P} 0900 \mathrm{P} 0870 \mathrm{P} 0830 \mathrm{P}$ $1162 R 580645000520 P 0520 P 0520 P 0520 P 0510 P 0480 P 0450 P 0730 P 1000 P 1140 P 1210 P 1180 P$ $1262 R 580645001150 P 1130 P 1110 P 1090 P 1060 P 0990 P 0850 P 0730 P 0640 P 0580 P 0540 P 0530 P$ $1116 R 580645000400 P 0400 P 0390 P 0380 P 0380 P 0400 P 0430 P 0450 P 0460 P 0470 P 0560 P 0710 P$ $1216 R 580645000810 P 0880 P 0890 P 0820 P 0730 P 0610 P 0470 P 0360 P 0340 P 0360 P 0380 P 0390 P$ $1147 \mathrm{P} 580645000340 \mathrm{P} 0330 \mathrm{P0} 310 \mathrm{P0} 310 \mathrm{P0} 320 \mathrm{P} 0350 \mathrm{P} 0380 \mathrm{P} 0420 \mathrm{PO} 460 \mathrm{P} 0510 \mathrm{P} 0560 \mathrm{P} 0620 \mathrm{P}$ $1247 P 580645000660 P 0670 P 0660 P 0630 P 0580 P 0550 P 0510 P 0490 P 0450 P 0420 P 0380 P 0360 P$ $90000 \quad 8033765157 \quad 40210 \quad 40330 \quad 35030 \quad 35105 \quad 35185 \quad 35310 \quad 30165 \quad 25050 \quad 25325 \quad 20030$ $\begin{array}{lllllllllll}20232 & 15175 & 10240 & 05160 & 05345 & 00060 & 00180 & 00225 & 00255-05080-05125-05200-10165\end{array}$ $-10350-15105-15240-20075-20265-25345-30095-30225-35050-35075-35200-35265-40345$ $-45095-45120-45240-45325-50015-50045-50200-50270-55105-60000-60330-65210-65240$ $-65265-75067-75277-80037-80300-85140-85225$ 

DATE $=5806 \quad$ DATA $=4500 \quad N=154 \quad P=52 \quad H=8 \quad F N=100$

PPII 12 PP2 $=36$ PP $3=52 \quad P H 2=4 \quad H I=4 \quad$ TA=2 SL $=6.0 \quad S 2=2.0$ $N A=142 \quad N C=59 \quad S=186.8 \quad M N=4$

$\mathrm{d}_{\mathrm{k}}$

GRTHO COEFF. 9.7796171E 01 $-7.9743505 E-n 1$ $-2.3183237 E^{01}$ $-7.2388791 \ddot{E}-01$ $1.4358329 E 00$ J. $2821402 E 00$ $-1.10866835-01$ $-1.1094761 \mathrm{~F} 00$ $5.17084 .30 E-01$ $-2.9567594 E-01$ 1. $9614815 E-01$ $9.0033002 E-01$ 1. $1211874 \mathrm{E}$ DO $-3.1900162 E-J 2$ 4. $2415078 E 110$ $1.8129360 E$ DO 4. 519783 RE 20 $-1.3758838 E$ UO $-1.4438721 \mathrm{E}-01$ 4. $2604412 E-J 1$ $-2.0292717 E 00$ $-8.58720001-01$ 1. 8782378 : 00 9.8311927E-02 $-2.1760287 E$ OO $-6.1193166 t-01$

$-1.384 \angle 770 \mathrm{~F}$ ก0 h. $598 \rightarrow 62$ it -01 3. $218 C 743 \mathrm{E} 00$ 4. $1557774 E-01$ $7.071 \equiv 965 t-01$ 2. $0153300 E-01$ $-3.1005224 E$ DO $-8.8725764 E-01$ $-6.5550982 E-01$ 1. $6988062 \mathrm{E}$ OC 1. $3383783 E$ UC 5. $3007979 E-(12$ 1. $4382064 \mathrm{~F}-\mathrm{n} \mathrm{l}$ $1.4322262 \ddot{E}$ JC -1.2305239 E UO $-6.1052668 \mathrm{E}-$ ?) 1 $-5.4<74504 E-01$ ?. $\$ 313019 E-01$ 4. $3273214 E-01$ 2. $+392665 E-01$ $3.420 ? 192 E-01$ $-1.1776633 E \quad 00$ $-6.9730944 E-01$ 4. $85344 \mathrm{CCE}-\mathrm{O} 1$ 1. $8633364 \mathrm{E} \rightarrow \mathrm{DL}$ $-2.8886722 E-01$ $1.5939509 E$ DO 1.1545718 O 1

\section{First Analysis}

$\mathrm{E}_{\mathrm{k}}$

SUMS $t K$

6.6465771 E 0.2

6. 6402160 E 02

1. 26559331 C2

1.2003531502

$1.2397369 \mathrm{~F} \cap 2$

1. $2232981 E$ D2

$1.2731752 \mathrm{E}$ C2

$1.2108658 E$ O2

1. 2 C81920E 02

1.2C73178E C2

1. 2 Co9330t 02

$1.1 .988271 E \quad 02$

1. $1852565 \mathrm{E}$ C2

1. $1862463 \mathrm{r}$ O2

1. $0 \mathrm{C} 63424 \mathrm{~F} \mathrm{C2}$

$9.7347503 \mathrm{E} \mathrm{Cl}$

$7.6919057 E$ E 1

7.502600UE O1

$7.5005152 \mathrm{E}$ \&I

$7.4823125 t$. 1

$7.0755182 \mathrm{E}$ OI

6. 7967787 E 01

S. $6440004 E$ OI

0.6430339 E OI

6.1691756E $\approx 1$

$6.1317295 E$ CI

5.9401072E CI

$5.8966928 \mathrm{E} \mathrm{Ol}$

4. $8610796 \mathrm{E} \mathrm{OI}$

4. $8438091 \mathrm{E} \cap 1$

$4.7938016 t 01$

4.7897401E CL

3. 8246920 t 11

$3.7459693 \mathrm{E} \mathrm{DI}$

3.703 CanoF $n 1$

$3.4144057 E$ CI

3. 03 H6747E CI

3.03४3G36E CI

3.C.363252E OI

2. $8311980 E$ OI

2.6797791 OI

$2.6425 \mathrm{C} 4 \mathrm{Ht}$ i 1

2.6073701E OI

2. $5993510 \mathrm{t}$ C.

\%.5300067E Ul

?. $5240567 t$ CI

2. $5123540 E \mathrm{Cl}$

2.3736649E CI

2.3249571t C I

?. $3014013 E$ OI

$2.2979272 \mathrm{E} \mathrm{OI}$

2. $237584 \mathrm{BE} \mathrm{Cl}$

2. C355168E Cl

1.2457914E त2

$e_{\mathrm{K}}$
KMS (EK)
$2.0842668 \mathrm{E} 00$
$2.0901111 \mathrm{E} 00$
$9.1550053 \mathrm{E}-01$
$9.1664355 \mathrm{E}-01$
$9.1216128 \mathrm{E}-01$
$9.0914947 \mathrm{E}-01$
$9.1219074 \mathrm{E}-01$
$9.1069211 \mathrm{E}-01$
$9.1281754 \mathrm{E}-01$
$9.1565011 \mathrm{E}-01$
$9.1869968 \mathrm{E}-01$
$9.1882774 \mathrm{E}-01$
$9.1723313 \mathrm{E}-01$
$9.2047918 \mathrm{E}-01$
$8.5087444 \mathrm{E}-01$
$8.3989086 \mathrm{E}-01$
$7.4930165 \mathrm{E}-01$
$7.4273936 \mathrm{E}-01$
$7.4538158 \mathrm{E}-01$
$7.4724931 \mathrm{E}-01$

$7.4724931 \mathrm{E}-01$

$7.2912132 \mathrm{E}-01$

7. $2805147 \mathrm{E}-01$

$7.1216262 \mathrm{~F}-01$

7. $1484445 \mathrm{E}-01$

6. $9154223 E-01$

$6.9212813 t-01$

6. $8390421 E-01$

6. $8409902 \mathrm{E}-01$

6. $2360753 E-01$

6. $2500380 E-01$

6. $2429157 t-01$

6. $2657931 E-01$

$5.6221903 E-C 1$

5. $5871648 E-01$

$5.5783193 E-01$

5.3771859E-01

5. $0962317 E-01$

5. $1179144 E-01$

5. $1383681 E-01$

4. $9834797 \mathrm{E}-01$

4. $86979 C 4 E-01$

4. $8573442 E-01$

$4.8466299 t-01$

4.8611175E-01

$4.8177869 E-01$

$4.8343453 E-01$

4.8456107E-01

4. $7321311 E-01$

4.7055763F-nl

$4.7041320 t-01$

4. $7233454 E-01$

4. $7378169 \dot{i}-01$

4. $4892796 E-01$

$9.0235400 E-01$ $\mathrm{d}_{\mathrm{k}} / \mathrm{e}_{\mathrm{K}}$

ORTHU COEFF/RMS

4.6921139E O1

$-3.8152758 E-01$

$-2.5323018 E$ OI

$-7.8971581 \mathrm{E}-01$

1. 5740999 E 00

$1.4102634 E$ OOO

$-1.2153909 E-01$

$-1.2182779 E$ OO

$5.6647279 E-01$

$-3.2291367 E-01$

2.1350628E-01

9. $7986813 E-01$

1. $2223582 E \quad 00$

$-3.4655285 F-02$

4. $9848809 \mathrm{~F} 00$

2. $1585376 E$ OO

6. 0319949 E OO

$-1.8524449 E 00$

$-1.9370911 \mathrm{E}-01$

5. $7095284 E-01$

$-2.7831743 E \quad 00$

-1.1794771 E 00

2.637372 OE 00

1. $3752912 E-01$

$-3.1477884 E \quad 00$

$-8.8413059 E-01$

$-2.02408 \cap 2 E 00$

$9.6315920 E-01$

5. 1604480 O 00

$6.6492034 \mathrm{E}-01$

1. $1327394 \mathrm{E} 00$

3. $2164004 E-01$

$-5.5254663 E \quad 00$

$-1.5880284 E 00$

$-1.1751027 E$ OO

3. $1581103 E 00$

$3.8035522 \mathrm{E} 00$

$1.0357340 E-01$

2. $7989555 E-01$

2. $8739480 E 0 O$

$-2.5268517 E$ E 00

$-1.2569146 E$ OO

$-1.2230045 E 00$

$5.8254132 \mathrm{E}-01$

$1.7284537 E$ OO

5. $0457017 \mathrm{E}-01$

7. $U 598308 E-01$

-2.4886532 E 00

-1.4831540 E 00

$1.0317398 E 00$

$3.7449505 E-01$

$-6.0970533 E-01$

3.5505716E OO

1.2795110E Cl 
$a_{k}$

ORTHO COEFF.

$1.1586693 E \quad 02$

$2.7317004 E \quad 00$

$-2.7691270 E$ OI

$-1.0710768 E 00$

$1.8120750 E$ OO

1.3887605E 00

$261874004 E-02$

$-9.0152808 E-01$

4. $1653732 E-01$

$-1.6968181 E-01$

$-2.5998666 E-01$

$1.2061595 E \quad 00$

$1.7125742 \mathrm{E} O 0$

$-4.7527078 E-01$

3.4918428 E 00

2.8463537E OC

$5.8259827 E \quad 00$

$-1.0570359 E$ OC

5. $7026108 \mathrm{E}-02$

$2.1162752 E-01$

$-1.7289138 \mathrm{E} \quad 00$

$-9.5828191 E-01$

$1.2780304 \mathrm{E} 00$

2. $9433686 \mathrm{E}-01$

$-1.4432438 E \quad 00$

$-7.1608432 \mathrm{E}-01$

$-1.4521510 E$ UO

$2.4560481 E-01$

$2.0283353 E$ OO

8.5172019E-01

1. $112.5955 E 00$

2.0158679E-01

$-2.1212865 E \quad 00$

$-9.7172902 E-01$

$-9.4321649 E-01$

$1.3584320 E \quad 00$

$1.4552336 \mathrm{E}$ OO

$7.0770034 \mathrm{E}-01$

2. $7800587 \mathrm{E}-01$

$9.6084980 \mathrm{E}-01$

$-9.1351080 E-01$

$-3.0404271 E-01$

$-8.6670141 E-01$

$1.9961724 \mathrm{E}-01$

1. $2900269 E-01$

6.7134 I66E-01

$1.2942037 E$ DO

-1.3200679 E 00

$-1.0531998 \mathrm{E} 00$

$-8.8752718 E-01$

$-1.6098626 E-01$

$1.0323948 \mathrm{E} \mathrm{CO}$

$1.5491854 \mathrm{E} 00$

1.5186295E 01

$-5.2349702 \mathrm{E} 00$

$-8.2212824 E$ OO

2. $3026811 E 00$

$-3.1106774 E-01$

$1.9968812 \mathrm{E} \quad 00$
$\mathrm{E}_{\mathrm{K}}$

SUMS EK

$9.1748523 E$ O2

$9.1002303 E \quad 02$

$1.4321663 \mathrm{E} 02$

$1.4206942 E \quad 02$

1.3878580 E 02

1.3685715 E 02

$1.3685667 E \quad 02$

$1.3604391 E 02$

1.3587041E 02

$1.3584162 \mathrm{E} \quad 02$

1. $3577402 \mathrm{E} 02$

1.3431920E 02

$1.3138629 E \quad 02$

1.3116040E 02

$1.1896743 E \quad 02$

$1.1086570 E 02$

$7.6923630 \mathrm{E} \mathrm{Ol}$

$7.5806304 \mathrm{E} \mathrm{OL}$

$7.5803052 \mathrm{E} \mathrm{Ol}$

$7.5758265 \mathrm{E} \mathrm{Cl}$

$7.2769122 \mathrm{E} \mathrm{Cl}$

$7.1850817 E$ OI

$7.0217456 E$ OI

$7.0130810 \mathrm{E} \mathrm{Cl}$

$6.8047842 \mathrm{E} \mathrm{Cl}$

$6.7535064 E$ OI

$6.5426322 \mathrm{E} \mathrm{O1}$

$6.5366000 \mathrm{E} \mathrm{Cl}$

$6.1251855 E$ OI

$6 . C 526428 \mathrm{E}$ O1

5.9288559E O1

$5.9247922 E \quad 01$

$5.4748065 E$ OI

$5.3803806 E$ Ol

$5.2914149 E$ OI

5.1068811E O1

$4.8951106 E$ O1

$4.8450266 E$ Ol

$4.8372979 E$ O1

4.7449746E O1

$4.6615244 E$ OI

$4.6522802 \mathrm{E} \mathrm{Ol}$

$4.5771630 E$ OI

$4.5731783 E$ OI

4.571514 IE 01

4.526444IE Ol

4.3589478E 01

$4.1846898 E$ OI

$4.0737668 \mathrm{E} \mathrm{O1}$

$3.9949963 \mathrm{E} \mathrm{Ol}$

3.5924047E OI

$3.8858207 \mathrm{E}$ O1

$3.6458232 E$ OI

$1.6917869 \mathrm{E}$ O2

1.4177378 E 02

$7.4184297 E$ OI

$6.8881957 E$ O1

$6.8785193 E$ OI

$6.4797658 E$ OI $e_{k}$

RMS (EK)

$2.0803270 E 00$

$2.0767536 E$ OO

8.2582319E-01

8.2447437E-01

8. $1684725 E-01$

$8.1310862 E-01$

8. $1507837 E-01$

8.1463417E-01

$8.1610746 E-01$

8.1802843E-01

8. $1984670 E-01$

$8.1746848 E-01$

$8.1051307 E-01$

8.1184818E-01

$7.7514232 \mathrm{E}-01$

$7.5018002 E-01$

$6.2647226 E-01$

$6.2349841 E-01$

$6.2508989 E-01$

$6.2652204 E-01$

$6.1563450 E-01$

$6.1333700 E-01$

$6.0791903 E-01$

$6.0914898 E-01$

$6.0162829 E-01$

$6.009576 .3 E-01$

$5.9308887 E-01$

$5.9441544 E-01$

$5.7696665 E-01$

$5.7510477 \mathrm{E}-01$

5. $7075503 E-01$

5.7213335E-01

$5.5150332 E-01$

$5.4825169 \mathrm{E}-01$

5. $4522518 E-01$

$5.3714463 E-01$

5. $2738153 E-01$

$5.2617360 E-01$

$5.2726238 E-01$

$5.2371365 \mathrm{E}-01$

$5.2059472 E-01$

$5.2159674 E-01$

5. $1888812 E-01$

5. $2019445 E-01$

$5.2164540 E-01$

5.2061940E-01

$5.1243264 E-01$

$5.0360457 E-01$

4. $9839785 E-01$

4. $9506747 E-01$

4. $9643200 E-01$

4. $9127927 E-01$

4.7735097E-01

8. $9331555 E-01$

$8.1970338 \mathrm{E}-01$

5. $9435557 E-01$

5.7408948E-01

5.7506351E-01

5.5949277E-01 $\mathrm{d}_{\mathrm{k}} / \mathrm{e}_{\mathrm{k}}$

ORTHO COEFF/RMS

5.5696498E 01

1. $3153705 E$ OO

$-3.3531717 E_{01}$

-1.2991025 E 00

$2.2183768 \mathrm{E} 00$

$1.7079643 E \quad 00$

2. $6836688 E-02$

$-1.1066662 E \quad 00$

5. $1039518 E-01$

$-2.0742777 E-01$

$-3.1711619 E-01$

$1.4754813 \mathrm{E} 00$

2. $1129507 E$ OO

$-5.8542568 E-01$

4.5047764E 00

3. $7942275 E$ OO

$9.2996657 E \quad 00$

$-1.6953306 E 00$

9. $1228651 E-02$

3. $3778145 E-01$

$-2.8083445 E$ OO

$-1.5624068 E$ OO

2. 1023037 E 00

4. $8322638 E-01$

$-2.3989044 E \quad 00$

$-1.1915721 \mathrm{E} 00$

$-2.4484543 E \quad 00$

4. $1318712 E-01$

3. $5155157 E \quad 00$

1. $4809826 \mathrm{E} \quad 00$

1. $9493397 E$ OO

3. $5234231 E-01$

$-3.8463712 E$ OO

$-1.7724152 \mathrm{E} 00$

$-1.7299577 E$ OO

2. $5289873 E \quad 00$

$2.7593565 E \quad 0 O$

1. $3449940 E \quad 00$

5. $2726285 E-01$

$1.8346854 E$ OO

-1.7547447 E 00

$-5.8290569 E-01$

-1.6703050 E 00

$3.8373581 E-01$

2. $4729959 E-01$

1.2895056E 00

2. $5256074 E$ OO

-2.6212389 E OO

-2.1131709E 00

$-1.7927399 E \quad 00$

$-3.2428662 E-01$

2. $1014417 E \quad 00$

$3.2453802 E \quad 00$

1. $6999922 E \quad 01$

$-6.3864201 E$ OO

-1.3832262 E 01

4.0110143E 00

$-5.4092762 E-01$

3. $5690922 \mathrm{E} \quad 00$ 
Residuals and their RMS

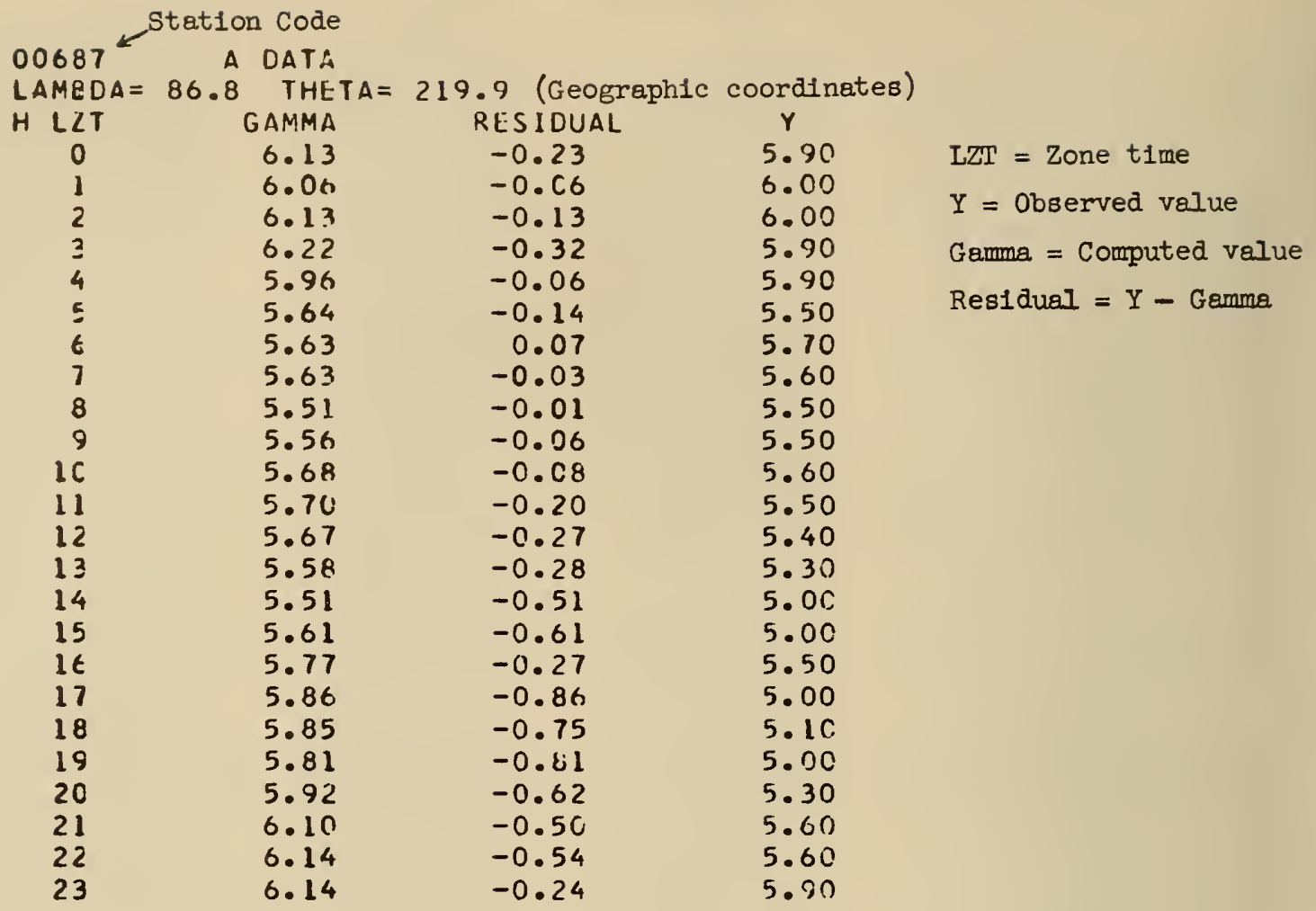

LOCAL RHS RESIDUAL 4. $105988 E-01$

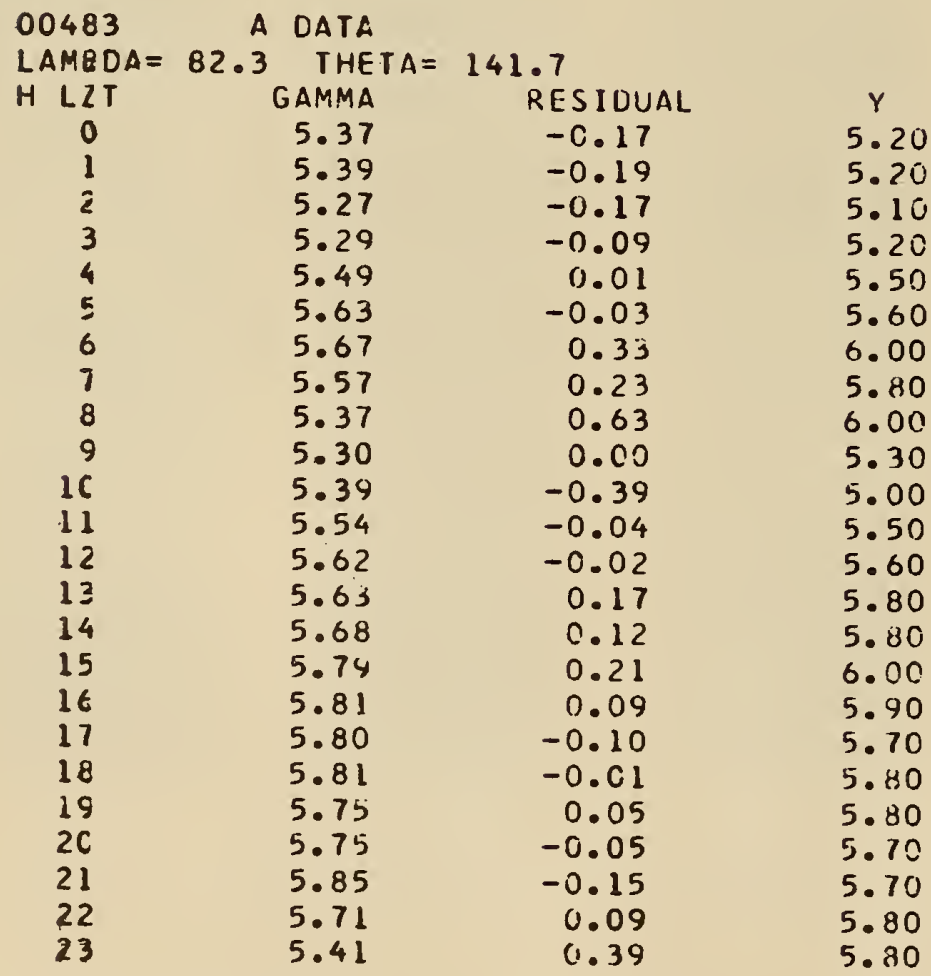




\begin{tabular}{|c|c|c|c|}
\hline $\begin{array}{l}00982 \\
\text { LAMBDA }=\end{array}$ & $\begin{array}{c}\text { A } \text { CATA } \\
79.9 \text { THETA }=\end{array}$ & 243.9 & \\
\hline$H L Z T$ & GAMMA & RES IDUAL & Y \\
\hline 0 & 5.61 & 0.09 & 5.70 \\
\hline 1 & 5.66 & -0.06 & 5.60 \\
\hline $\bar{z}$ & 5.65 & 0.15 & 5.80 \\
\hline 3 & 5.67 & 0.18 & 5.85 \\
\hline 4 & 5.63 & 0.22 & 5.85 \\
\hline 5 & 5.61 & -0.01 & 5.60 \\
\hline$\epsilon$ & 5.71 & -0.21 & 5.50 \\
\hline 7 & 5.67 & -0.17 & 5.50 \\
\hline 8 & 5.4 .5 & 0.15 & 5.60 \\
\hline s & 5.43 & -0.03 & 5.40 \\
\hline 10 & 5.56 & -0.06 & 5.50 \\
\hline 11 & 5.53 & -0.03 & 5.50 \\
\hline 12 & 5.47 & 0.13 & 5.60 \\
\hline 13 & 5.50 & $-c .00$ & 5.50 \\
\hline 14 & 5.49 & 0.21 & 5.70 \\
\hline 15 & 5.45 & 0.10 & 5.55 \\
\hline 16 & 5.41 & 0.14. & 5.55 \\
\hline 17 & 5.36 & 0.04 & 5.40 \\
\hline 18 & 5.40 & 0.30 & 5.70 \\
\hline 19 & 5.54 & 0.11 & 5.65 \\
\hline $2 C$ & 5.64 & -0.24 & 5.40 \\
\hline 21 & 5.64 & 0.06 & 5.70 \\
\hline 22 & $5.5 b$ & 0.05 & 5.60 \\
\hline 23 & $5.5 \%$ & -0.02 & 5.50 \\
\hline
\end{tabular}

LOCAL RMS RESIUUAL

$1.416 C 85 \mathrm{E}-01$

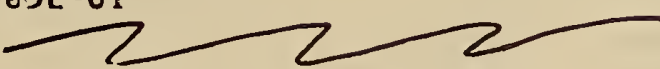

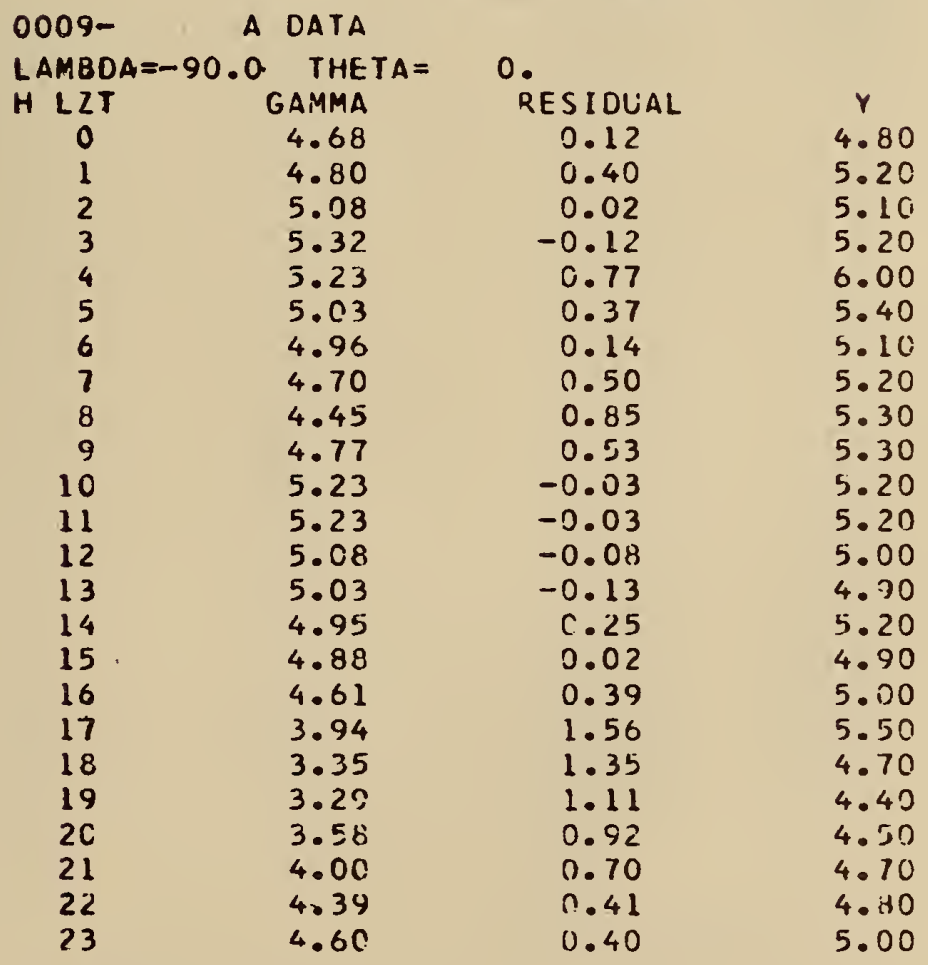

LOCAL RMS RESIDUAL

6. $320838 \mathrm{E}-01$

RMS RESIDUAL

$6.318335 E-(1)$

A DATA 79 


\begin{tabular}{|c|c|c|c|}
\hline $\begin{array}{l}00471 \\
\text { LAMEDA }\end{array}$ & $\begin{array}{c}\text { B DATA } \\
71.6 \text { THETA }\end{array}$ & 128.9 & \\
\hline $\begin{array}{l}\text { LAMEDA } \\
H L Z T\end{array}$ & $\begin{array}{l}\text { GAMMA } \\
\text { GAM- }\end{array}$ & RESIDUAL & $Y$ \\
\hline C & 5.77 & 0.63 & 6.40 \\
\hline 1 & 5.73 & 0.67 & 6.40 \\
\hline 2 & 5.66 & 0.74 & 6.40 \\
\hline 3 & 5.66 & 1). 64 & 6.30 \\
\hline 4 & 5.72 & 0.38 & 6.10 \\
\hline 5 & 5.68 & 0.22 & 5.90 \\
\hline 6 & 5.64 & 0.16 & 5.80 \\
\hline 7 & 5.68 & 0.12 & 5.80 \\
\hline 8 & 5.72 & 0.08 & 5.80 \\
\hline 9 & 5.76 & 0.04 & 5.80 \\
\hline 10 & 5.90 & 0.00 & 5.90 \\
\hline 11 & 6.03 & -0.08 & 6.00 \\
\hline 12 & 6.21 & -0.21 & 6.00 \\
\hline 13 & 6.26 & -0.16 & 6.10 \\
\hline 14 & 6.20 & 0.00 & 6.20 \\
\hline 15 & 6.06 & 0.34 & 6.40 \\
\hline 16 & 5.96 & 0.54 & 6.50 \\
\hline 17 & 5.93 & 0.67 & 6.60 \\
\hline 16 & 5.90 & 0.80 & 6.10 \\
\hline 19 & 5.84 & 0.86 & 6.70 \\
\hline 20 & 5.80 & 0.80 & 6.60 \\
\hline 21 & 5.82 & 0.68 & 6.50 \\
\hline 22 & 5.33 & 0.07 & 6.50 \\
\hline 2.3 & 5.80 & 0.60 & 6.40 \\
\hline
\end{tabular}

LOCAL RMS RESIDUAL

5.112251E-01

$\begin{array}{cccc}0047 P & \text { B DATA } & & \\ \text { LAMBDA }=-78.4 & \text { THETA } & 106.9 & \\ H L Z T & \text { GAMMA } & \text { RESIDUAL } & Y \\ 0 & 4.2 \% & -0.85 & 3.40 \\ 1 & 3.90 & -0.60 & 3.30 \\ 2 & 3.59 & -0.49 & 3.10 \\ 3 & 3.40 & -0.30 & 3.10 \\ 4 & 3.33 & -0.13 & 3.20 \\ 5 & 3.48 & 0.02 & 3.30 \\ 6 & 3.76 & 0.04 & 3.80 \\ 7 & 3.94 & 0.26 & 4.20 \\ 8 & 4.13 & 0.41 & 4.60 \\ 9 & 4.88 & 0.22 & 5.10 \\ 10 & 5.73 & -0.13 & 5.60 \\ 11 & 6.25 & -0.05 & 6.20 \\ 12 & 6.49 & 0.11 & 6.60 \\ 13 & 6.55 & 0.15 & 6.70 \\ 14 & 6.43 & 0.17 & 6.60 \\ 15 & 6.37 & -0.07 & 6.30 \\ 16 & 6.33 & -0.53 & 5.80 \\ 17 & 6.06 & -0.56 & 5.50 \\ 18 & 5.65 & -0.55 & 5.10 \\ 15 & 5.34 & -0.44 & 4.40 \\ 20 & 5.05 & -0.55 & 4.50 \\ 21 & 4.77 & -0.57 & 4.20 \\ 22 & 4.62 & -0.82 & 3.80 \\ 23 & 4.50 & -0.90 & 3.60 \\ & & & \end{array}$

LOCAL RMS KESIDUAL

4.569347E-OL

RMS RESIDUAL

B DATA

$6.237257 E-01$

RMS RESIDUAL OF A ANO B .DATA $6.3 .12054 E-01$ 
One Per Card Coefficients $D_{\text {sk }}$ (See Card Format 5)

\begin{tabular}{|c|c|c|c|c|c|c|c|c|c|c|c|c|}
\hline M & DLC & $\mathbb{N}$ & $\mathrm{P}$ & $\mathrm{H}$ & FNCD & PP1 & PP2 & $\mathrm{T}$ & SN & $\mathrm{s}$ & $\mathrm{k}$ & $\mathrm{D}_{\text {sk }}$ \\
\hline 5806 & 4500 & 213 & 52 & 8 & 100 & 12 & 36 & 1 & 186.8 & 0 & 0 & $1.0847341 \mathrm{E} \quad 01$ \\
\hline 5806 & 4500 & 213 & 52 & 8 & 100 & 12 & 36 & 1 & 186.8 & 0 & 1 & $6.0068659 E-01$ \\
\hline 5806 & 4500 & 213 & 52 & 8 & 100 & 12 & 36 & 1 & 186.8 & 0 & 2 & $-2.4230472 \mathrm{E} \quad 01$ \\
\hline 5806 & 4500 & 213 & 52 & 8 & 100 & 12 & 36 & 1 & 186.8 & 0 & 3 & $1.7365042 \mathrm{E}$ ol \\
\hline 5806 & 4500 & 213 & 52 & 8 & 100 & 12 & 36 & 1 & 186.8 & 0 & 4 & $1.8869887 \mathrm{E} \mathrm{O2}$ \\
\hline 5806 & 4500 & 213 & 52 & 8 & 100 & 12 & 36 & 1 & 186.8 & 0 & 5 & $-1.1593593 E \quad 02$ \\
\hline 5806 & 4500 & 213 & 52 & 8 & 100 & 12 & 36 & 1 & 186.8 & 0 & 6 & $-7.6300942 E \quad 02$ \\
\hline 5806 & 4500 & 213 & 52 & 8 & 100 & 12 & 36 & 1 & 186.8 & 0 & 7 & $2.6676274 \mathrm{E} \quad 02$ \\
\hline 5806 & 4500 & 213 & 52 & 8 & 100 & 12 & 36 & 1 & 186.8 & 0 & 8 & $1.4264726 \mathrm{E} \quad 03$ \\
\hline 5806 & 4500 & 213 & 52 & 8 & 100 & 12 & 36 & 7 & 186.8 & 0 & 9 & $-2.5996887 \mathrm{E} \quad 02$ \\
\hline 5806 & 4500 & 213 & 52 & 8 & 100 & 12 & 36 & 1 & 186.8 & 0 & 10 & $-1.2412525 \mathrm{E} 03$ \\
\hline 5806 & 4500 & 213 & 52 & 8 & 100 & 12 & 36 & 1 & 186.8 & 0 & 11 & $9.1843662 \mathrm{E}$ O1 \\
\hline 5806 & 4500 & 213 & 52 & 8 & 100 & 12 & 36 & 1 & 186.8 & 0 & 12 & $4.0777261 \mathrm{E} \mathrm{O2}$ \\
\hline 5806 & 4500 & 213 & 52 & 8 & 100 & 12 & 36 & 1 & 186.8 & 0 & 13 & $1.4352705 \mathrm{E}-01$ \\
\hline 5806 & 4500 & 213 & 52 & 8 & 100 & 12 & 36 & 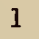 & 186.8 & 0 & 14 & $9.6570256 \mathrm{E}-01$ \\
\hline 5806 & 4500 & 213 & 52 & 8 & 100 & 12 & 36 & 1 & 186.8 & 0 & 15 & $-8.4557281 \mathrm{E}-01$ \\
\hline 5806 & 4500 & 213 & 52 & 8 & 100 & 12 & 36 & 1 & 186.8 & 0 & 16 & $-4.7783220 \mathrm{E} \quad 00$ \\
\hline 5806 & 4500 & 213 & 52 & 8 & 100 & 12 & 36 & 1 & 186.8 & 0 & 17 & $-1.3976016 \mathrm{E} 01$ \\
\hline 5806 & 4500 & 213 & 52 & 8 & 100 & 12 & 36 & 1 & 186.8 & 0 & 18 & $-2.3884222 \mathrm{E} \quad 01$ \\
\hline 5806 & 4500 & 213 & 52 & 8 & 100 & 12 & 36 & 1 & 186.8 & 0 & 19 & $4.4348199 E \quad 01$ \\
\hline 5806 & 4500 & 213 & 52 & 8 & 100 & 12 & 36 & 1 & 186.8 & 0 & 20 & $1.1777619 \mathrm{E} \quad 02$ \\
\hline 5806 & 4500 & 213 & 52 & 8 & 100 & 12 & 36 & 1 & 186.8 & 0 & 21 & $1.1766320 \mathrm{E} 02$ \\
\hline 5806 & 4500 & 213 & 52 & 8 & 100 & 12 & 36 & 1 & 186.8 & 0 & 22 & $1.5439476 \mathrm{E} 02$ \\
\hline 5806 & 4500 & 213 & 52 & 8 & 100 & 12 & 36 & 1 & 186.8 & 0 & 23 & $-2.9505143 \mathrm{E} \quad 02$ \\
\hline 5806 & 4500 & 213 & 52 & 8 & 100 & 12 & 36 & 1 & $186 \cdot 8$ & 0 & 24 & $-5.8452889 \mathrm{E} \mathrm{OZ}$ \\
\hline 5806 & 4500 & 213 & 52 & 8 & 100 & 12 & 36 & 1 & 186.8 & 0 & 25 & $-3.3965383 E \quad 02$ \\
\hline 5806 & 4500 & 213 & 52 & 8 & 100 & 12 & 36 & 1 & 186.8 & 0 & 26 & $-3.8447369 E \quad 02$ \\
\hline 5806 & 4500 & 213 & 52 & 8 & 100 & 12 & 36 & 1 & 186.8 & 0 & 27 & $7.7576793 E \quad 02$ \\
\hline 5806 & 4500 & 213 & 52 & 8 & 100 & 12 & 36 & 1 & 186.8 & 0 & 28 & $1.2218275 \mathrm{E} 03$ \\
\hline 5806 & 4500 & 213 & 52 & 8 & 100 & 12 & 36 & 1 & 186.8 & 0 & 29 & $3.9903615 \mathrm{E} \mathrm{O2}$ \\
\hline 5806 & 4500 & 213 & 52 & 8 & 100 & 12 & 36 & 1 & - 8 & 0 & 30 & $4.1502135 \mathrm{E} \quad 02$ \\
\hline 5806 & 4500 & 213 & 52 & 8 & 100 & 12 & 36 & 1 & 186.8 & 0 & 31 & $-8.8033071 \mathrm{E} \mathrm{O2}$ \\
\hline 5806 & 4500 & 213 & 52 & 8 & 100 & 12 & 36 & 1 & - 8 & 0 & 32 & $-1.1519065 \mathrm{E} \quad 03$ \\
\hline 5806 & 4500 & 213 & 52 & 8 & 100 & 12 & 36 & 1 & 186.8 & 0 & 33 & $-1.6575612 \mathrm{E} \mathrm{O2}$ \\
\hline 5806 & 4500 & 213 & 52 & 8 & 100 & 12 & 36 & 1 & 186.8 & 0 & 34 & $-1.6211853 \mathrm{E} \mathrm{O2}$ \\
\hline 5806 & 4500 & 213 & 52 & 8 & 100 & 12 & 36 & 1 & 18 & 0 & 35 & $3.6065598 \mathrm{E} 02$ \\
\hline 5806 & 4500 & 213 & 52 & 8 & 100 & 12 & 36 & 1 & 186.8 & 0 & 36 & $4.0243153 \mathrm{E} \mathrm{O2}$ \\
\hline 5806 & 4500 & 213 & 52 & 8 & 100 & 12 & 36 & ] & 186.8 & 0 & 37 & $2.8422108 \mathrm{E}-01$ \\
\hline 5806 & 4500 & 213 & 52 & 8 & 100 & 12. & 36 & 1 & 18 & 0 & 38 & $3.9405910 E-01$ \\
\hline 5806 & 4500 & 213 & 52 & 8 & 100 & 1.2 & 36 & 1 & . 8 & 0 & 39 & $1 E \quad 00$ \\
\hline 5806 & 4500 & 213 & 52 & 8 & 100 & 12 & 36 & 1 & 18 & 0 & 40 & $-3.6131784 \mathrm{E} \quad 00$ \\
\hline 5806 & 4500 & 213 & 52 & 8 & 100 & 12 & 36 & T & 186.8 & 0 & 41 & $-5.2786767 \mathrm{E} \quad 00$ \\
\hline 5806 & 4500 & 213 & 52 & 8 & 100 & 12 & 36 & 1 & 186.8 & 0 & 42 & $-4.8036404 E \quad 00$ \\
\hline 5806 & 4500 & 213 & 52 & 8 & 100 & 12 & 36 & 1 & 186.8 & 0 & 43 & $2.1448102 E \quad 01$ \\
\hline 5806 & 4500 & 213 & 52 & 8 & 100 & 12 & 36 & 1 & & 0 & 44 & $3.3071747 \mathrm{E} \quad 01$ \\
\hline 5806 & 4500 & 213 & 52 & 8 & 100 & 12 & 36 & 1 & 186.8 & 0 & 45 & $1.8113526 \mathrm{E} 01$ \\
\hline 5806 & 4500 & 213 & 52 & 8 & 100 & 12 & 36 & 1 & 186.8 & 0 & 46 & $9.1406965 \mathrm{E} \mathrm{OC}$ \\
\hline 5806 & 4500 & 213 & 52 & 8 & 100 & 12 & 36 & 1 & 186.8 & 0 & 47 & $-4.7457672 \mathrm{E} \quad 01$ \\
\hline 5806 & 4500 & 213. & 52 & 8 & 100 & 12 & 36 & 1 & 186.8 & 0 & 48 & $1269085 E \quad 01$ \\
\hline 5806 & 4500 & 213 & 52 & 8 & 100 & 12 & 36 & 1 & $186 \cdot 8$ & 0 & 49 & $-1.5238267 \mathrm{E}$ ol \\
\hline 5806 & 4500 & 213 & 52 & 8 & 100 & 12 & 36 & 1 & 186.8 & 0 & 50 & $3477439 E \quad 00$ \\
\hline 5806 & 4500 & 213 & 52 & 8 & 100 & 12 & 36 & 1 & 186.8 & 0 & 51 & $2.9248889 \mathrm{E} \quad 01$ \\
\hline 5806 & 4500 & 213 & 52 & 8 & 100 & 12 & 36 & 1 & 186.8 & 0 & 52 & $5.5277724 \mathrm{E} 01$ \\
\hline 306 & 4500 & 213 & 52 & 8 & 100 & 12 & 36 & 1 & 186.8 & 1 & 0 & 00 \\
\hline 5806 & 4500 & 213 & 52 & 8 & 100 & 12 & 36 & 1 & 186.8 & 1 & 1 & $-1.7650886 E \quad 00$ \\
\hline
\end{tabular}


One Per Card Coefficients $h_{\text {sk }}$ (See Card Format 5)

\begin{tabular}{|c|c|c|c|c|c|c|c|c|c|c|c|c|}
\hline Y M & DIC & $\mathrm{N}$ & $P$ & H & FNCD & PP1 & PP2 & $\mathrm{T}$ & SN & 8 & k & $\mathrm{h}_{\mathrm{sk}}$ \\
\hline 5806 & 4500 & 213 & 52 & 8 & 100 & 12 & 36 & 2 & 186.8 & 0 & 0 & $9.4565125 E \quad 01$ \\
\hline 5806 & 4500 & 213 & 52 & 8 & 100 & 12 & 36 & 2 & 186.8 & 0 & 1 & $4.0170246 E 00$ \\
\hline 5806 & 4500 & 213 & 52 & 8 & 100 & 12 & 36 & 2 & 186.8 & 0 & 2 & $-2.1605705 E$ Ol \\
\hline 5806 & 4500 & 213 & 52 & 8 & 100 & 12 & 36 & 2 & 186.8 & 0 & 3 & $-7.8164387 E-01$ \\
\hline 5806 & 4500 & 213 & 52 & 8 & 100 & 12 & 36 & 2 & 186.8 & 0 & 4 & $1.4642438 \mathrm{E} \quad 00$ \\
\hline 5806 & 4500 & 213 & 52 & 8 & 100 & 12 & 36 & 2 & 186.8 & 0 & 5 & $1.3993547 E \quad 00$ \\
\hline 5806 & 4500 & 213 & 52 & 8 & 100 & 12 & 36 & 2 & 186.8 & 0 & 6 & $-3.2498074 E-02$ \\
\hline 5806 & 4500 & 213 & 52 & 8 & 100 & 12 & 36 & 2 & 186.8 & 0 & 7 & $-3.7577779 E-01$ \\
\hline 5806 & 4500 & 213 & 52 & 8 & 100 & 12 & 36 & 2 & 186.8 & 0 & 8 & $1.3522217 E-01$ \\
\hline 5806 & 4500 & 213 & 52 & 8 & 100 & 12 & 36 & 2 & 186.8 & 0 & 9 & $-3.9923328 E-01$ \\
\hline 5806 & 4500 & 213 & 52 & 8 & 100 & 12 & 36 & 2 & 186.8 & 0 & 10 & $-6.4115469 E-01$ \\
\hline 5806 & 4500 & 213 & 52 & 8 & 100 & 12 & 36 & 2 & 186.8 & 0 & 11 & $7.1357547 \mathrm{E}-01$ \\
\hline 5806 & 4500 & 213 & 52 & 8 & 100 & 12 & 36 & 2 & 186.8 & 0 & 12 & $1.5940220 \mathrm{E} 00$ \\
\hline 5806 & 4500 & 213 & 52 & 8 & 100 & 12 & 36 & 2 & 186.8 & 0 & 13 & $-9.0769068 E-01$ \\
\hline 5806 & 4500 & 213 & 52 & 8 & 100 & 12 & 36 & 2 & 186.8 & 0 & 14 & $1.8921489 E \quad 00$ \\
\hline 5806 & 4500 & 213 & 52 & 8 & 100 & 12 & 36 & 2 & 186.8 & 0 & 15 & $2.6680483 E 00$ \\
\hline 5806 & 4500 & 213 & 52 & 8 & 100 & 12 & 36 & 2 & 186.8 & 0 & 16 & $5.1834916 \mathrm{E} \quad 00$ \\
\hline 5806 & 4500 & 213 & 52 & 8 & 100 & 12 & 36 & 2 & 186.8 & 0 & 17 & $-6.0173756 E-01$ \\
\hline 5806 & 4500 & 213 & 52 & 8 & 100 & 12 & 36 & 2 & 186.8 & 0 & 18 & $2.8737972 E-01$ \\
\hline 5806 & 4500 & 213 & 52 & 8 & 100 & 12 & 36 & 2 & 186.8 & 0 & 19 & $7.5293761 \mathrm{E}-02$ \\
\hline 5806 & 4500 & 213 & 52 & 8 & 100 & 12 & 36 & 2 & 186.8 & 0 & 20 & $-1.5618081 \mathrm{E} \quad 00$ \\
\hline 5806 & 4500 & 213 & 52 & 8 & 100 & 12 & 36 & 2 & 186.8 & 0 & 21 & $-8.1786337 E-01$ \\
\hline 5806 & 4500 & 213 & 52 & 8 & 100 & 12 & 36 & 2 & 186.8 & 0 & 22 & $1.0628657 \mathrm{E} \quad 00$ \\
\hline 5806 & 4500 & 213 & 52 & 8 & 100 & 12 & 36 & 2 & 186.8 & 0 & 23 & $3.9685505 E-01$ \\
\hline 5806 & 4500 & 213 & 52 & 8 & 100 & 12 & 36 & 2 & 186.8 & 0 & 24 & $-7.7826549 E$ \\
\hline 5806 & 4500 & 213 & 52 & 8 & 100 & 12 & 36 & 2 & 186.8 & 0 & 25 & $-3.5562921 \mathrm{E}-01$ \\
\hline 5806 & 4500 & 213 & 52 & 8 & 100 & 12 & 36 & 2 & 186.8 & 0 & 26 & $-1.2530024 \mathrm{E} \quad 00$ \\
\hline 5806 & 4500 & 213 & 52 & 8 & 100 & 12 & 36 & 2 & 186.8 & 0 & 2 & $1.6143535 \mathrm{E}-01$ \\
\hline 5806 & 4500 & 213 & 52 & 8 & 100 & 12 & 36 & 2 & 186.8 & 0 & 28 & $1.2648626 \mathrm{E} \quad 00$ \\
\hline 5806 & 4500 & 213 & 52 & 8 & 100 & 12 & 36 & 2 & 186.8 & 0 & 29 & $7.4794657 E-01$ \\
\hline 5806 & 4500 & 213 & 52 & 8 & 100 & 12 & 36 & 2 & 186.8 & 0 & 30 & $1.2934358 \mathrm{E} \quad 00$ \\
\hline 5806 & 4500 & 213 & 52 & 8 & 100 & 12 & 36 & 2 & 186.8 & 0 & 31 & $6.1983575 E-02$ \\
\hline 5806 & 4500 & 213 & 52 & 8 & 100 & 12 & 36 & 2 & 186.8 & 0 & 32 & $-1.8562712 E \quad 00$ \\
\hline 5806 & 4500 & 213 & 52 & 8 & 100 & 12 & 36 & 2 & 186.8 & 0 & 33 & $-9.3592011 E-01$ \\
\hline 5806 & 4500 & 213 & 52 & 8 & 100 & 12 & 36 & 2 & & 0 & 3 & $38558 E-01$ \\
\hline 5806 & 4500 & 213 & 52 & 8 & 100 & 12 & 36 & 2 & 186.8 & 0 & 35 & $1.0113917 \mathrm{E} 00$ \\
\hline 5806 & 4500 & 213 & 52 & 8 & 100 & 12 & 36 & 2 & 186.8 & 0 & 36 & $1.1285386 E \quad 00$ \\
\hline 5806 & 4500 & 213 & 52 & 8 & 100 & 12 & 36 & 2 & 186.8 & 0 & 37 & $3.4079790 E-01$ \\
\hline 5806 & 4500 & 213 & 52 & 8 & 100 & 12 & 36 & 2 & 186.8 & 0 & 38 & $3.2231821 E-01$ \\
\hline 5806 & 4500 & 213 & 52 & 8 & 100 & 12 & 36 & 2 & .8 & 0 & 39 & $8341281 E-01$ \\
\hline 5806 & 4500 & 213 & 52 & 8 & 100 & 12 & 36 & 2 & & 0 & 40 & $1879728 E-01$ \\
\hline 5806 & 4500 & 213 & 52 & 8 & 100 & 12 & 36 & 2 & 186.8 & 0 & 41 & $-9.5740420 E-02$ \\
\hline 5806 & 4500 & 213 & 52 & 8 & 100 & 12 & 36 & 2 & 186.8 & 0 & 42 & $-6.3193738 \mathrm{E}-01$ \\
\hline 5806 & 4500 & 213 & 52 & 8 & 100 & 12 & 36 & 2 & 186.8 & 0 & 43 & $1.1002588 \mathrm{E}-01$ \\
\hline 5806 & 4500 & 213 & 52 & 8 & 100 & 12 & 36 & 2 & .08 & 0 & 44 & $-9.0577019 E-02$ \\
\hline 5806 & 4500 & 213 & 52 & 8 & 100 & 12 & 36 & 2 & 186.8 & 0 & 45 & $261891 \mathrm{E}-01$ \\
\hline 5806 & 4500 & 213 & 52 & 8 & 100 & 12 & 36 & 2 & 186.8 & 0 & 46 & $1.2591517 E 00$ \\
\hline 5806 & 4500 & 213 & 52 & 8 & 100 & 12 & 36 & 2 & .8 & 0 & 47 & $-1.0611030 E 00$ \\
\hline 5806 & 4500 & 213 & 52 & 8 & 100 & 12 & 36 & 2 & 18 & 0 & 4 & $-1.1026031 \mathrm{E} 00$ \\
\hline 5806 & 4500 & 213 & 52 & 8 & 100 & 12 & 36 & 2 & & 0 & 49 & $-8.0437840 E-01$ \\
\hline 5806 & 4500 & 213 & 52 & 8 & 100 & 12 & 36 & 2 & 186.8 & 0 & 50 & $-1.7631563 \mathrm{E}-01$ \\
\hline 5806 & 4500 & 213 & 52 & 8 & 100 & 12 & 36 & 2 & 186.8 & 0 & 51 & $8.2920978 E-01$ \\
\hline 5806 & 4500 & 213 & 52 & 8 & 100 & 12 & 36 & 2 & 186.8 & 0 & 52 & $1.4233196 E 00$ \\
\hline 5806 & 4500 & 213 & 52 & 8 & 100 & 12 & 36 & 2 & 186.8 & 1 & 0 & $1.4133058 \mathrm{E}$ ol \\
\hline 5806 & 4500 & 213 & 52 & 8 & 100 & 12 & 36 & 2 & 186.8 & 1 & 1 & $-3.7146698 \mathrm{E} \quad 00$ \\
\hline
\end{tabular}






\section{THE NATIONAL BUREAU OF STANDARDS}

The scope of activities of the National Bureau of Standards at its major laboratories in Washington, D.C., and Bouldcr. Colorado, is suggested in the following listing of the divisions and sections engaged in technical work. In general, each section carries aut specialized research, development, and engineering in the field indicated by itstitle. A brief description of the activities, and of the resultant publications, appears on the inside of the iront cover.

\section{A ASIIINGTON, D. C.}

Electricity. Resistance and Reactance. Electrochemistry. Electrical Instruments. Magnetic Measurements Dielectrics. High Voltage.

Metrology. Photometry and Colorimetry. Refractometry. Photographic Research. Length. Engineering Metrology. Mass and Scale. Volumetry and Densimetry.

Heat. Temperature Physics. Heat Measurements. Cryogenic Physics. Equation of State. Statistical Physics. Radiation Physics. X-ray. Radioactivity. Radiation Theory. High Energy Radiation. Radiological Equipment. Nucleonic lnstrumentation. Neutron Physics.

tnalytical and Inorganic Chemistry. Pure Substances. Spectrochemistry. Solution Chemistry. StandardReference Matcrials. Applied Analytical Research. Crystal Chemistry.

Mechanics. Sound, Pressure and Vacuum. Fluid Mechanics. Engineering Mechanics. Rheology. Combustion Controls.

Polymers. Macromolecules: Synthesis and Structure. Polymer Chemistry. Polymer Physics. Polymer Characterization. Polymer Evaluation and Testing. Applied Polymer Standardsand Research. Dental Research.

Metallurgy. Fngineering Metallurgy. Microscopy and Diffraction. Metal Reactions. Metal Physics. Flectrolysis and Metal Deposition.

Inorganic Solids. Engineering Ceramics. Glass. Solid State Chemistry. Crystal Growth. Physical Properties. Cirystallography.

Building Research. Structural Engineering. Fire Research. Mechanical Systems. Organic Building Materials. Codes and Safety Standards. Heat Transfer. Inorganic Building Materials. Metallic Building Materials.

Applied Mathenatics. Numerical Analysis. Computation. Statistical Engineering. Mathematical Physics. Operations Research.

Data Processing Systems. Components and Techniques. Computer Technology. Measurements Automation. Engineering Applications. Systems Analysis.

Itomic Physics. Syectroscopy. Infrared Spectroscopy. Far Illtraviolet Physics. Solid State Plysics. Electron l'hysics. Atouic Pliysics. Plasma Spectroscopy.

Instrumentation. Fingineering Electronics. Electron Devices. Electronic lnstrumentation. Mechanical Instrulients. Basic Instrumentation.

Physical Chemistry. Thermochemistry. Surface Chemistry. Organic Cliemistry. Molecular Spectroscopy. Fileicntary Proccsses. Mass Spectrometry. Photochemistry and Kadiation Chemistry.

office of Weights and Measures.

\section{BOULDER, COLO.}

Cryogenic Engineering Laboratory. Cryogenic Equipment. Cryogenic Processes. Properties of Materials. Cryogenic Technical Services.

\section{CENTRAI, RADIO PROPAGATION LABORATORY}

Innosphere Research and Propagation. Low Frequency and Very Low Frequency Research. Ionosphere Research. Prediction Services. Sun-Earth Kelationships. Field Engineering. Radio Warning Services. Vertical Soundings Research.

Radio Propagation Engineering. Data Reduction Instrumentation. Radio Noise. Tropospheric Measurements. Tropospheric Analysis. Propagation-Terrain Effects. Radio-Meteorology. Lower Atmosphere Physics.

Radio Systems. Applied Flectromagnetic Theory. High Frequency and Very High Frequency Research. Frequcncy Utilization. Modulation Research. Antenna Kesearch. Radiodetermination.

Upper Atmosphere and Space Physics. Upper Atmosphere and Plasma Physics. High Latitude Ionosphere Physics. Ionosphere and F.xosphere Scatter. Airglow and Aurora. Ionospheric Hadio Astronomy.

\section{RAUIO STANDARDS LABORATORY}

Radio Physics. Radio Broadcast Service. Radio and Microwave Materials. Atomic Frequency and Time-Interval Standards. Radio Plasma. Millimeter-Wave Research.

Circuit Standards. High Frequency Electrical Standards. High Frequency Calibration Services. Higl Frequency Impedance Standards. Microwave Calibration Services. Microwave Circuit Standards. Low Frequency Calibration Services. 
